\title{
Sistema Hipermídia de Apoio à Documentação de Software: Uma Investigação sobre a "Mudança de Domínio de Software"
}

\author{
Willian Francisco da Silva
}

Orientadora: Profa. Dra. Renata Pontin de Mattos Fortes

Dissertação apresentada ao Instituto de Ciências Matemáticas e de Computação - ICMC-USP, como parte dos requisitos para obtenção do título de Mestre em Ciências - Área: Ciências de Computação e Matemática Computacional.

USP - São Carlos

Junho de 2000 
Este trabalho é dedicado à todos aqueles que, por algum motivo, não tiveram a chance de estudar. 


\section{Agradecimentos}

"A vitória é para aqueles que estão sempre dispostos a recomeçar!"

[Autor Desconhecido]

Existem muitas pessoas que preciso agradecer.

À Renata, por me orientar e pela sempre acreditar em mim. Obrigado por me mostrar que o mais importante em um mestrado não é o trabalho e sim o quanto a gente aprende com ele. Valeu o apoio, a amizade e os conselhos. Força nos estudos e saiba que estarei sempre torcendo por você.

Aos meus grandes amigos Walter, Cláudia, Gedson, Renato, Enzo e Cláudio, por compartilharem comigo sorrisos e lágrimas. Obrigado por todos os momentos que passamos juntos. Tenham certeza que jamais os esquecerei.

À Débora, por me ajudar na revisão deste trabalho, pela compreensão e companheirismo. Obrigado por me entender.

Aos meus outros grandes amigos: Tatiana, Luciana, Valéria, Thelma, Rodrigo, Waine, Eglen, Adenilso, Andrea, Reginaldo, Auri, Ellen, Igor, Zé, Denilson, Vangrei, Daniela, Aline, Elisandra, João, Emerson, André, Dinamérico, Janaína, Mayb, Willie, Rurik, Regiane e Maristela. Muito obrigado por fazerem parte de minha vida.

Aos meus grandes amigos de Foz, Marcelo e Jefferson. Obrigado pela força e coragem dada. Tizú, aí do céu, continue olhando por nós.

Às professoras Rosely Sanches, Roseli Francelin e Graça Nunes. Obrigado pelas palavras amigas de incentivo e pela amizade.

À Beth, Laura e Marilia. Obrigado pela dedicação com que sempre me atenderam. Desculpem-me pelas amolações.

À Capes, pelo apoio financeiro desde os tempos de PET.

À minha família. Obrigado meu pai, obrigado minha mãe e obrigado minha irmã por sempre me apoiarem, mesmo nos momentos mais dificeis dessa vida. Obrigado por me oferecer seu carinho e seu amor. Saibam que a distância entre nós somente faz aumentar o meu amor por vocês. Amo vocês com toda a força do meu coração.

E principalmente a DEUS. Obrigado Pai Eterno pelo seu amor incondicional, pela minha vida e por todas essas pessoas que fizeram e fazem parte de minha vida. Você que está 
sempre comigo nos momentos de alegria, de tristeza, na saúde, na doença.... A certeza de saber que estás sempre comigo me faz prosseguir nessa dificil jornada que é viver. 


\section{Resumo}

Este trabalho discute o processo de mudança de domínio de software, ou seja, a adaptação do software para um domínio de informações diferente do original. A investigação é fundamentada em um exercício prático: o sistema SASHE (Sistema de Autoria e Suporte Hipermidia para Ensino) foi adaptado para o domínio da Engenharia de Software. A partir desse exercício, um novo sistema, o SASHDoc, foi projetado com base no SASHE com o objetivo de tornar-se um sistema hipermídia de apoio à documentação de software. 


\section{Abstract}

This work addresses the process of software domain change, i.e., the software adaptation to a different information domain from original one. The issue is based on a practical exercise: the system SASHE (System of Authorship and Hypermedia Support for Teaching) was customized for the Software Engineering domain. Then, a new system, called SASHDoc, was designed based on SASHE, aiming at providing a hypermedia system to support software documentation. 


\section{Sumário}

CAPÍTULO 1 - INTRODUÇÃO _.................................................................................... 1

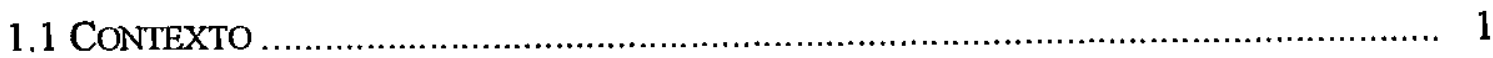

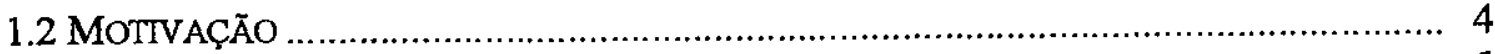

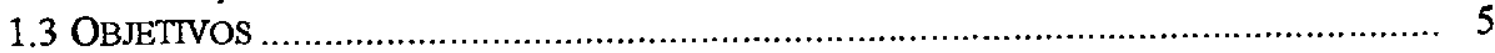

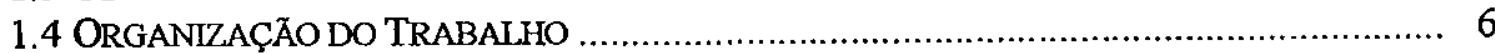

CAPÍTULO 2 - DOCUMENTAÇÃO DE SOFTWARE ............................................... 7

2.1 CONSIDERAÇÕES INICIAIS ............................................................................... 7

2.2 DOCUMENTAÇÃO DE SOFTWARE …………………....................................... 8

2.3 FERRAMENTAS HIPERMIDIA DE DOCUMENTAÇÃO DE SOFTWARE .............................. 15

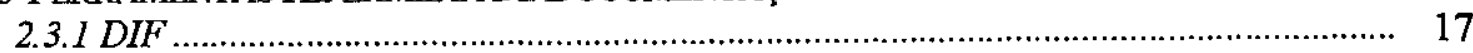

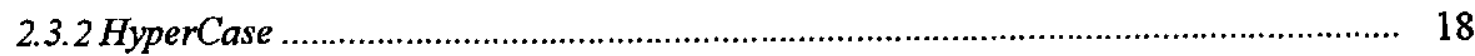

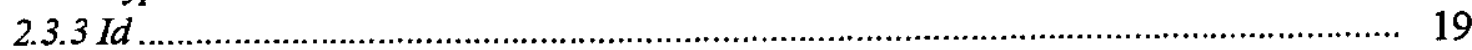

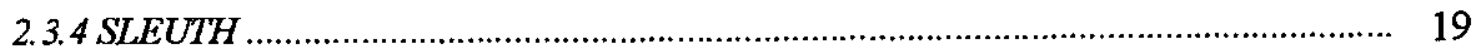

2.3.5 DynaDoc .............................................................................................. 20

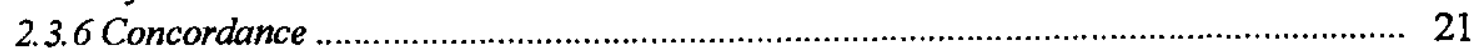

2.3.7 Outras Ferramentas de Documentą̧ão de Software ……...................................... 22

2.4 ANÁLISE CRITICA DAS FERRAMENTAS REVISADAS .............................................. 23

2.4.1 Independência da Metodologia de Desenvolvimento ................................................... 24

2.4. 2 Visões do Sistema e do Software ............................................................................. 25

2.4.3 Relacionamento entre Documentos .......................................................................... 26

2.4.4 Ambiente Integrado de Autoria e Navegą̧ão de Documentos ..................................... 26

2.4.5 Suporte de um Banco de Dados ......................................................................... 27

2.5 CONSDERAÇõES FINAIS ...................................................................................... 27

CAPÍTULO 3 - O SISTEMA SASHE …...................................................................... 30

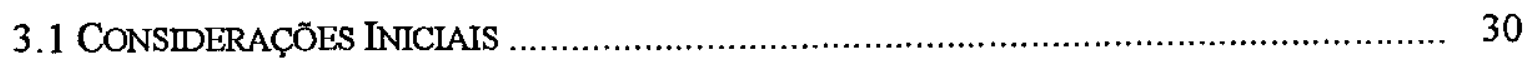

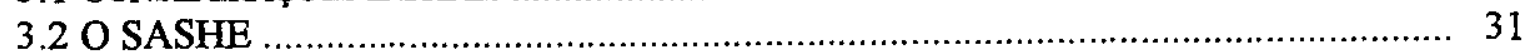

3.2.1 Módulo de Autoria ……………………………………................................. 32

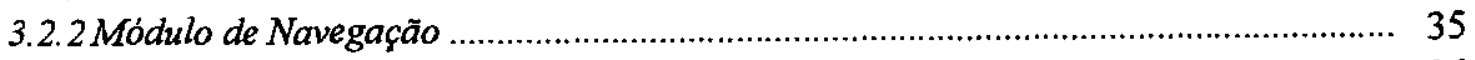

3.3 REUSO DE RECURSOS DO SASHE .................................................................. 36

3.4 ESTUDO DE CASO 1: DOCUMENTOS DE SOFTWARE NO SASHE ............................... 39

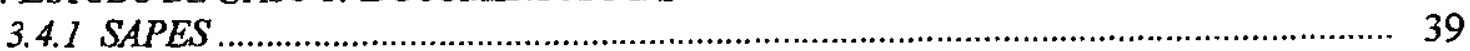

3.4.2 UML

3.4.3 Rational Rose 98 ..................................................................................... 42

3.4.4 Resultados Obtidos ..................................................................................... 42

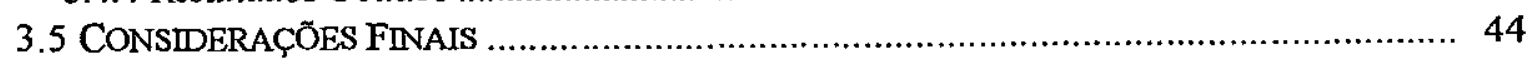

CAPÍTULO 4 - O SISTEMA SASHDOC .................................................................. 47

4.1 CONSIDERAÇÕES INICIAIS .............................................................................. 47

4.2 ESTUDO DE CASO 2: HIPERDOCUMENTOS DE SOFTWARE …................................... 48 


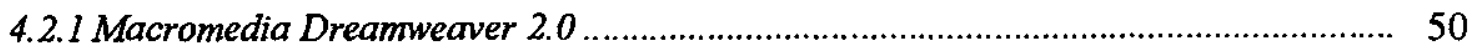

4.2.2 Microsoft Internet Explorer 5.0 …................................................................. 51

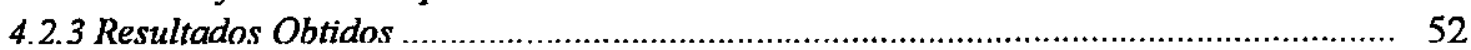

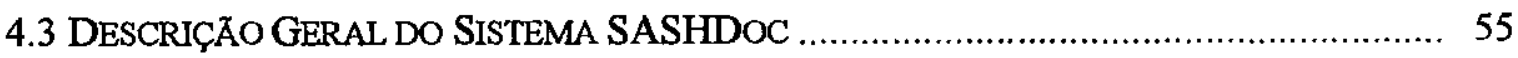

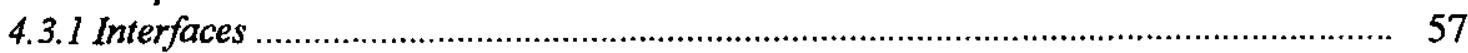

4.3.2 Propriedades de Documentos de Software …........................................................ 59

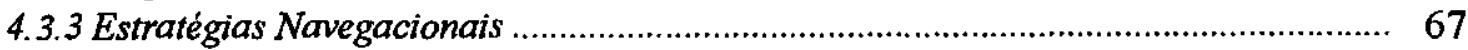

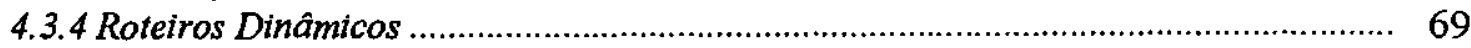

4.4 ANÁlISE DA MUDANÇA DE DOMÍNIO DO SASHE PARA SASHDOC ....................... 69

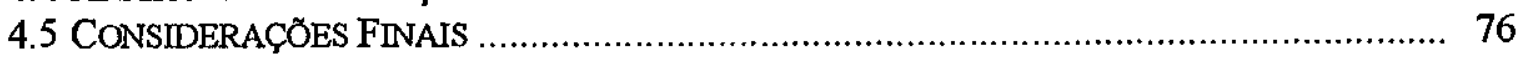

CAPÍTULO 5 - A MUDANÇA DE DOMÍNIO DE SOFTWARE ................................ 78

5.1 CONSTDERAÇŐES INICIAIS ............................................................................ 78

5.2 ASSERTIVAS SOBRE MUDANÇA DE DOMINIO DE SOFTWARE ................................. 79

5.2.1 A Familiaridade com o Dominio Alvo e a Experiência com o Software Base Facilitam a Mudança de Dominio de Software ....................................................... 79

5.2.2 A Familiaridade com o Dominio Alvo Facilita o Ciclo de Vida de Software no Dominio

5.2.3 A Familiaridade com o Domínio Auxilia na Avaliação de Softwares Desenvolvidos para Solucionar Problemas do Dominio ................................................................ 81

5.2.4 A Familiaridade com o Domínio Auxilia na Identificação de Caracteristicas do Dominio no Software ............................................................................................ 83

5.2.5 A Experiência com o Software Permite Visualizar a Aplicação de seus Recursos em Outros Dominios ............................................................................................... 85

5.2.6 A Experiência com o Software Proporciona Identificar Questöes de Usabilidade no Software ..................................................................................................... 86

5.2.7 A Experiência em Projetos Anteriores no Dominio Alvo Auxilia na Mudança de Dominio de Software ...................................................................................... 87

5.3 AUXILIANDO A MUDANÇA DE DOMÍNIO DE SOFTWARE …................................. 88

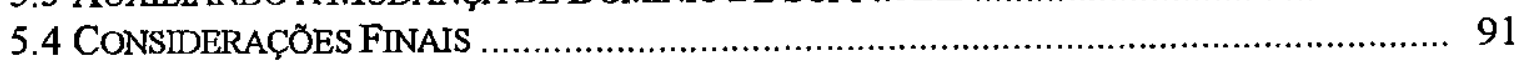

CAPÍTULO 6 - CONCLUSÕES ................................................................................... 92

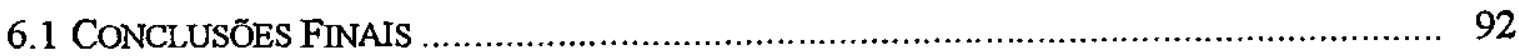

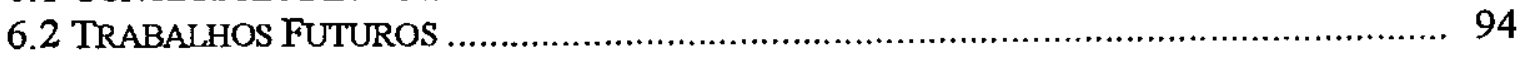

REFERÊNCIAS BIBLIOGRÁFICAS ....................................................................... 95

APÊNDICE A - SUGESTÕ É PARA MELHORIA DO SASHEE 2.0 …................................... 103

APÊNDICE B - DOCUMENTO DE REQUISTTOS Do SISTEMA SASHDOC ............................ 106 


\section{Lista de Figuras}

FIGURA 1 Adaptação de Componentes entre Softwares de Dominios Distintos ......................... 3

FIGURA 2 Documento de Especificação de Sistema [PRE95a] .................................................. 10

FIGURA 3 Documento de Especificação de Requisitos de Software [PRE95a] ........................... 10

FIGURA 4 Documento de Especificação do Projeto [PRE95a] ................................................. 11

FIGURA 5 Documento de Especificação de Teste [PRE95a] ................................................. 12

FIGURA 6 Plano de Garantia de Qualidade de Software [PRE95a] ........................................ 13

FIGURA 7 Documentação de Programas ................................................................................... 14

FIGURA 8 Documentação de Rotinas, Funções e Sub-Rotinas ................................................ 15

FIGURA 9 Arquitetura do SASHE 2.0 [HAB99] ............................................................. 32

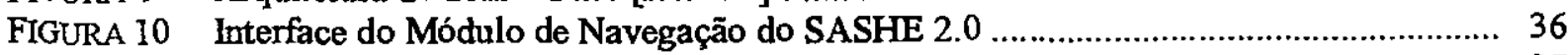

FIGURA 11 Exemplo de Diagrama de Transição de Estados do SASHE 2.0 ............................... 37

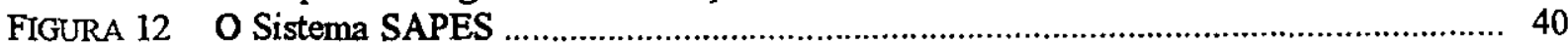

FIGURA 13 Aplicação no SASHE formada por Hiperdocumentos de Software ........................... 44

FIGURA 14 Macromedia Dreamweaver 2.0 .................................................................... 51

FIGURA 15 A Navegação entre Hiperdocumentos de Software Precedentes e Subseqüentes ........ 52

FIGURA 16 A Navegação por Links em Hiperdocumentos de Software ........................................ 53

FIGURA 17 A Navegação por Busca de Palavras-Chaves em Hiperdocumentos de Software ........ 54

FIGURA 18 Interface de Abertura do SASHDoc ................................................................... 57

FIGURA 19 Interface do Módulo de Autoria do SASHDoc ..................................................... 58

FIGURA 20 Interface do Módulo de Navegação do SASHDoc .................................................... 58

FIGURA 21 Nível e Grau de Abstração de Documentos no Ciclo de Vida do Software ................. 61

FIGURA 22 Visualizações no Ciclo de Desenvolvimento de Software [COS97] ........................... 63

FIGURA 23 Estratégia Navegacional para "Mais Abstração" $\theta$ "Menos Abstração" ...................... 67

FIGURA 24 Estratégia Navegacional para "Mais Formalidade" e "Menos Formalidade" .............. 68

FIGURA 25 Diagrama de Classes do SASHE para Autoria [FEL99] ........................................ 70

FIGURA 26 Diagrama de Classes do SASHE para Navegação [FEL99] .................................... 71

FIGURA 27 Diagrama de Classes do SASHDoc para Autoria ................................................. 71

FIGURA 28 Diagrama de Classes do SASHDoc para Navegação ................................................ 72

FIGURA 29 Diagrama de Casos de Uso do Sistema SASHDoc ................................................... 81

FIGURA 30 Checklist de Avaliação de Conteúdo de Hiperdocumentos de Software ...................... 82

FIGURA 31 Checklist de Verificação da Estrutura de Hiperdocumentos de Software .................... 83 


\section{Lista de Quadros}

QUADRO 1 Recursos do SASHE Aplicáveis em Outros Sistemas ............................................. 38

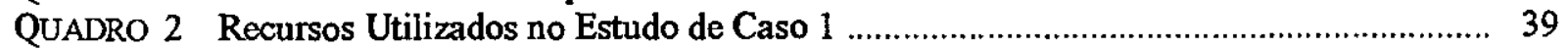

QUADRo 3 Descrição dos Diagramas da UML ......................................................................... 41

QUADRO 4 Aspectos Motivadores e Aspectos Inibidores do Reuso do SASHE .......................... 45

QUADRO 5 Recursos Utilizados no Estudo de Caso 2 ................................................................. 50

QUADRO 6 Relação da Navegação com os Recursos de Hiperdocumentos e do Browser .............. 55

QUADRo 7 Correspondência entre Classes Alteradas na Mudança de Dominio ............................ 73

QUADRO 8 Correspondência entre Classes Não-Alteradas na Mudança de Domínio .................... 74

QUADRO 9 Classes Constrúdas para o SASHDoc …............................................................... 75

QUADRO 10 Classes do SASHE não-Reusadas no SASHDoc ....................................................... 75

QUADRO 11 Requisitos propostos por [CAB94] atendidos pelo SASHDoc …............................. 77 


\section{Capitulo 1 Introdução}

\subsection{Contexto}

Em 1985 Adelson e Soloway investigaram como o conhecimento e as habilidades do projetista de software influem no desenvolvimento do software [ADE85]. Em especial, levando-se em consideração as características do domínio ao qual o software pertence - o Domínio de Software ${ }^{1}$. A investigação foi realizada com a colaboração de cinco projetistas: três com grande experiência em projeto de software e dois com experiência em programação, mas com pouca experiência em projeto.

A tarefa dos projetistas consistiu em projetar sistemas em três contextos diferentes: (1) projeto de um software desconhecido em um domínio no qual possuíam experiência (um sistema de mensagem eletrônica); (2) projeto de um software desconhecido em um domínio no qual não possuíam experiência (um sistema de biblioteca); e (3) projeto de um software conhecido em um domínio no qual possuíam experiência (um manipulador de interrupções). Analisando o comportamento, as habilidades $\mathrm{e}$ os conhecimentos empregados pelos projetistas, os pesquisadores concluíram que a experiência e a familiaridade do projetista com o software e com o seu respectivo domínio influem diretamente no modo como o software é compreendido.

De acordo com o dicionário Michaelis, familiaridade e experiência podem ser descritas como [MIC99]:

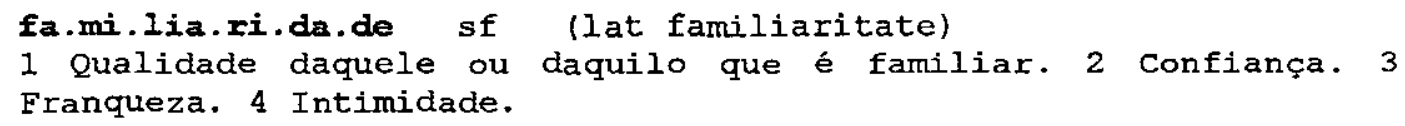

${ }^{1}$ Dominio de Software pode ser definido como o campo de atividade ou informação de um problema proposto o qual necessita de uma solução implementada em linguagem de programação [COA91]. 


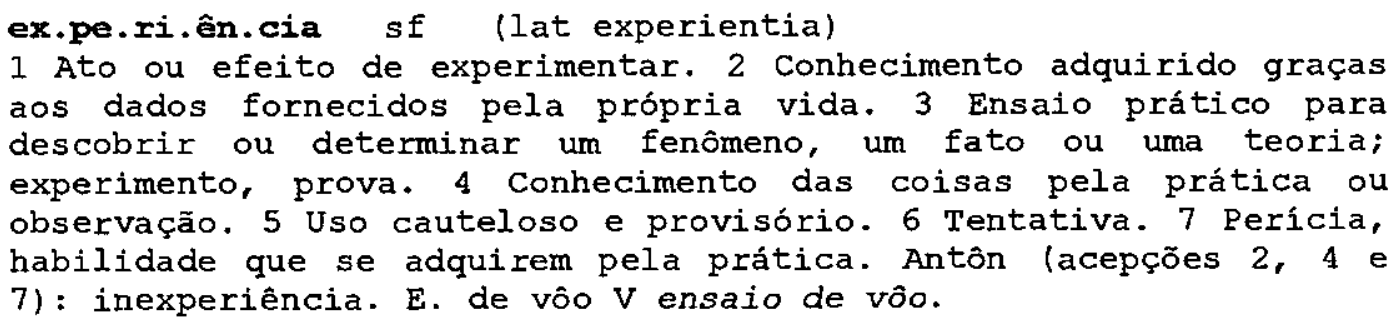

Sob a luz da Engenharia de Software, os termos familiaridade e experiência podem assumir interpretações mais apropriadas. A familiaridade pode ser entendida como o conhecimento ou percepção que o engenheiro de software possui sobre o contexto de informações ao qual o software pertence. A experiência, por sua vez, pode ser entendida como a habilidade ou perícia do engenheiro de software com um software. Esses foram os significados adotados na pesquisa de Adelson e Soloway [ADE85].

Além de Adelson e Soloway, outros pesquisadores já apontaram a familiaridade e a experiência do projetista como elementos importantes para o desenvolvimento de software [SOU93;BAS94:LIN98]. Muito embora essas pesquisas apontem sua importância no desenvolvimento tradicional de software, consideramos que esses fatores são igualmente importantes em se tratando do reuso de software. Neste trabalho, a pesquisa se orienta pela investigação desses fatores em reuso de software.

Reuso de Software consiste em utilizar componentes de software existentes na construção de um novo software [TRA95]. O reuso pode ser aplicado a qualquer produto do ciclo de vida do software, não somente a fragmentos do código fonte. Produtos como arquiteturas, dados, projetos, documentação, modelos, interfaces, planos, requisitos, casos de teste, estruturas, idéias, e conceitos também podem ser reutilizados [KRU92;FRA96].

$O$ reuso de componentes de software pode ser encarado sob diferentes perspectivas (facetas). Na literatura são encontradas diversas propostas de classificação da atividade de reuso de acordo com a sua perspectiva de atuação [PRI91;PRI93;FRA96]. Uma classificação bastante adotada é a proposta por Prieto-Diaz, na qual o reuso é classificado sob seis facetas [PRI93]:

- Conforme Substância: onde a essência do item do software a ser reutilizado é claramente definida. Essa essência pode ser vista: como Idéias e Conceitos (reutilização que envolve conceitos formais), como Artefatos e Componentes (reuso de componentes de software de fato) ou como Procedimentos e Habilidades (reuso de processos de desenvolvimento de software). 
- Conforme Escopo: define a forma e a extensão do reuso. Pode ser classificado como Vertical, que diz respeito à reutilização dentro de um mesmo domínio de informação ou área de aplicação, ou como Horizontal, onde componentes genéricos podem ser reutilizados em diferentes aplicações em diferentes domínios.

- Conforme Modo: define como a reutilização é conduzida. Pode ser: Planejada e Sistemática (reuso formal e sistemático) ou Ad-hoc e Oportunista (prática informal, conduzido individualmente).

- Conforme Técnica define a abordagem utilizada para implementar o reuso. Pode ser do tipo Composição (reuso de componentes construídos como blocos a serem encaixados em novos sistemas) ou Geração (reuso no nível de especificação através de uma aplicação ou geradores de código).

- Conforme Intenção: define como os elementos serão reutilizados. Pode ser do tipo CaixaPreta sem Modificação (reutilização ocorre sem modificação dos componentes) ou Caixa-Branca com Modificação (ocorre modificação e adaptação dos componentes).

- e Conforme Produto: define quais são os tipos de produtos que serão reutilizados. Os produtos podem ser: o Código-Fonte, o Projeto, a Especificaçăo, Objetos, um Texto ou uma Arquitetura.

No reuso do tipo horizontal a tônica é a adaptação de componentes de um software para outro pertencente a um dominio diferente daquele [PRI93]. A princípio, a mudança de domínio de software pode ser considerada uma atividade aplicável a qualquer tipo de software [Figura 1] . Essa adaptação de componentes prontos é uma estratégia que pode reduzir o custo e o esforço envolvidos no desenvolvimento do software. Contudo, na literatura são encontradas poucas experiências práticas de reuso sob essa perspectiva [TA95;GAS98;NG99]. E apesar de não se poder garantir que ocorra perfeitamente, a disciplina de Engenharia de Software tem avançado em pesquisas relacionadas ao tema reuso nos diversos níveis de abstração do processo de software [SAM97].

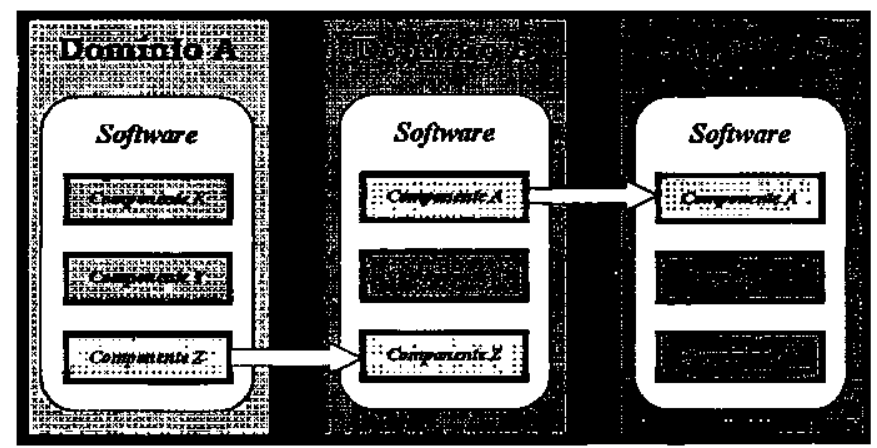

Figura 1. Adaptação de Componentes entre Softwares de Domínios Distintos. 
Outro fato constatado é que não se tem dado a devida importância sobre a influência de fatores subjetivos como a familiaridade e a experiência do engenheiro de software em um processo de mudança de domínio de software. Se esses fatores proporcionam melhor compreensão do domínio e do software em um ciclo de vida tradicional de software [ADE85], os consideramos também bastante úteis em uma mudança de domínio de software.

\subsection{Motivação}

Na última década houve uma grande expansão e sedimentação dos sistemas hipermídia. Os sistemas hipermídia são ferramentas de software que realizam tarefas de criação, manipulação e navegação de aplicações hipermídia [SHN88;NIE95]. Por sua vez, uma aplicação hipermídia corresponde a um conjunto de hiperdocumentos relacionados sobre um determinado tema cujas informações podem ser relacionadas por links.

As características dos sistemas hipermídia tais como a flexibilidade na exploração da informação e a interatividade motivaram o desenvolvimento de aplicações nos mais diversos domínios de conhecimento. Pode-se encontrar sistemas hipermídia em domínios como a Medicina e a Odontologia, [GAR96;GIL98;SPR98;JEN98], a Biologia [NOG92;LAL96], a Agricultura [LEW98], a Ecologia [VAS98;THO98], a Otimização [COL98], as Engenharias [BOA96;NEI98], a Física [JOH98], dentre outros. Entretanto, nos últimos anos - Ensino tem sido alvo de inúmeras pesquisas nesse âmbito [CAM94;MOR95;LUC97; SAN97;PAN99]. Principalmente, motivado pelo fato das aplicações hipermídia criarem um ambiente favorável à aquisição de conhecimento [CAM94].

Um exemplo de sistema hipermidia de destaque nesse contexto é o SASHE, Sistema de Autoria e Suporte Hipermidia para Ensino [NUN97a]. O sistema SASHE possibilitou, entre outras coisas, o relacionamento de diferentes tipos de mídias de informação em uma mesma aplicação e a posterior navegação dessa aplicação por meio estratégias navegacionais prédefinidas [NUN97b;NUN97c]. A organização das informações no sistema é suportada pelo Modelo de Contextos Aninhados, um modelo conceitual hipermídia baseado nos conceitos de nós e elos [CAS91;SOA95a;SOA95b].

Os primeiros experimentos com o SASHE apontaram para a aplicabilidade de seus recursos em outros domínios de informação [NUN97a]. A Engenharia de Software, por exemplo, foi apontada como domínio no qual determinados recursos do SASHE poderiam ser aplicados com sucesso, especialmente em atividades de documentação de software como a apresentação e exploração de (hiper)documentos do processo de software. 
Sob o ponto de vista do Reuso de Software, a identificação de recursos do SASHE adaptáveis para outro domínio (Engenharia de Software) se apresenta como uma atividade de um processo de mudança de domínio de software.

\subsection{Objetivos}

Em vista dos beneficios que a reutilização de componentes entre softwares de domínios distintos podem trazer, este trabalho tem como objetivo investigar a questão da mudança de domínio de software. Para tanto, um sistema hipermídia foi alvo de mudança de domínio de modo a visualizar mais claramente os elementos envolvidos nessa questão.

Neste trabalho foi realizada a mudança de domínio do SASHE para o domínio de Engenharia de Software. De fato, foi feito um levantamento dos componentes do sistema que puderam ser reutilizados, assim como novas partes foram desenvolvidas no sistema, com o propósito de adaptá-lo como auxílio ao engenheiro de software na tarefa de documentação de software. Para a realização dessa mudança, foi seguida uma estratégia inicial de modo a também observar as características do processo em relação aos fatores de familiaridade e experiência com o software.

Em virtude da relevância dos fatores subjetivos para a compreensão do software e do domínio do software, este trabalho investigou a relação da familiaridade e da experiência do engenheiro de software com os softwares e com os domínios envolvidos em um processo de mudança de domínio de software.

O produto final esperado da mudança de domínio do SASHE foi o desenvolvimento de um protótipo de sistema hipermídia de documentação de software no qual foram incorporados componentes do SASHE. Para alcançar tais objetivos, a estratégia seguida foi:

- Passo 1: Familiaridade com o Domínio Alvo. Essa atividade consistiu do estudo do tema "Documentação de Software": seus aspectos positivos, aspectos negativos, etc.

- Passo 2: Familiaridade e Experiência com Softwares do Domínio Alvo. Essa atividade consistiu de um estudo mais aprofundado sobre as características de sistemas que produzem documentação de software no formato hipertexto.

- Passo 3: Experiência com o Software Base. Essa atividade consistiu de um maior estudo do sistema SASHE, visto que é o software base do processo de mudança de domínio proposto neste trabalho. 
- Passo 4: Aplicação do Software Base no Domínio Alvo. Essa atividade consistiu em utilizar os recursos do SASHE no desenvolvimento de uma aplicação hipermídia composta por documentos de software.

- Passo 5: Desenvolvimento do Software Alvo. Com o conhecimento e a experiência adquiridos nas atividades anteriores, essa atividade consistiu do desenvolvimento de um protótipo de sistema hipermídia de documentação de software baseado nos recursos do SASHE.

Esses passos conduziram para o desenvolvimento do produto ressaltando-se a familiaridade e a experiência do engenheiro de software na mudança de domínio do SASHE. Ao final do exercício, foi possível observar a relação desses fatores com os domínios e os softwares envolvidos na mudança de domínio.

\subsection{Organização do Trabalho}

Neste' primeiro capítulo foi apresentado o contexto deste trabalho, as suas motivações e objetivos. No Capitulo Dois é apresentada uma revisão bibliográfica sobre a documentação de software e sua integração com a tecnologia hipermídia. No terceiro capítulo são apresentados estudos com o sistema SASHE com o objetivo de fundamentar a proposição do sistema hipermídia para produção de documentos de software. A proposta desse sistema é efetivamente apresentada no Capitulo Quatro. No quinto capitulo é apresentado um conjunto de assertivas sobre a mudança de domínio de software do ponto de vista dos fatores subjetivos (familiäridade e experiência) do engenheiro de software. Nas Conclusões estão enumeradas as contribuições deste trabalho e propostas para trabalhos futuros. Por fim, as Referências Bibliográficas e Apêndices. 


\section{Capitulo 2}

\section{Documentação de Software}

\subsection{Considerações Iniciais}

Durante o desenvolvimento do software é comum encontrar três situações: o software construído paralelamente à sua documentação, o software construído antes de sua documentação e o software construído sem que nenhuma documentação tenha sido redigida. Essas duas últimas situações podem ser explicadas pelo fato de que.muitos engenheiros de software consideram a documentação como uma tarefa burocrática no desenvolvimento do software [PAR94]. Muito embora reconheçam que documentar software é importante, na prática consideram a documentação uma atividade exigente em termos de tempo e esforço humano.

Diante desse quadro, nos últimos anos muitos esforços têm sido empregados para mudar a visão da documentação como um "mal necessário" [HOR86a;CUR89;TL92]. E consequentemente, atribuir uma maior qualidade aos documentos e à sua produção. Em síntese, esses esforços buscam encontrar respostas para questões fundamentais tais como "quais itens do software documentar?" e "como produzir melhores documentos?".

Como uma primeira resposta para a questão do conteúdo dos documentos recorre-se à adoção de padrões para documentos de software. Esses padrões sugerem um conteúdo mínimo para que o documento produzido retrate adequadamente o software de acordo com o período em que se encontra no ciclo de vida. Os padrões mais respeitados são aqueles regidos por entidades como a IEEE (Institute of Electrical and Eletronics Engineers) e a ISO (International Organization for Standardization). Há casos também de entidades e empresas que resolveram adotar seu próprio padrão de documentação de software como, por exemplo, a NASA (Agência Espacial Norte-Americana) e o Departamento de Defesa dos Estados Unidos. 
Para responder à segunda questão, tem sido pesquisada a integração da tecnologia hipermídia para suportar documentos de software [GAR90;CYB92;PHO97]. Esta integração é motivada por características da hipermídia que possibilitam novas formas de organização e exploração das informações presentes nos documentos.

Sendo assim, como as diversas nuances que envolvem a produção de documentos de software são importantes no decorrer deste trabalho, neste capítulo é apresentada uma revisão bibliográfica acerca do tema "documentação de software". Na seção seguinte são apontadas as diversas facetas de documentos de software: seus aspectos positivos, aspectos negativos, e modelos de documentos sugeridos pela literatura. Na Seção 2.3. é apresentada uma relação de ferramentas de documentação de software integradas à tecnologia hipermídia. Em seguida, as principais características dessas ferramentas e a sua integração com a documentação de software são discutidas. Por fim, as considerações finais do capítulo.

\subsection{Documentação de Software}

A documentação de software é atividade fundamental no processo de desenvolvimento de software. Em suma, cabe à documentação registrar a evolução do software para que as bases necessárias para uma melhor utilização e manutenção do software sejam criadas.

Estima-se que cerca de vinte a trinta por cento de todo o tempo exigido para o desenvolvimento de um software é dedicado à sua documentação [PAR94]. Em vista da quantidade de atividades realizadas no desenvolvimento do software, há de se considerar que o tempo requerido pela documentação é bastante representativo.

Nesse período podem ser produzidos inúmeros documentos; cada um retratando particularidades do software ou do seu ciclo de vida. Por exemplo, o documento de teste registra os testes executados e os seus resultados; já o documento de manutenção registra as mudanças ocorridas no software ao longo de sua existência. É importante que todo documento retrate fielmente o software de modo que atividades como a avaliação e a modificação do software possam ser realizadas sem maiores transtornos.

Muitos outros beneficios são obtidos a partir de uma documentação cuidadosamente elaborada. Bons documentos podem resultar na redução do tempo e do esforço despendidos no desenvolvimento do software; os usuários tornam-se mais aptos a manusear o software de maneira mais fácil e eficiente; as estruturas do software tornam-se mais explícitas, facilitando a localização de informações e sua compreensão [PHO97]. 
Por outro lado, existem aqueles aspectos preocupantes com relação à produção de documentos. Fatores como altos custos, imprecisão e dificuldade de manipulação comprometem a criação e atualização dos documentos [TEI76;BLA97]. A combinação desses fatores inevitavelmente acarreta em documentos incompletos, desatualizados, inconsistentes e caros de se manter. A inconsistência em documentos de software também pode ser decorrente da ausência de um relacionamento mais explicito entre os documentos, uma vez que estes registram isoladamente uma etapa ou atividade do desenvolvimento do software.

Conforme se observa, não são poucos os problemas que afligem a documentação de software. No entanto, o impacto desses maleficios pode ser minimizado através da adoção de modelos que orientem na seleção do conteúdo dos documentos. A literatura dispõe de diversos modelos que podem ser seguidos [SOM96;PRE95a;PRE97]. Alguns modelos de documentos de software são:

- Documento de Especificação de Sistema

- Documento de Especificação de Requisitos de Software

- Documento de Especificação do Projeto

- Documento de Especificação de Teste

- e o Plano de Garantia de Qualidade

O Documento de Especificação de Sistema descreve a função, o desempenho e as restrições do sistema. No documento também são descritas as informações (dados e controle) que entram e saem do sistema. Os itens que constituem o documento são ilustrados na figura abaixo [Figura 2].

\begin{tabular}{|l|}
\multicolumn{1}{|c|}{ Documento de Especificação do Sistema } \\
I. Introdução \\
1. Escopo e propósito do documento \\
2. Visão geral \\
a. Objetivos \\
b. Restrições \\
II. Descrição funcional e de dados \\
1. Arquitetura do sistema \\
a. Diagrama de contexto da arquitetura \\
b. Descrição do diagrama de contexto da arquitetura \\
III. Descrições dos subsistemas \\
1. Especificação do diagrama de arquitetura para o subsistema n \\
a. Diagrama de fluxo de arquitetura \\
b. Narrativa modular do sistema \\
c. Questões de desempenho \\
d. Restrições de projeto
\end{tabular}


e. Alocação de componentes de sistemas

2. Dicionário de arquitetura

3. Diagramas dé interligação de arquitetura e descrição

IV. Resultados da modelagem e simulação do sistema

1. Modelo de sistema usado na simulação

2. Resultados da simulação

3. Questões de desempenho especiais

V. Questões de projeto

1. Custos de desenvolvimento projetados

2. Prazo projetado

VI. Apêndices

Figura 2. Documento de Especificação de Sistema [PRE95a].

O Documento de Especificação de Requisitos de Software é produzido durante a fase de análise de requisitos. Apresenta uma descrição detalhada da informação, dos requisitos de desempenho, das restrições de projeto, dos critérios de validação e de outros dados relevantes que compõem os requisitos do software [Figura 3].

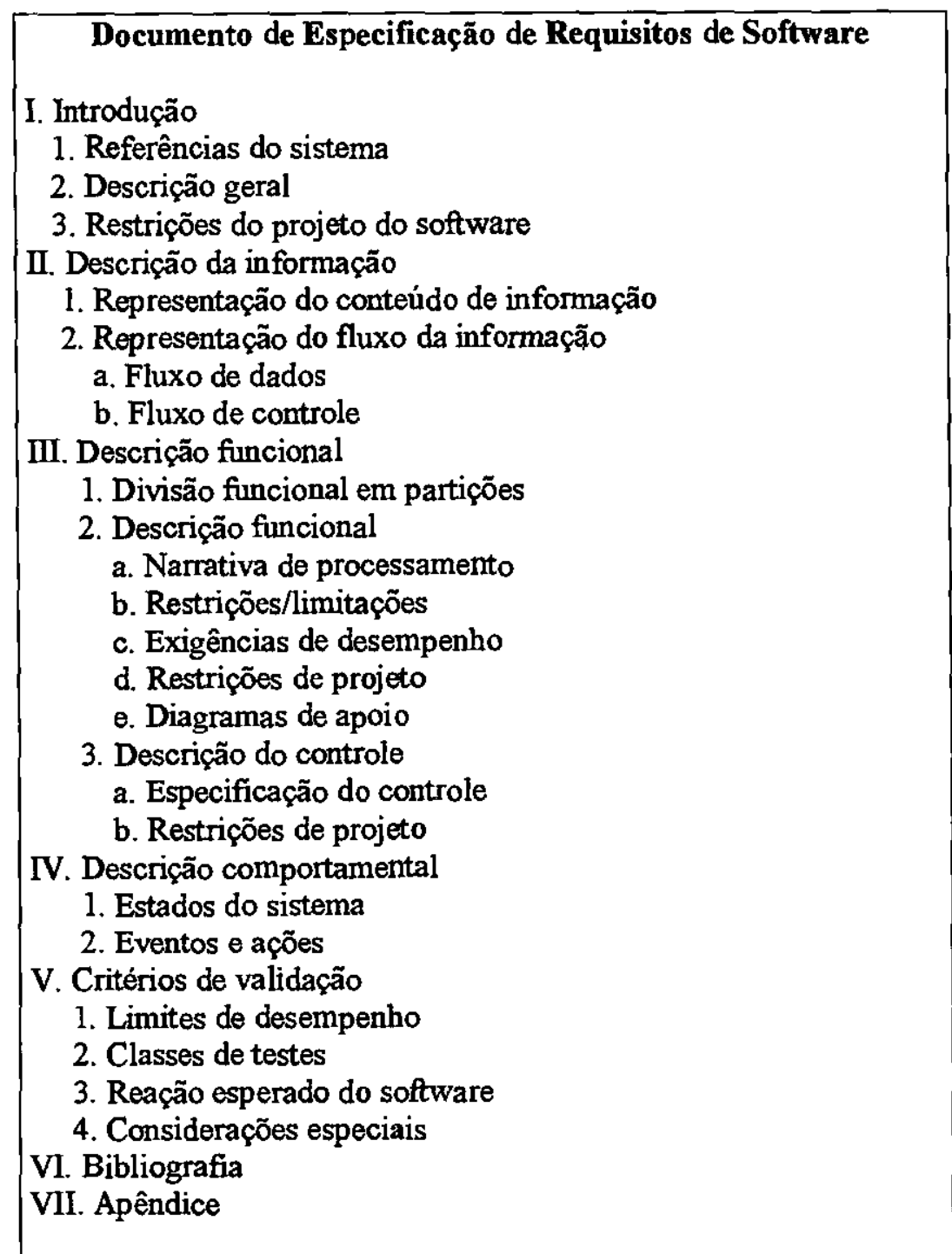

Figura 3. Documento de Especificação de Requisitos de Software[PRE95a]. 
O Documento de Especificação do Projeto apresenta uma descrição completa do projeto do software. No documento é descrita a arquitetura do software, os fluxos, as representações dos dados desenvolvidos durante a análise de requisitos, a interface do sistema, os módulos (rotinas, sub-rotinas, funções e procedimentos), a organização dos dados, os algoritmos e os procedimentos alternativos [Figura 4].

\begin{tabular}{|l}
\multicolumn{1}{c|}{ Documento de Especificação de Projeto } \\
I. Escopo \\
1. Objetivos do sistema \\
2. Maiores requisitos de software \\
3. Limitações e restrições do projeto \\
II. Projeto de dados \\
1. Objetos de dados e estruturas de dados resultantes \\
2. Arquivos e estruturas de banco de dados \\
a. Estrutura de arquivo extemo \\
i. Estruturas lógicas \\
ji. Descrição dos registros lógicos \\
iii. Métodos de acesso \\
b. Dados globais \\
c. Referência cruzada de dados e arquivos \\
III. Projeto da arquitetura \\
1. Revisão dos dados e controle de fluxos \\
2. Estrutura de programas derivados \\
IV. Projeto da interface \\
1. Especificação da interface homem-computador \\
2. Regras de projeto de interface homem-computador \\
3. Projeto da interface externa \\
a. Dados para interfaces extemas \\
b. Interfaces para sistemas ou dispositivos externos \\
V. Projeto procedural (Módulos; para cada módulo) \\
1. Narrativa do processamento \\
2. Descrição da interface \\
3. Descrição da linguagem de projeto \\
4. Módulos usados \\
5. Organização de dados \\
6. Comentários \\
VI. Referência cruzada dos requisitos \\
VII. Provisões de teste \\
1. Diretrizes de teste \\
2. Estratégia de integração \\
3. Considerações especiais \\
IX. Notas especiais \\
X. Apêndices \\
\end{tabular}

Figura 4. Documento de Especificação do Projeto [PRE95a]. 
O Documento de Especificação de Teste descreve os testes realizados com o software. O documento é responsável por apresentar desde a estratégia dẹ testes dos dados até os resultados esperados e obtidos [Figura 5].

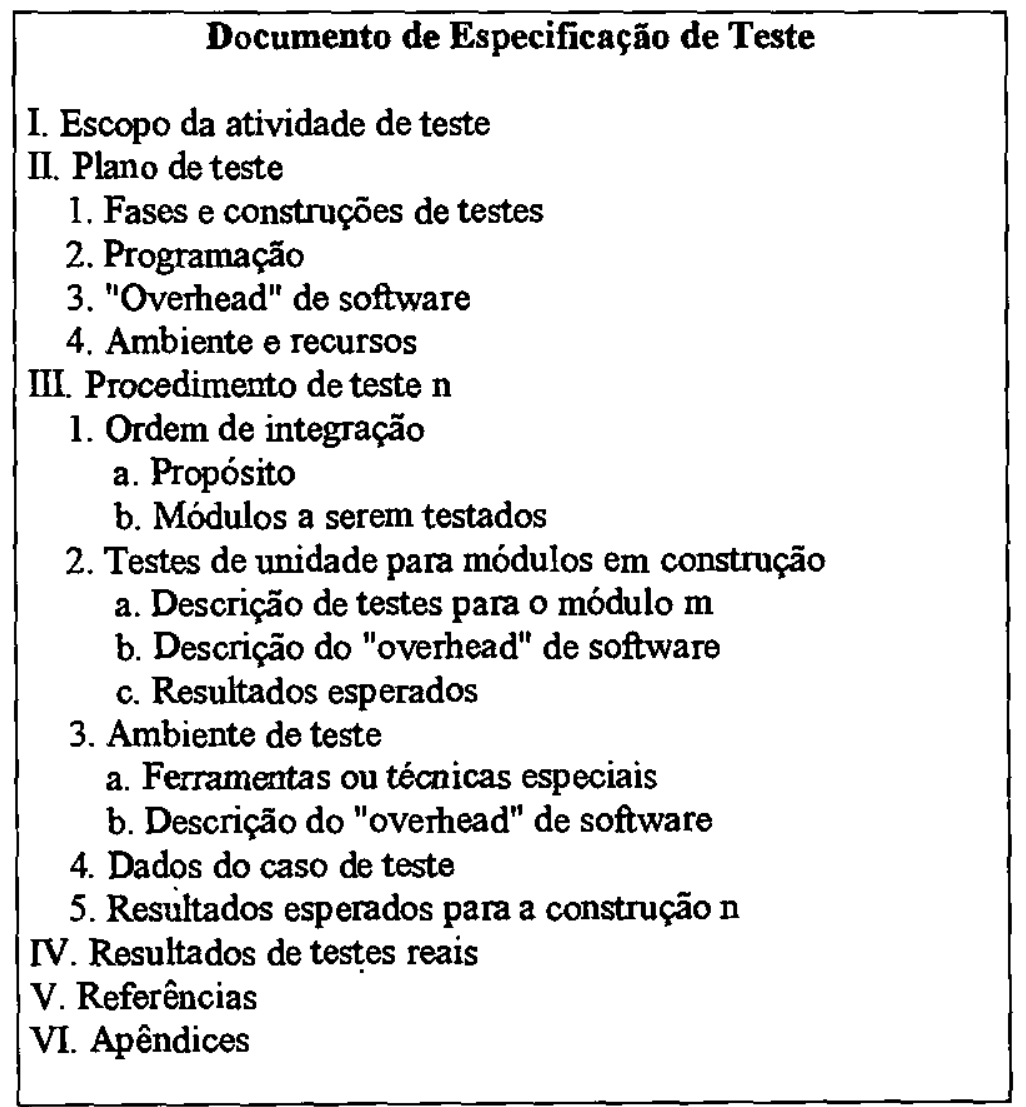

Figura 5. Documento de Especificaçã̃o de Teste [PRE95a].

O Plano de Garantia de Qualidade descreve os métodos, ferramentas, as revisões técnicas, as estratégias e técnicas de teste, procedimentos e mecanismos para assegurar qualidade ao software [Figura 6].

\begin{tabular}{|l|}
\multicolumn{1}{|c|}{ Plano de Garantia de Qualidade de Software } \\
I. Propósito do plano \\
II. Referências \\
III. Gerenciamento \\
1. Organização \\
2. Tarefas \\
3. Responsabilidades \\
IV. Documentação \\
1. Propósito \\
2. Documentos de engenharia de software requeridos \\
3. Outros documențos \\
V. Padrões, práticas e convenções \\
1. Propósito \\
2. Revisão dos requisitos \\
VI Revisões e Auditoria
\end{tabular}




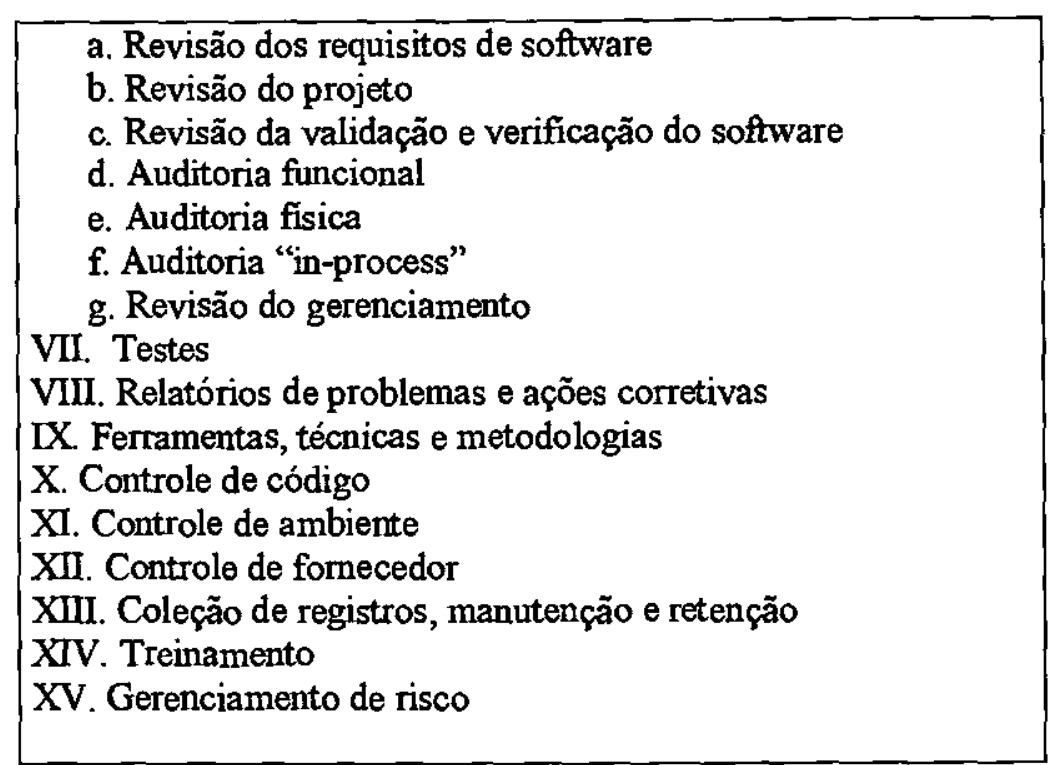

Figura 6. Plano de Garantia de Qualidade de Software [PRE95a].

A documentação do software não se limita, entretanto, somente ao registro das informações em papel impresso. Anotações no próprio código fonte do software são bastante úteis, pois podem auxiliar na compreensão das estruturas que formam o código do software. $O$ Laboratório Nacional de Computação Científica dispõe de dois modelos de anotações (documentos) em código fonte que podem ser seguidos: o Documento de Programa e o Documento de Rotinas, Procedimentos e Sub-Rotinas [LAB99].

O Documento de Programa fornece uma descrição clara e concisa da finalidade do programa e de outras informações que o programador julgar importante. Os itens do software documentados são os seguintes [Figura 7]:

- Nome do Programa: nome dado ao programa.

- Autor e Data: nome do(s) autor(es) do software e a data em que foi. liberado para. utilização.

- Descrição: descrição detalhada da finalidade do programa, contendo informações importantes.

- Linguagem: linguagem e versão em que foi implementado o programa.

- Palavras-Chave: palavras ou termos que auxiliem na identificação do software e de sua área de aplicação.

- Forma de Utilização: maneira pela qual o software é ativado.

- Entrada e Saída: nome de todos os arquivos de entrada e saída de dados.

- Mensagens de Erro: relação das mensagens de erro do programa, juntamente com as possíveis causas e indicações de correção de cada erro. 
- Requisitos: característica do hardware (exigência mínima), do sistema operacional e de outros softwares requeridos.

- Observação: demais informações contendo eventuais particularidades do programa, caso as informações acima desċritas não sejam suficientes.

Documentação de Programa
I. Nome do programa
II. Autor e data
III. Descrição
IV. Linguagem
V. Palavras-chave
VI. Formas de utilização
VII. Entrada e saída
VIII. Mensagens de erro
IX. Requisitos
X. Observação

Figura 7. Documentação de Programas.

O Documento de Rotinas, Procedimentos e Sub-Rotinas descreve as rotinas, funções ou sub-rotinas do software. Os itens documentáveis são [Figura 8]:

- Tipo e Nome da Rotina: trata-se uma rotina, sub-função ou função? Qual e que tipo de valor retorna (inteiro, real, etc, ...)? Que nome é atribuído?

- Autor e Data: nome do(s) autor(es) da rotina e a data em que foi liberada para utilização.

- Descrição: descrição detalhada da finalidade da rotina, contendo informações importantes.

- Linguagem: linguagem e versão em que foi implementada a rotina.

- Palavras-Chave: palavras ou termos que auxiliem na identificação da rotina.

- Forma de Utilização: maneira pela qual a rotina é ativada.

- Entrada e Saída: nome de todos os arquivos de entrada e saída de dados.

- Mensagens de Erro: relação das mensagens de erro da rotina, juntamente com as possíveis causas e indicações de correção de cada erro.

- Chamadas: relação das funções não pertencentes à biblioteca padrão da linguagem utilizada.

- Variáveis Externas: relação das variáveis externas utilizadas na rotina, fazendo observação sobre possíveis alterações dos seus valores.

- Portabilidade: dependências de hardware, software, versões, etc..

- Disponibilidade: esclarecimento sobre os tipos de usuários autorizados a ter acesso à rotina. 
- Observação: demais informações contendo eventuais particularidades do programa, caso as informações acima descritas não sejam suficientes.

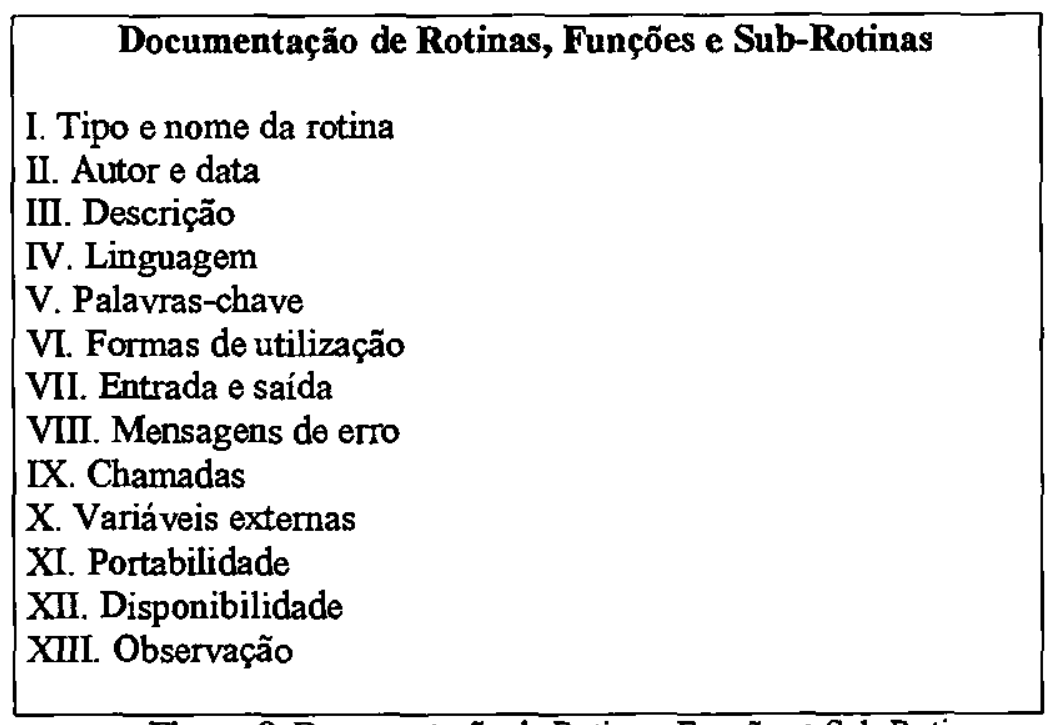

Figura 8. Documentação de Rotinas, Funções e Sub-Rotinas.

Entende-se que as anotações no código fonte estão mais fortemente vinculadas ao programador, caracterizando-se como um tipo de documentação muitas vezes de caráter pessoal. Recomenda-se então o uso de anotações tais como as apresentadas acima para assim tornar o código menos proprietário do programador. Outros modelos para anotações em código fonte podem ser encontrados em [PRE95a] e em [MAL99].

Nos últimos, anos tem-se investido muito em suportes automatizados ao processo de documentação de software. Estima-se que cada vez mais os documentos sejam produzidos por ferramentas automatizadas de modo a favorecer a produção de melhores documentos de software [PRE95a]. Em vista dessa tendência, na seção seguinte é apresentado um retrato da automatização do processo de documentação de software, em especial daquelas ferramentas que integram a hipermídia na produção e nos próprios documentos de software.

\subsection{Ferramentas Hipermídia de Documentação de Software}

As ferramentas de suporte ao desenvolvimento de software surgiram no início da década de setenta. Conhecidas como Ferramentas CASE (Computer-Aided Software Environment), tinham como objetivo automatizar as principais atividades manuais do engenheiro de software [BIG88]. Hoje, trinta anos depois, essas ferramentas oferecem suporte às mais variadas atividades do processo de desenvolvimento de software. 
As primeiras ferramentas de auxílio à documentação de software eram suportadas basicamente por um banco de dados. SODOS (Software Documentation Support Environment) é considerado um exemplo clássico [HOR86a] no qual podiam ser criados documentos altamente estruturados com as informações obtidas em cada una das fases do ciclo de vida do software. Ao banco de dados cabia à função de armazenar e associar todos os documentos criados [HOR86b].

Ao longo dos anos, as ferramentas de documentação de software foram evoluindo. Verificou-se que a integração dessas ferramentas às mais recentes tecnologias proporcionava um melhor desenvolvimento do software e garantia uma melhor qualidade ao produto final [DR097]. Dentre essas tecnologias pode-se citar a hipermídia.

$\mathrm{Na}$ literatura são encontradas diversas ferramentas que se utilizam da hipermídia para a documentação de software. Acredita-se que características como a possibilidade de leitura não-linear, diferentes formas de navegação, exploração e relacionamento da informação são, em grande parte, responsáveis pelo sucesso da aplicabilidade dessa tecnologia para documentação de software e na própria Engenharia de Software [GAR90;CYB92;FRE97].

Tamanha integração possibilitou que fosse identificado um conjunto de requisitos desejáveis em um sistema hipertexto com o objetivo de produzir documentos do ciclo de vida do software [CAB94]. Os requisitos são os seguintes:

- Suporte a trabalho cooperativo: necessidade de cooperação entre membros da equipe de desenvolvimento do software.

- Configurável: adaptabilidade da ferramenta a qualquer metodologia de desenvolvimento de software e integrável a outras ferramentas.

- Suporte a ambiente multiprojeto: relacionamento de documentos de projetos diferentes.

- Relacionamento de documentos: a documentação exige que os documentos estejam relacionados de alguma forma.

- Suporte a ambiente distribuído: desenvolvimento de software de grande porte requer grandes equipes.

- Controle de versões: registro das alterações e mudanças nos documentos.

- Geração de documentação impressa: viabilidade de documentos impressos em papel.

- Visões: documentação tratada sob diferentes pontos de vista, dos diferentes tipos de usuários.

- Consistência: mecanismos de consistência entre documentos.

- Informações complementares: registro de anotações, explicações e recomendações do desenvolvimento de software. 
A seguir é apresentada a revisão de ferramentas hipermídia de documentação de software encontradas na literatura. As ferramentas estão ordenadas conforme seu ano de construção e descritas apenas em suas características e recursos principais; mais detalhes podem ser obtidos consultando-se o trabalho original de cada uma.

\subsubsection{DIF [GAR90]}

Desenvolvido em 1990, DIF (Document Integration Facility) é um ambiente para desenvolvimento, manutenção e navegação de documentos hipertexto de sistemas de grande porte.

Uma importante característica dessa ferramenta é que os documentos produzidos estão diretamente associados com a fase do ciclo de vida a que pertencem, desde a análise de requisitos até a fase de testes do software. Além de relacioná-los com a respectiva fase ạ que pertencem, a ferramenta realiza a integração e gerenciamento desses documentos em uma única documentação.

Uma outra particularidade da ferramenta é o tratamento de cada segmento do documento como um objeto diferente. Esses objetos são processados, navegados, revisados, reutilizados e armazenados em uma estrutura de armazenamento hiperțexto. Assim, os links hipertexto entre documentos são vistos como relacionamentos entre objetos. Esses relacionamentos são armazenados em um banco de dados relacional.

Toda documentação produzida no DIF é baseada no método System Factory Documentation Method, desenvolvido na University of Southern California. Este método divide o processo de software em atividades, onde cada atividade culmina na produção de um documento. Os oito documentos definidos pelo método são: Especificação de Requisitos, Especificação Funcional, Especificação Arquitetural, Especificação Detalhada do Projeto, Código Fonte, Teste e Garantia de Qualidade, Manual do Usuário e Guia de Manutenção do Sistema

Outras características interessantes da ferramenta são: análise da consistência e completitude dos documentos, navegação por indexação ou por query, templates para criação de documentos, multiversões do documento, catálogo de componentes reutilizáveis e desenvolvimento paralelo de documentos.

DIF é uma das ferramentas analisadas que apresenta maior variedade de recursos e funções. Contudo, impõe uma séria restrição: todos os documentos produzidos enquadram-se 
no método de documentação System Factory. Caso o engenheiro de software precise criar um documento diferente, a ferramenta não possui a flexibilidade necessária para a criação desse documento.

\subsubsection{HyperCase [CYB92]}

HyperCase é um sistema que incorpora um conjunto de ferramentas para criação, edição e apresentação de documentos de software baseados em hipertexto. A tecnologia hipertexto é utilizada para proporcionar um melhor gerenciamento da informação e uma melhor navegação entre os documentos. O sistema visa auxiliar engenheiros de software no gerenciamento de projetos, análise de sistemas, e códigos fonte. Para realizar tais atividades, combina três ferramentas diferentes: uma ferramenta gráfica, uma base de conhecimento e um dicionário de dados.

As atividades de autoria, modificação e navegação de documentos são realizadas na ferramenta denominada HyperEdit [CYB92]. Essa ferramenta dispõe de um editor que permite a construção de textos e diagramas, tais como documento de requisitos, diagramas entidade-relacionamento, fluxogramas, código-fonte, etc. Uma importante característica dessa ferramenta é que a autoria pode ser condicionada ao tipo de usuário: por exemplo, analistas podem modificar documentos de projeto do software sem nenhuma restrição enquanto que os programadores apenas poderão visualizar tais documentos.

HyperBase é o repositório hipertexto [CYB92]. A ferramenta é dividida em dois módulos: o primeiro disponibiliza mecanismos e estruturas para organizar um sistema hipertexto genérico, e o segundo garante a consistência e a completitude dos documentos de forma que seus componentes possam ser reutilizados.

Por fim, todos os documentos são armazenados em um dicionário de dados comum, denominado HyperDict [CYB92]. A principal função do dicionário é controlar a integridade e a consistência do banco de dados.

A principal desvantagem do sistema HyperCase é a centralização do controle da documentação nos gerentes e nos engenheiros de software diretamente envolvidos em um projeto; pouco suporte é dado para os outros tipos de usuárioş que desejem manipular os documentos.

Contudo, HyperCase é um bom exemplo de ferramenta que integra os conceitos de

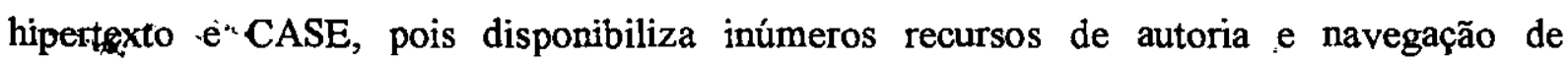
documentos. Dentre as outras características relevantes do sistema, vale citar: verificação da 
consistência de documentos por meio de parsing, registro da evolução do projeto, indexação e classificação de textos e diagramas, e múltiplas visões de um mesmo componente.

\subsubsection{Id [CAB94]}

Id é um sistema desenvolvido na Universidade Federal de Pernambuco cuja principal característica é apresentar uma arquitetura hipertexto para a organização documentos de software.

Duas características estimularam o desenvolvimento de uma arquitetura hipertexto para o sistema. Em primeiro lugar, os documentos deveriam ser organizados hierarquicamente, de forma que certos tipos de nós funcionassem como um agrupador de outros nós. Em segundo lugar, o sistema deveria permitir a utilização de documentos manipulados por diferentes ferramentas que desconheceriam a existência de um sistema hipertexto. Assim sendo, foi proposta uma arquitetura que funcionasse como um protocolo de comunicação entre as ferramentas externas e a máquina hipertexto.

De forma que os projetos pudessem ser desenvolvidos com facilidade de manutenção e extensão, e também para permitir a reusabilidade de componentes, o sistema foi desenvolvido segundo o paradigma de orientação a objetos e especificado formalmente usando a linguagem de especificação formal Mooz (Modular Object Oriented Z). Mooz é uma extensão da linguagem $\mathrm{Z}$ para incluir modularização através de classes, herança e polimorfismo usados pela OO [CAB94].

Dentre os produtos do trabalho, destacam-se os vários requisitos identificados para integração de documentos do ciclo de vida de software através de um sistema. hipertexto. Relembrando, estes requisitos são: suporte a ambiente distribuído, suporte ao trabalho cooperativo, arquitetura configurável, suporte ao ambiente multiprojeto, relacionamento de documentos, controle de versões, geração de documentação impressa, visões dos documentos, consistência e informações complementares.

Sem dúvida, Id é uma pesquisa relevante pois conseguiu integrar, em um mesmo sistema, diversas tecnologias como o hipertexto, orientação a objetos e métodos, formais. Contudo, o sistema construído somente atende o requisito Configurável.

\subsubsection{SLEUTH [FRE97]}


SLEUTH (Software Literacy Enhancing Usefulness to Humans) é um sistema desenvolvido na University of Virginia cujo objetivo é realizar o gerenciamento da documentação de software.

Uma característica interessante deste sistema são os tipos de links entre documentos. Os links são definidos por uma lista de termos (palavras-chave) criada pelo usuário durante a autoria de um documento. Automaticamente, o sistema gera links entre documentos que contiverem tal termo. De acordo com o autor, esse recurso encoraja a consistência de termos usados entre os documentos [FRE97].

Um caso especial ocorre durante a criação de links no código fonte. $O$ sistema permite criar link entre o texto e o respectivo arquivo ao qual o texto se refere. Por exemplo, se o código fonte possui o texto "biblioteca.h", um link é criado com o arquivo externo "biblioteca. $\mathrm{h}$ ".

Um outro importante recurso do sistema é o mecanismo de recuperação de informações. Esse mecanismo é uma variante da search engine WAIS (Wide Area Information Server) [KAH91], cuja técnica baseia-se na busca de informações por meio de expressões booleanas. Uma vez realizada a busca por um termo, os documentos são indexados numa lista de acordo com o número de vezes em que o termo ocorre, a localização da palavra, a frequiência daquele termo no conjunto de documentos, o tamanho do documento e outros demais índices.

Entretanto, os documentos criados no SLEUTH possuem uma formatação rígida. Dessa forma, as tarefas de criação e visualização dos documentos ficam condicionadas à estrutura hipertexto do documento. Outra restrição é que o sistema apresenta apenas uma única visão dos documentos criados, não considerando as necessidades navegacionais dos usuários.

O ponto forte do sistema são os mecanismos de busca e recuperação de informações. Para aumentar a granularidade da pesquisa, cada parágrafo de um documento é tratado como um documento à parte.

\subsubsection{DynaDoc [BRA98a]}

DynaDoc é uma ferramenta de geração automática de documentos de software a partir do código fonte de um sistema. Sob o ponto de vista do deșenvolvedor, o sistema auxilia em atividades como o entendimento e manutenção do software; sob o ponto de vista do usuário, no esclarecimento da utilização do próprio software. 
O processo de documentação efetuado pelo DynaDoc é fácil de ser entendido. Basicamente, o processo divide-se na transformação do código, no armazenamento das informações geradas e na navegação dos documentos.

Numa primeira etapa, o código fonte é analisado sintaticamente e uma árvore abstrata é gerada a partir desse código (arquivo externo). Em seguida, um conjunto de transformações é aplicado a essa árvore com o objetivo de obter informações estruturais do código. Essas transformações são executadas por uma instanciação do sistema transformacional Draco-PUC [LEI95]. Realizadas as transformações, as informações obtidas são armazenadas em um banco de dados relacional por meio de scripts implementados em linguagem Lua [IER96]. Por último, a navegação dessas informações dispostas em um documento HTML é feita via browser. A exploração das informações também pode ser feita por meio de queries SQL, dispostas também em páginas HTML.

No browser, os documentos gerados são organizados em dois frames. O frame da esquerda é um índice para os elementos do sistema. Esse é subdividido em pastas, as quais possuem links para os módulos, classes, funções e tipos dos elementos. $\mathrm{O}$ segundo frame, o da direita, apresenta a informação referente ao elemento selecionado no primeiro frame.

Analisando a ferramenta e seu processo de documentação, observou-se que DynaDoc destina-se à documentação de sistemas que foram implementados sob o conceito da orientação a objetos. A ferramenta não gera transformações de sistemas implementados procedimentalmente. Outra desvantagem da ferramenta é a exigência de um browser para a atividade de navegação dos documentos. Embora não esteja mencionado no artigo, acredita-se que os documentos não são compatíveis com outras ferramentas navegacionais.

DynaDoc é mais uma boa opção de ferramenta de Engenharia Reversa de sistemas. A geração automática da documentação é um recurso que poupa tempo e esforço do engenheiro de software.

\subsubsection{Concordance [MUN99]}

Concordance é um projeto em desenvolvimento da University of Wisconsin-Milwaukee que visa estudar como a tecnologia hipermídia pode fornecer melhores ferramentas para gerenciamento dos documentos produzidos pelo ciclo de vida de software.

A pesquisa envolve o desenvolvimento de representações de interoperabilidade entre os diferentes tipos de documentos. Essa interoperabilidade é expressa por meio de 
relacionamentos entre fragmentos de documentos e também por ligações bidirecionais entre tais fragmentos.

Uma segunda linha de investigação do projeto é o desenvolvimento de uma taxonomia de relacionamento entre os documentos de software. Essa taxonomia pretende identificar os tipos de relacionamentos entre os documentos e então criar uma representação para os relacionamentos. Essa representação: relacionará partes do documento, ao invés dos documentos inteiros; refletirá a natureza dinâmica dos documentos quando esses sofrerem alterações; suportará ligações bidirecionais; proporcionará uma representação compatível com as convenções da web; e outras características.

Uma terceira e última linha de investigação é o desenvolvimento de recursos para auxiliar a manutenção e o entendimento dos relacionamentos entre os documentos. Esses recursos permitirão a criação, inspeção e remoção desses relacionamentos além de propiciar a elaboração de queries para verificar a conformidade entre os documentos.

As idéias do projeto estão sendo implementadas em um ambiente para edição de programas Java e documentos XML (Extended Markup Language). $\mathrm{O}$ ambiente fornece ainda mecanismos sistemáticos para definição, manutenção e análise dos relacionamentos.

Sobre o Concordance há duas considerações a se fazer: em primeiro lugar, como ainda está em desenvolvimento, a pesquisa não possui resultados concretos; e em segundo lugar, a pesquisa enfatiza $o$ aspecto gerencial dos documentos. Não menciona mecanismos para a navegação e a exploração das informações presentes nos documentos.

De fato, essa pesquisa é uma interessante investigação da potencialidade da hipermídia na documentação de software devido a possibilidade de explorar recursos atuais como Java e XML. E principalmente, com relação à questão do relacionamento entre documentos.

\subsubsection{Outras Ferramentas de Documentação de Software}

Documentu [BRA98b] é um sistema bastante similar à ferramenta DynaDoc, pois utiliza um sistema transformacional para recuperar informações de sistemas. Essas informações são posteriormente armazenadas, validadas e formatadas pela ferramenta CASE Talisman [BRA98b]. A navegação e a exploração das informações são realizadas por meio de um browser comum.

Rigi é uma ferramenta de Engenharia Reversa de extração, navegação, análise e documentação da estrutura de sistemas [TIL92]. Para tanto, utiliza um sistema transformacional para recuperar informações de sistemas implementados em diferentes 
linguagens (incluindo $\mathrm{C}$ e $\mathrm{COBOL}$ ). Essas informações são apresentadas e relacionadas no formato hipertexto em um editor gráfico; entretanto, nenhum documento HTML é gerado. A principal vantagem da ferramenta é a variedade de visões das informações disponibilizadas.

HyperWeb não é propriamente uma ferramenta, mas um framework que suporta a construção de ambientes hipermídia de desenvolvimento de software [FER92]. O framework, de maneira geral, acessa um banco de dados para armazenar componentes de software e coordena o conjunto de ferramentas que relacionam, integram e modelam esses componentes. Baseado nesses conceitos foi desenvolvido um ambiente em que uma das tarefas é relacionar anotações em formato hipermídia sobre componentes do software.

\subsection{Análise Crítica das Ferramentas Revisadas}

Numa primeira análise, constatou-se que as ferramentas apresentadas nas Seções 2.3.1. a 2.3.7. possuem um rol de características e recursos bastante expressivo. Percebeu-se também que certas características são comuns a duas ou mais ferramentas. Vale lembrar que o estudo das ferramentas baseou-se na literatura científica, uma vez que não foram disponibilizadas para download de modo que uma aplicação prática pudesse ser desenvolvida. Abaixo estão relacionadas características e funcionalidades citadas nas ferramentas:

- Mecanismos de verificação de consistência e completitude dos documentos.

- Independência de metodologia de desenvolvimento do software.

- Mecanismos de busca e recuperação de informação.

- Disponibilidade de visões do software.

- Relacionamento entre documentos.

- Ambiente integrado de suporte às atividades de autoria e navegação de documentos.

- Suporte de um banco de dados.

- Disponibilidade de templates.

- Suporte a diferentes tipos de mídia (texto, áudio, vídeo e imagem).

- Reuso de elementos dos documentos.

- Interface WYSIWYG (What You See Is What You Get).

- Suporte multiprojeto.

- Integração com outras ferramentas.

- Controle de versões dos documentos. 
- Possibilidade de fazer anotações, esclarecimentos e recomendações sobre o software.

- Compatibilidadé dos' documentos com a WWW.

- Interoperabilidade entre documentos.

- Geração automática de documentos.

- Recursos navegacionais como history e bookmarks.

- Classificação dos documentos por conteúdo ou por relacionamento.

- Mecanismos de gerenciamento e manutenção das informações.

- Registro da evolução da documentação.

De todas as características observadas, cinco destacam-se pela sua alta aplicabilidade no contexto de requisitos gerais para suporte à documentação de software:

- independência de metodologia de desenvolvimento do software,

- disponibilidade de visões do software,

- relacionamento entre documentos,

- ambiente integrado de suporte às atividades de autoria e navegação de documentos $\mathrm{e}$

- stporte de um banco de dados.

Essas cinco características são discutidas a seguir.

\subsubsection{Independência da Metodologia de Desenvolvimento do Software}

Uma metodologia de desenvolvimento de software pode ser entendida como o conjunto de normas, procedimentos e técnicas para o desenvolvimento de projetos de sistemas [PRE97; FER99]. Constatou-se que grande parte das ferramentas estudadas possui independência da metodologia de desenvolvimento de software, uma vez que permitem o usuário produzir documentos de acordo com os seus próprios interesses, não estando necessariamente atrelados a um ciclo de vida ou processo de desenvolvimento pré-definido.

De fato, quanto maior a liberdade atribuída à criação de documentos, maior é a aplicabilidade da ferramenta na produção dos mais distintos documentos. A flexibilidade da ferramenta na manipulação de diferentes contextos de informação possibilita que o usuário documente o software sob diferentes ângulos de modo a proporcionar um retrato mais fiel do software e uma leitura posterior dos documentos mais agradável. 
Algumas outras vantagens dessa flexibilidade são a possibilidade da documentação de sistemas de portes diferentes e a adaptabilidade da ferramenta a diferentes equipes de desenvolvimento de software, as quais podem adotar seu próprio estilo de documentação.

Entretanto, a flexibilidade de criação de documentos não significa uma aversão total a documentos pré-definidos (templates). Templates podem fornecer uma orientação a usuários inexperientes, pois apontam um conjunto de informações básicas que $o$ documento de software deve conter sobre uma determinada etapa do desenvolvimento do software.

\subsubsection{Visões do Sistema e do Software}

Uma visão de software representa um estado do software em um determinado momento de seu desenvolvimento. As visões são úteis pois podem: enfatizar componentes que precisam ser melhor analisados e discutidos, retratar análises das mudanças, impactos ou desempenho do software, auxiliar na tomada de decisões gerenciais, recuperar informações do software e melhorar a compreensão do sistema [TIL92].

Uma grande parte das ferramentas analisadas disponibiliza modos de visualizar o software através dos documentos produzidos. Essa visualização ocorre ora pela simples exploração dos documentos (ou um conjunto deste), ora por estratégias navegacionais definidas pelo ambiente de navegação.

A visualização do software pode ser destinada tanto a usuários experientes, 0 engenheiro de software, como a usuários inexperientes. A necessidade da ferramenta atender ao maior número de usuários justifica-se pelo fato que as visões estão diretamente relacionadas com o grau de abstração com que os diferentes usuários entendem o software. Essa relação é importante porque várias pessoas manipulam a documentação do software em busca das informações: o engenheiro de software, por exemplo, pode estar interessado nos requisitos do software; por outro lado, o usuário final pode estar interessado somente no documento que descreve uma visão geral do software.

Portanto, os usuários "enxergam" o software sob diferentes pontos de vista através de seus documentos. Desse modo, as ferramentas que apresentam formas efetivas de visualização assistem na compreensão do software e na própria compreensão dos documentos. Allison dizia que "uma efetiva visualização requer formas de abstração do software para então reduzir a informação apresentada ao usuário." [ALL97]. 


\subsubsection{Relacionamento entre Documentos}

Muito embora um documento registre uma etapa ou atividade realizada isoladamente, todos os documentos produzidos são relacionados. Munson ilustra esse fato pela seguinte consideração: "Requisitos motivam o projeto; o projeto requer a implementação; o relatório de erros reporta falhas entre os requisitos e a implementação; o manual do usuário documenta o projeto e a implementação." [MUN99]. Ou seja, inerentemente, todos os documentos criados ao longo do ciclo de vida do software possuem algum tipo de relacionamento entre si.

Analisando as ferramentas, verificou-se ao menos uma forma de relacionar os documentos de software produzidos. As ferramentas permitem criar relacionamentos entre os documentos ou entre partes de documentos de modo que a documentação final esteja integrada com vistas a atingir uma maior eficiência na.atividade de navegação.

Nota-se que os relacionamentos entre documentos são basicamente atribuídos ao suporte hipermídia na ferramenta. A importância da hipermídia auxilia, portanto, não somente no que se refere à navegação pelas informações, mas também em proporcionar uma maior associação dessas mesmas informações. Assim, obtém-se um melhor entendimento do software pelo usuário e facilita-se as atividades de gerenciamento e manutenção das informações.

\subsubsection{Ambiente Integrado de Autoria e Navegação de Documentos}

As duas principais atividades de uma ferramenta hipermídia de documentação de software são a autoria e a navegação dos documentos. Em suma, autoria consiste na criação, qualificação e organização dos nós (documentos); por sua vez, navegação refere-se à atividade de exploração e recuperação das informações contidas nesses documentos [CYB92].

Verificou-se que um número expressivo de ferramentas possui um ambiente integrado de autoria e navegação de documentos. Tal característica facilita o trabalho do usuário, uma vez que não precisa manipular diferentes ferramentas para criar, manipular ou mesmo visualizar os documentos de software. A partir de um ambiente integrado é possível obter uma melhor interação do usuário com a ferramenta, evitando-se problemas de usabilidade tal como inconsistência entre interfaces.

Percebeu-se ainda que algumas das ferramentas que geram documentos no formato HTML, de modo dinâmico ou não, exigem um browser para a navegação dos documentos. Esse fato gera preocupações de integração e a interoperabilidade da ferramenta com o 
browser, uma vez que o usuário tem que manipular um segundo aplicativo além da própria ferramenta.

\subsubsection{Suporte de um Banco de Dados}

Conforme visto, a união de ferramentas de documentação de software com a tecnologia de banco de dados é bastante comum. Nas primeiras ferramentas essa tecnologia já era utilizada para o armazenamento, gerenciamento e associação dos documentos produzidos no processo de desenvolvimento de software [HOR86a].

Nesse contexto, muitas das ferramentas analisadas são suportadas por bancos de dados cuja função não reside somente em armazenar as informações, mas também prover um relacionamento e organização mais regulares destas mesmas informações. Outra característica observada diz respeito à recuperação das informações. Como são disponibilizados recursos de busca e consulta das informações, é importante que as informações estejam devidamente organizadas na base de dados de forma que essas buscas sejam rápidas e precisas.

Embora banco de dados seja muito empregado, algumas ferramentas adotam outra forma de armazenamento de documentos. São encontrados exemplo de armazenamento de documentos em árvore de arquivos e diretórios Unix [GAR90] e o armazenamento dos documentos em ferramentas externas [CAB94].

\subsection{Consideraçōes Finais}

A análise das ferramentas identificou úm vasto conjunto de características que, a princípio, auxiliam o usuário a produzir uma melhor documentação. Essas características proporcionam também o suporte necessário à atividade de navegação dos documentos, de forma que as atividades de busca e a exploração de informações sejam realizadas eficientemente.

Desse conjunto, cinco foram selecionadas como as mais representativas no contexto de uma ferramenta com tal propósito. Acredita-se que esses reçursos, juntamente com demais outras, formam um conjunto de características que proporciona suporte adequado às tarefas de produção e exploração de documentos de software. No entanto, há outras características que, se acrescentadas, podem proporcionar um aumento no entendimento da documentação pelo usuário assim como melhorias na navegação e na organização das informações dos 
documentos. Como exemplo dessas características, pode-se citar as estratégias navegacionais de documentos e o suporte de um modelo hipertexto.

Observou-se que a navegação dos documentos é de certo modo limitada pela presença de estratégias convencionais de exploração da informação. Essas estratégias baseiam-se principalmente na exploração dos relacionamentos entre os documentos; as estratégias mais sofisticadas baseiam-se em queries no banco de dados ou no próprio texto do documento. Uma alternativa para que o usuário consiga explorar a totalidade do conteúdo da documentação sob diferentes ângulos seria através de estratégias navegacionais condicionadas a características dos documentos. Por exemplo, assumindo que os documentos são caracterizados por um conjunto de respectivos atributos, o usuário poderia navegar pela documentação a partir de estratégias relativas a um único atributo desses documentos. Dessa forma, a navegação seria orientada por documentos com características semelhantes.

A útilização de um modelo conceitual hipertexto em uma ferramenta hipermídia de documentação de software permitiria que as informações de documentos fossem armazenadas e organizadas, tendo-se por base os conceitos de nós e links. A principal vantagem dessa proposta é que a máquina hipertexto formaria na ferramenta uma camada separada da camada de armazenamento e apresentação das informações. Na literatura podem ser encontrados diversos exemplos de modelos hipertexto [CAM88;SOA95a].

$O$ fato das características citadas anteriormente serem contempladas em uma ferramenta também não assegura propriamente qualidade aos documentos produzidos. Mas sem dúvida, quanto maior o número de recursos, maiores também são as chances de se produzir melhores documentos. A completitude e a qualidade da documentação dependem de fatores subjetivos como o bom-senso, profissionalismo e a experiência do engenheiro de software.

Neste capitulo foram revisadas as muitas facetas da documentação de software: os seus aspectos positivos (redução do tempo e do esforço no desenvolvimento do software), aspectos negativos (altos custos e tempo requeridos) e modelos para documentos de software. Verificou-se, entre outras coisas, que a documentação de software não é tarefa fácil e que ainda requer muita pesquisa.

Em vista dos problemas relacionados com a produção de documentos de software, houve a necessidade de se desenvolver mecanismos que auxiliassem o engenheiro de software a produzir documentos de maneira mais eficiente. Esses mecanismos, implementados em ferramentas automatizadas, posteriormente proporcionaram um aumento na produtividade e na qualidade dos documentos de software [CYB92;FRE97].

A partir da integração da hipermídia nessas ferramentas foi então possivel estabelecer mais facilmente os relacionamentos entre os diferentes documentos produzidos. Assim como 
foi possivel também avaliar com mais cuidado as dependências existentes entre os documentos que descrevem o ciclo de vida do software.

Diante do quadro da automatização da documentação, várias ferramentas hipermídia de documentação de software foram analisadas com o objetivo de identificar suas principais características e recursos. Os resultados da análise identificaram características (como a independência de método de desenvolvimento, o suporte a diferentes tipos de mídia, o suporte à autoria e navegação de documentos, múltiplas visões dos documentos e a incorporação da tecnologia de recuperação de informação) importantes na produção, controle, navegação e gerenciamento de toda a documentação. Uma experiência maior com essas ferramentas não foi possivel devido não estarem disponiveis para download; contudo, esse fato não interferiu na análise das características descritas.

Algumas das características coletadas das ferramentas hipermídia de documentação de software também podem ser encontradas no sistema SASHE, um ambiente de desenvolvimento de aplicações hipermídia para o domínio Ensino. Sendo assim, investigou-se a predisposição do SASHE a atender a atividade de documentação de software. A investigação dessa hipótese é mostrada no capítulo seguinte. 



\section{Capitulo 3}

\section{O Sistema SASHE}

\subsection{Considerações Iniciais}

O SASHE é um sistema projetado para o desenvolvimento e apresentação de aplicações hipermídia do domínio Ensino [NUN97a;NUN97b]. Os primeiros experimentos com o sistema indicaram que alguns de seus recursos poderiam ser aplicados em outros domínios de informação, além do Ensino; entre esses recursos está a construção de roteiros, cuja utilização independe do caráter da informação que constitui a aplicação. De acordo com Nunes [NUN97a], a construção de roteiros poderia ser aproveitada na tarefa de navegação de documentos de software (os quais comporiam uma aplicação), proporcionando ao engenheiro de software uma melhor visualização dos componentes do sistema retratados nos documentos.

A observação de que os recursos do SASHE poderiam ser aplicados na Engenharia de Software foi a principal motivação deste trabalho. Também consideramos que o reuso de recursos do SASHE para atender a esse domínio possibilitaria que identificássemos procedimentos iniciais necessários à generalização do SASHE para outros domínios de informação. Inicialmente, procuramos identificar quais os recursos passíveis de reutilização. Essa atividade também permitiu obter mais conhecimento e mais informações acerca do SASHE, que serviriam como referência nas futuras atualizações do sistema ou em eventuais aplicações de seus recursos em outros sistemas.

A ausência de relatos na literatura sobre o reuso de recursos do SASHE somada aos benefícios que podem ser atingidos com a identificação desses recursos motivaram os estudos apresentados neste capítulo. No primeiro estudo foi realizada uma investigação da hipótese da existência de componentes do SASHE propícios à reutilização em outros sistemas. No segundo estudo, pesquisou-se a utilização desses mesmos recursos no domínio da 
documentação de software. Ambas as investigações, além de seus objetivos principais, proporcionaram um maior embasamento do SASHE e de possibilidades de sua aplicação.

Assim, na Seção 3.2. o sistema SASHE é apresentado com suas características principais. Na Seção 3.3. é descrita a investigação na qual foram apontados aqueles recursos do SASHE aplicáveis em outros domínios de informação. Na seção seguinte é apresentada a investigação na qual o SASHE é manipulado tal como uma ferramenta de documentação de software. Ao final, as considerações finais do capítulo.

\subsection{O SASHE}

SASHE, acrônimo de Sistema de Autoria e Suporte Hipermídia para Ensino, é um sistema desenvolvido para a autoria e navegação de aplicações hipermídia para o Ensino. Projetado e implementado no Instituto de Ciências Matemáticas e de Computação da USP/São Carlos, integra o conjunto de pesquisas do projeto ProTeM/HyperProp [SOA95;NUN97a].

Sua primeira versão foi desenvolvida em 1997 por [SAN97] como uma extensão do sistema Hip/Windows, um ambiente de autoria de hiperbases multimídia [NUN96]. Dois anos depois, a segunda versão é implementada por [HAB99;PAN99]. Independentemente da versão, o sistema contempla dois tipos de usuários: aquele que cria a aplicação hipermídia (hiperbase), denominado autor, e aquele que navega a aplicação, o leitor. Visto que as aplicações pertencem ao domínio Ensino, o autor e o leitor são também conhecidos como professor e estudante, respectivamente.

O.SASHE é um sistema do qual se originaram importantes pesquisas:

- Santos discutiu o potencial e, principalmente, os problemas decorrentes do uso de sistemas hipermídia tradicionais em aplicações de ensino e aprendizagem [SAN97]. $O$ trabalho propôs e implementou o primeiro protótipo do SASHE, cuja versão apresentava recursos básicos para a autoria e a navegação de aplicações hipermídia.

- Feltrim investigou uma estrutura adequada de hipertexto para apoiar a documentação requerida durante o processo de Engenharia Reversa de software [FEL99]. A investigação é baseada na experiência de autodocumentar o SASHE. Um de seus resultados foi desenvolvimento de um modelo de hiperdocumento para o domínio de informações referentes ao processo de Engenharia Reversa de software. 
- Pansanato apresentou um método para projeto de hiperdocumentos para Ensino (EHDM Educational Hyperdocuments Design Method) que proporciona uma abordagem sistemática para apoiar o projeto e desenvolvimento de aplicações. hipermídia para o domínio Ensino [PAN99]. O método oferece um modelo de representação adequado para descrever o domínio de conhecimento e os aspectos navegacionais de hiperdocumentos para o Ensino. O protótipo de uma ferramenta que suporta o método foi desenvolvido e integrado ao SASHE.

- Haber investigou a integração de documentos HTML (Hypertext Markup Language) advindos da WWW para representação interna no ambiente SASHE [HAB99]. O trabalho estende a capacidade do editor original de nós de informação do ambiente para que o autor possa, além de navegar pelo hiperdocumento, remodelar sua estrutura organizacional.

Essas duas últimas pesquisas resultaram no desenvolvimento do SASHE 2.0, a atual versão do sistema. Basicamente, nessa versão foram acrescentadas novas funcionalidades e sanados os problemas observados na versão anterior. Sobretudo, foram feitas grandes mudanças em sua arquitetura original. A atual arquitetura é formada pelo módulo de autoria e o módulo de navegação, conforme apresentado na figura a seguir [Figura 9]. A seguir, ambos os módulos são descritos com mais detalhes.

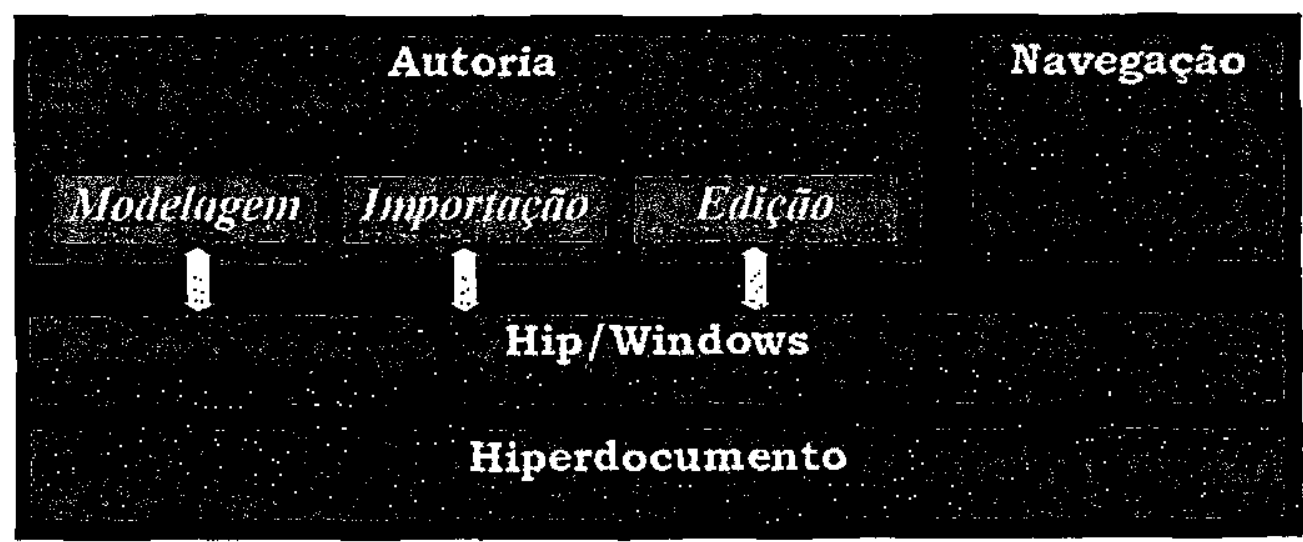

Figura 9. Arquitetura do SASHE 2.0 [HAB99].

\subsubsection{Módulo de Autoria}

O módulo de autoria destina-se ao projeto e o desenvolvimento das aplicaçð̃es hipermídia. Este módulo é dividido em três submódulos: Edição, Modelagem e Importação. 


\subsubsection{Módulo de Edição}

O módulo de edição visa realizar as tarefas de edição de uma aplicação hipermídia [NUN97a]. Uma aplicação no SASHE é formada por um ou mais hiperdocumentos, por sua vez, os hiperdocumentos são formados por nós e elos. No sistema são definidos dois tipos especiais de nós: os nós terminais, que podem conter objetos com informações textuais, gráficas, de áudio, de vídeo ou mesmo arquivos executáveis, e os nós de composição, elementos responsáveis por agrupar outros nós.

Os nós terminais são caracterizados pelas informações atribuídas às suas propriedades. Suas propriedades são: Nome, que define o título do nó; Palavras-Chave, que define um conjunto de termos que identificam o conteúdo do nó; Função Didática, que define um conjunto de classes que o nó pode assumir na aplicação (essas classes são Introdução, Motivação, Exercício, Definição, Bibliografia, Glossário, Resumo, Exemplo e Ajuda); Dificuldade, que indica o nível de dificuldade do nó terminal (Fácil, Regular ou Dificil); e, por fim, Arquivo, que define o arquivo externo associado ao nó.

Os principais nós de composição são nós do tipo trilha e nós de contexto. Os nós de contexto indicam o assunto de que tratam os nós nele contidos, de acordo com o valor atribuído à sua propriedade Nome. Tais nós podem ser nós terminais ou mesmo outros nós de contexto. A principal vantagem dos nós de contexto é permitir que os hiperdocumentos tenham uma hierarquia aninhada de seus elementos. Os nós do tipo trilha representam os caminhos que devem ser ou foram percorridos pelo leitor durante a navegação da aplicação.

No SASHE, os nós são relacionados por elos. Elo é a entidade que estabelece uma ligação unidirecional entre os nós da hiperbase. Os elos possuem duas propriedades: Apresentação Simultânea, que indica se o nó destino deve ser apresentado simultaneamente ao nó origem, e Apresentar os Nós Terminais do Contexto, que indica se, na apresentação de um nó de contexto destino do elo, todos os seus nós terminais devem ser mostrados.

Uma das principais atividades também desenvolvidas no módulo de Edição é a autoria de roteiros. Roteiro é uma seqüência de nós (hiperdocumentos) que são apresentados a um determinado grupo de usuários na navegação.

Os roteiros são caracterizados pelas suas propriedades e pelo grau de liberdade associado a cada nó. As propriedades de um roteiro são: Nome, que define o título do roteiro; Contexto, que apresentam os contextos da aplicação; Palavras-Chave, que define um conjunto de termos que identificam o conteúdo do nó; Função Didática, que define um conjunto de classes que o nó pode assumir na aplicação (Introdução, Motivação, Exercício, Definição, Bibliografia, Glossário, Resumo, Exemplo, Ajuda e Todas); Dificuldade, que indica o nível 
de dificuldade do nó terminal, que pode ser Fácil, Regular, Dificil ou Todas. O grau de liberdade de nós de um roteiro significa o limite máximo que o leitor pode se afastar da trilha do roteiro sem que o entendimento dos hiperdocumentos seja comprometido.

O módulo de autoria dispõe ainda de recursos visualizadores como o browser gráfico $\mathrm{e}$ o browser estrutural. $\mathrm{O}$ browser gráfico permite que o usuário visualize a estrutura de um hiperdocumento tal como se fora um grafo. São mostrados no browser apenas os nós e elos contidos no atual contexto, mas também é possível visualizar aqueles contextos mais aninhados. Por outro lado, o browser estrutural apresenta a estrutura de um hiperdocumento na forma de diretórios. Podem ser visualizados os nós terminais, os nós de contexto e o nó do tipo trilha.

\subsubsection{Módulo de Modelagem}

O módulo de modelagem surgiu como uma solução para o problema da estruturação lógica de nós no hiperdocumento [PAN99]. O módulo é apoiado pelo método EHDM (Educational Hyperdocuments Design Method) cuja abordagem proporciona suporte ao projeto e ao desenvolvimento de aplicações hipermídia para Ensino. O método é composto basicamente por três fases: modelagem conceitual hierárquica, projeto navegacional de contextos e, por último, construção e teste.

A fase de modelagem conceitual hierárquica consiste na descrição do domínio de conhecimento do hiperdocumento; nessa fase, um modelo é construído para representar os aspectos relevantes do domínio. A fase de projeto navegacional de contextos deriva um ou mais modelos navegacionais de contextos a partir do modelo criado na fase anterior. A fase de construção e teste consiste na conversão do modelo navegacional de contextos em uma aplicação hipermídia final. Atualmente, uma ferramenta que suporta o método EHDM encontra-se incorporada à interface do SASHE (EHDT - Educational Hyperdocuments Development Tool).

\subsubsection{Módulo de Importação}

O módulo de importação visa integrar documentos HTML advindos da WWW nas aplicações do SASHE [HAB99]. A importação desses documentos pode proporcionar ao estudante aplicações mais ricas e com um conteúdo mais atualizado. Esse mecanismo de importação é implementado pela $\mathrm{Html} 2 \mathrm{Hip}$, uma segunda ferramenta acoplada à interface do SASHE [HAB99]. 
Em síntese, a ferramenta converte a estrutura de um documento HTML para a estrutura interna do SASHE. O mecanismo reconhece a estrutura organizacional desses documentos e os traduz para uma estrutura de nós e contextos.

\subsubsection{Módulo de Navegação}

O módulo de navegação visa à navegação e a exploração dos hiperdocumentos que constituem um roteiro [NUN97a]. Para isso, utiliza-se de uma barra de controle onde estão dispostos botões associados a estratégias de navegação. $\mathrm{Na}$ realidade, essas estratégias são funções que se utilizam das informações dos atributos e da contextualização dos nós definidos durante a atividade de autoria da aplicação. Os botões da barra de controle de navegação são os seguintes:

- Está Fácil/Está Difícil: apresentam informações ao usuário de acordo com o grau de dificuldade do hiperdocumento.

- Bibliografia: apresenta a bibliografía relacionada ao nó.

- Glossário: apresenta uma interface para busca e apresentação de termos relacionados ao nó.

- Exercícios: mostra uma lista de exercícios associados ao nó.

- Ajuda: realiza uma busca no contexto por um nó de igual atributo, que contenha perguntas e respostas mais freqüentes do tópico em questão.

- Onde Estou?: situa graficamente o nó atual do roteiro que está sendo percorrido.

- Histórico: situa o nó atual na trilha de nós já percorridos.

- Contexto: mostra o contexto correspondente ao grau de liberdade do nó atual, incluindo demais nós e todas as ligações do nó de contexto.

- Mais Informaçōes: executa uma busca por nós que possuam uma ou mais palavras-chave em comum com o nó atual.

- Tópicos: avança ou retrocede no roteiro.

- Histórico: avança ou retrocede na trilha percorrida pelo estudante.

Diferentemente dos demais, os botões Está Fácil e Está Dificil associam estratégias sofisticadas para a seleção dos próximos nós. A primeira estratégia procura por nós no mesmo contexto com maior ou menor grau de dificuldade em relação ao nó atual. Nesse caso, a busca 
utiliza-se das informações do atributo Grau de Dificuldade do nó. Já a segunda estratégia, um pouco mais complexa, mostra os nós com a Função Didática dependente do nó atual. Ou seja, considera a informação do atributo Função Didática para a seleção do próximo nó. A seleção do nó por essa estratégia ocorre por meio de correspondências entre atributos do nó.

A interface do módulo de navegação é ilustrada pela figura abaixo [Figura 10].

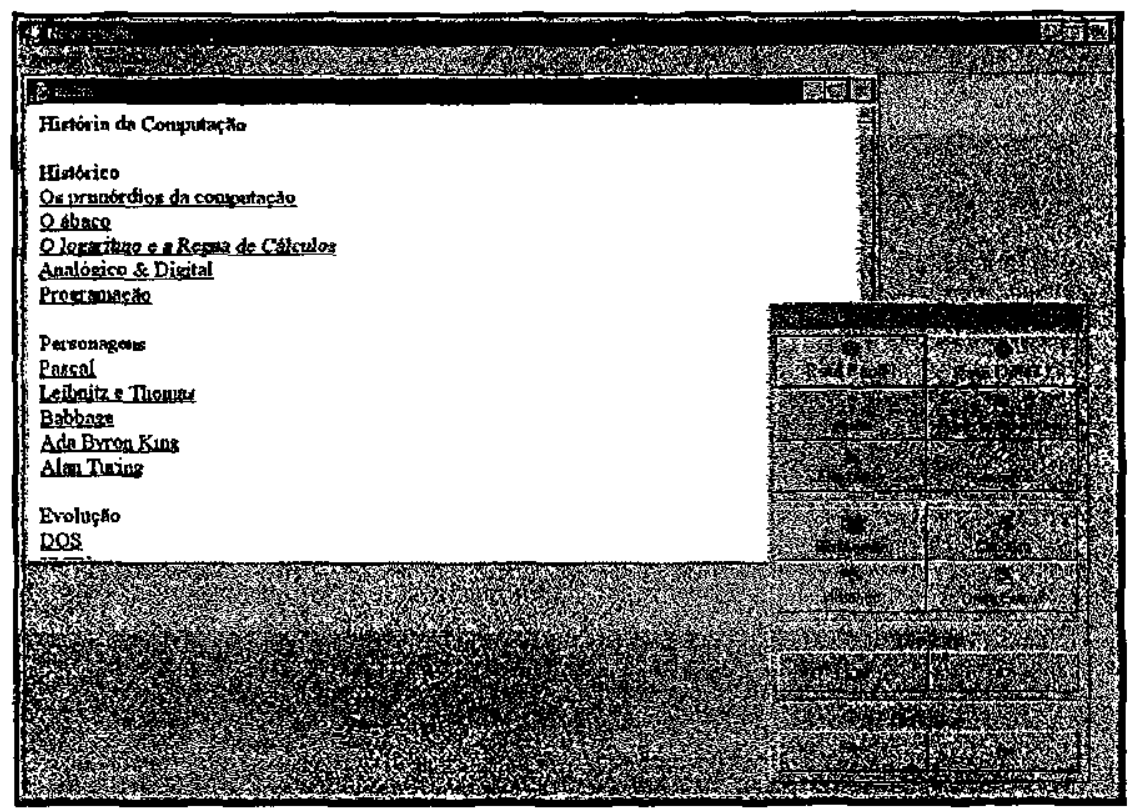

Figura 10: Interface do Módulo de Navegação do SASHE 2.0.

\subsection{Reuso de Recursos do SASHE}

Como mencionado, nos primeiros experimentos com o SASHE foi observado que o sistema apresenta recursos com chances de serem aproveitados em outros domínios de informação, além de seu domínio de Ensino original [NUN97a]. Embora exista uma riqueza de recursos no SASHE, não constam pesquisas sobre o emprego desses recursos em outros sistemas. Uma forma de estimular pesquisas nessa linha seria identificar quais são os recursos do SASHE que poderiam ser utilizados em outros sistemas, independente do domínio que pertençam.

Os ganhos com essa atividade são: acréscimo à base de informações, maior embasamento do sistema, identificação de erros e problemas de usabilidade, identificação de domínios em que os recursos poderiam ser aplicados e oportunidades de melhoria do sistema no dominio Ensino. 
Assim, esses beneficios motivaram a identificação desses recursos no SASHE. A identificação, realizada por meio do desenvolvimento de aplicações e da leitura da documentação disponível, enfatizou aqueles recursos que podem ser empregados em sistemas pertencentes a qualquer domínio.

Com o objetivo de assegurar maior confiabilidade nessa tarefa, foram construídos diagramas de transição de estados (DTEs) para retratar o comportamento do usuário na manipulação da interface do SASHE. Os DTEs são representações gráficas que expressam a ação do usuário no sistema e apontam os efeitos que isso provoca [SHU88].

Os diagramas foram construídos a partir das sentenças que compõem o modelo de ciclo de vida do SASHE. Esse modelo foi derivado obtido a partir do processo de Engenharia Reversa do SASHE realizado por Feltrim [FEL99]. A [Figura 11] ilustra um dos vários DTEs construídos a partir das sentenças que compõem o modelo de ciclo de vida. Vale lembrar ainda que a construção dos DTEs contou com o suporte da ferramenta Rational Rose (a ser descrita mais adiante) [RAT99].

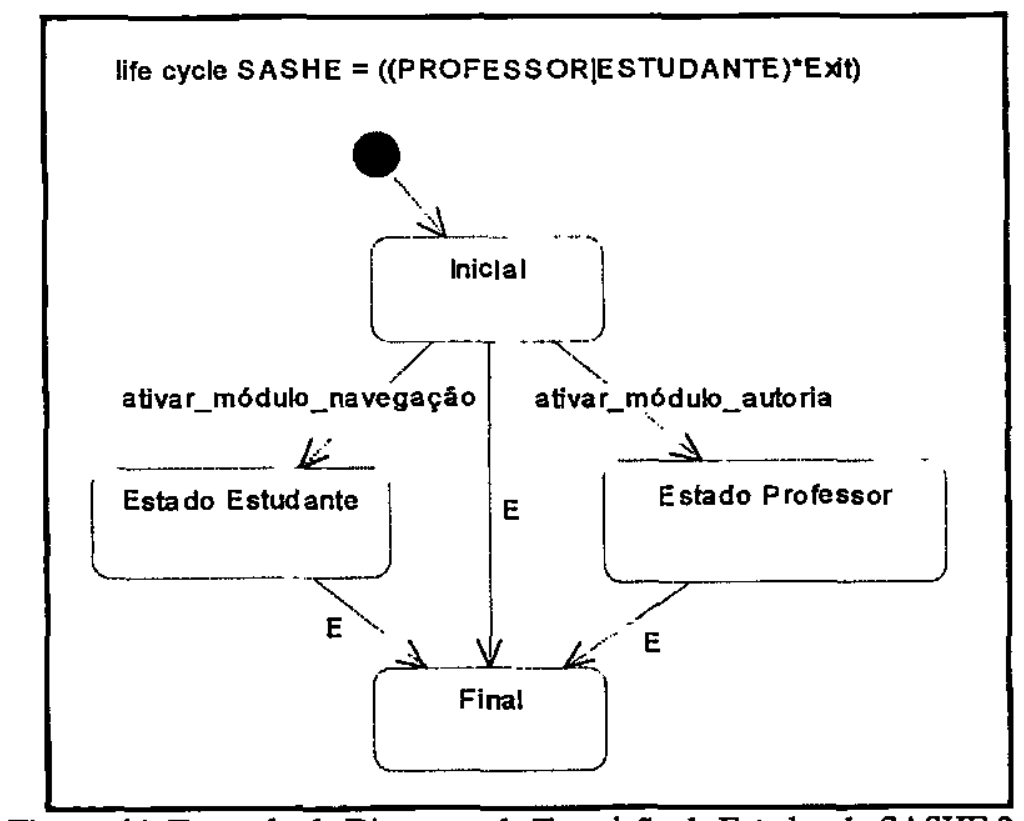

Figura 11. Exemplo de Diagrama de Transição de Estados do SASHE 2.0.

Com o desenvolvimento de aplicações, exploração da documentação e construção de DTEs da interface foi possivel identificar e relacionar com maior segurança os recursos do SASHE que podem ser empregados a outros sistemas [Quadro 1]. Assim, verificou-se a presença de dezessete recursos, sendo dez pertencentes ao módulo de Autoria e sete pertencentes ao módulo de Navegação. 
Quadro 1. Recursos do SASHE Aplicáveis em Outros Sistemas.

\begin{tabular}{|c|c|c|}
\hline 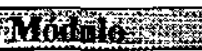 & 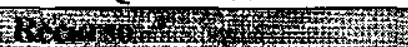 & Now \\
\hline \multirow{10}{*}{ Autoria } & $\begin{array}{l}\text { Construção de Nós de } \\
\text { Contexto }\end{array}$ & $\begin{array}{l}\text { A principal função desse recurso é permitir que a hiperbase } \\
\text { tenha uma hierarquia aninhada de nós identificados pelo mesmo } \\
\text { assunto, facilitando sua compreensão e sua estruturação pelo } \\
\text { autor }\end{array}$ \\
\hline & $\begin{array}{l}\text { Construção de Nós } \\
\text { Terminais }\end{array}$ & $\begin{array}{l}\text { Esse recurso caracteriza cada um dos elementos que formam a } \\
\text { hiperbase por meio das informações atribuidas às suas } \\
\text { propriedades. A suas propriedades são "Nome", "Palavras- } \\
\text { Chave", "Função Didática" "Dificuldade" e "Arquivo". } \\
\end{array}$ \\
\hline & $\begin{array}{l}\text { Visualização de Nó } \\
\text { Terminal }\end{array}$ & $\begin{array}{l}\text { Esse recurso possibilita o autor visualizar o conteúdo do arquivo } \\
\text { extermo associado a um nó terminal. }\end{array}$ \\
\hline & Edição de Nós Terminais & $\begin{array}{l}\text { Esse recurso permite o autor editar o conteúdo do arquivo } \\
\text { extermo associado a um nó terminal por meio de aplicativos } \\
\text { invocados por funções do ambiente. A exceção ocorre com nós } \\
\text { associados a arquivos texto, cuja edição é realizada por um } \\
\text { editor de texto básico disponibilizado pelo sistema. }\end{array}$ \\
\hline & Construção de Elos & $\begin{array}{l}\text { Esse recurso estabelece uma ligação unidirecional entre nó da } \\
\text { hiperbase. Suas propriedades são "Apresentação Simultânea" e } \\
\text { "Apresentar os Nós Terminais do Contexto". }\end{array}$ \\
\hline & Construgäo de Roteiros & $\begin{array}{l}\text { Esse recurso permite a construção de uma sequência de } \\
\text { informaçães e contextos que são apresentados ao ustário } \\
\text { durante a navegação. Suas propriedades são "Nome", } \\
\text { "Contexto", "Palavras-Chave", "Função Didática" e } \\
\text { "Dificuldade". }\end{array}$ \\
\hline & $\begin{array}{l}\text { Visualização pelo Browser } \\
\text { Estrutural }\end{array}$ & $\begin{array}{l}\text { Esse recurso permite o autor visualizar toda a estrutura da } \\
\text { aplicação: os contextos e os nós contidos nesses contextos. }\end{array}$ \\
\hline & $\begin{array}{l}\text { Disponibilização de } \\
\text { Informaçóes de Ajuda }\end{array}$ & $\begin{array}{l}\text { Esse recurso apresenta informações auto-explicativas ao autor } \\
\text { quando o ponteiro do mouse é posicionado sobre determinados } \\
\text { elementos da interface. }\end{array}$ \\
\hline & $\begin{array}{l}\text { Importação de } \\
\text { Hiperdocumentos }\end{array}$ & $\begin{array}{l}\text { Esse recurso permite a importação de hiperdocumentos da web } \\
\text { para o contexto de organização por nós e contextos. }\end{array}$ \\
\hline & $\begin{array}{l}\text { Definição de Grau de } \\
\text { Liberdade de Navegação }\end{array}$ & $\begin{array}{l}\text { Esse recurso define um grau de profundidade de navegação } \\
\text { atribuído ao tipo de usuário que navega no roteiro. }\end{array}$ \\
\hline \multirow[t]{7}{*}{ Navegação } & Navegação por Tópicos & $\begin{array}{l}\text { Esse recurso permite o leitor avançar ou retroceder na } \\
\text { navegação do roteiro. }\end{array}$ \\
\hline & Navegação por Histórico & $\begin{array}{l}\text { Esse recurso permite o leitor avançar ou retroceder a nós do } \\
\text { roteiro já percorridos. }\end{array}$ \\
\hline & Localizaçåo no Roteiro & $\begin{array}{l}\text { Esse recurso situa o leitor no nó atual do roteiro que está sendo } \\
\text { percorrido, acionando-se o botão "Onde Estou?" da barra de } \\
\text { controle de navegação. }\end{array}$ \\
\hline & Navegação pelo Contexto & $\begin{array}{l}\text { Esse recurso informa o contexto correspondente ao grau de } \\
\text { liberdade do nó atual, incluindo todos os demais nós e ligaçóes } \\
\text { do nó de contexto, acionando-se o botão "Contexto" da barra de } \\
\text { controle de navegação. }\end{array}$ \\
\hline & $\begin{array}{l}\text { Busca por Documentos } \\
\text { Relacionados }\end{array}$ & $\begin{array}{l}\text { Esse recurso dispara uma busca por uma lista, em toda a } \\
\text { hiperbase, de nós que possuam uma ou mais palavras-chave em } \\
\text { comum com o nó atual, acionado-se o botão "Mais } \\
\text { Informaçốes" da barra de controle de navegação. }\end{array}$ \\
\hline & Navegação de Bibliografia & $\begin{array}{l}\text { Esse recurso apresenta a bibliografia relacionada com a } \\
\text { hiperbase, acionando-se o botão "Bibliografia" da barra de } \\
\text { controle de navegação. }\end{array}$ \\
\hline & Construção de Glossário & $\begin{array}{l}\text { Esse recurso apresenta um glossário de termos relacionados } \\
\text { com a hiperbase, acionando-se o botão "Glossário" da barra de } \\
\text { controle de navegação. }\end{array}$ \\
\hline
\end{tabular}

Em uma análise inicial dos recursos acima, percebeu-se que esses podem ser empregados em sistemas hipermídia de documentação de software tais como aqueles revisados no capítulo anterior. Contudo, para obter um maior esclarecimento da aplicação 
desses recursos na manipulação de documentos de software foi preciso um novo estudo. Esse estudo consistiu em criar no SASHE uma aplicação hipermídia formada por documentos de software de tal forma que o sistema se comportasse como um sistema de documentação de software. Os documentos produzidos no estudo de caso dizem respeito ao SAPES [CEN98], um sistema de auxílio à pesquisa bibliográfica, e foram redigidos baseados em modelos preconizados pela UML (Unified Modeling Language) com o apoio automatizado da ferramenta Rational Rose [RAT99].

\subsection{Estudo de Caso 1: Documentos de Software no SASHE}

Em síntese, as duas tarefas principais realizadas no estudo foram: 1) a modelagem do SAPES, que consistiu da construção de documentos de software compostos por diagramas UML criados na Rational Rose [RAT99]; 2) a criação da aplicação hipermídia no SASHE, que consistiu no desenvolvimento de uma hiperbase formada pelos documentos criados anteriormente; 3) navegação da aplicação.

Todas as tarefas foram realizadas no Laboratório de Engenharia de Software do ICMC, onde foram empregados os seguintes recursos listados no quadro abaixo [Quadro 2]. Em seguida são descritos os recursos utilizados e os resultados obtidos.

Quadro 2. Recursos Utilizados no Estudo de Caso 1.

\begin{tabular}{|c|c|c|}
\hline 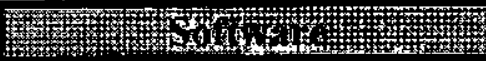 & 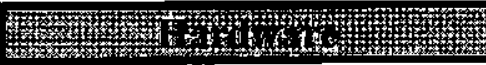 & 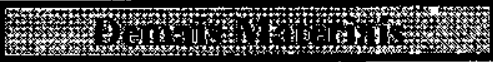 \\
\hline $\begin{array}{l}\text { SAPES } \\
\text { SASHE } 2.0 \\
\text { Rational Rose } 98 \\
\text { Microsoft Word } 97\end{array}$ & $\begin{array}{l}\text { Pentium } 166 \mathrm{MHz} \\
32 \mathrm{M} \text { de } \mathrm{RAM} \\
4.8 \mathrm{~Gb} \text { de } H D \\
\text { Impressora } H P \text { 695C }\end{array}$ & $\begin{array}{l}\text { Papel } \\
\text { Cartuchos para impressão }\end{array}$ \\
\hline
\end{tabular}

\subsubsection{SAPES}

O Sistema de Apoio à Escrita é um sistema desenvolvido no ICMC com o objetivo de prover auxílio à pesquisa bibliográfica. O sistema visa armazenar referências sobre publicações lidas por pesquisadores durante uma pesquisa. Essas publicações referem-se à artigos, livros, periódicos, ensaios, e assim por diante [CEN98;COL99].

As referências são armazenadas na forma de itens bibliográficos, podendo ser alterados e consultados conforme a necessidade do pesquisador. Os itens bibliográficos, por sua vez, são armazenados e constituem uma bibliografia geral. 
$O$ pesquisador pode também utilizar o sistema durante a redação de textos científicos. $O$ sistema é capaz de reconhecer as citações em um documento e gerar automaticamente a referência bibliográfica. Outras características do sistema são [Figura 12]:

- Geração automática de citação da publicação segundo o padrão da ABNT (Associação Brasileira de Normas Técnicas);

- Manutenção de uma lista de sinônimos;

- Emissão de diversos relatórios;

- Mecanismos de busca e de ordenação de itens bibliográficos a partir informações como o autor da publicação, assunto, editora, periódico, local, ano de publicação, etc.

- Criação e impressão de fichas técnicas;

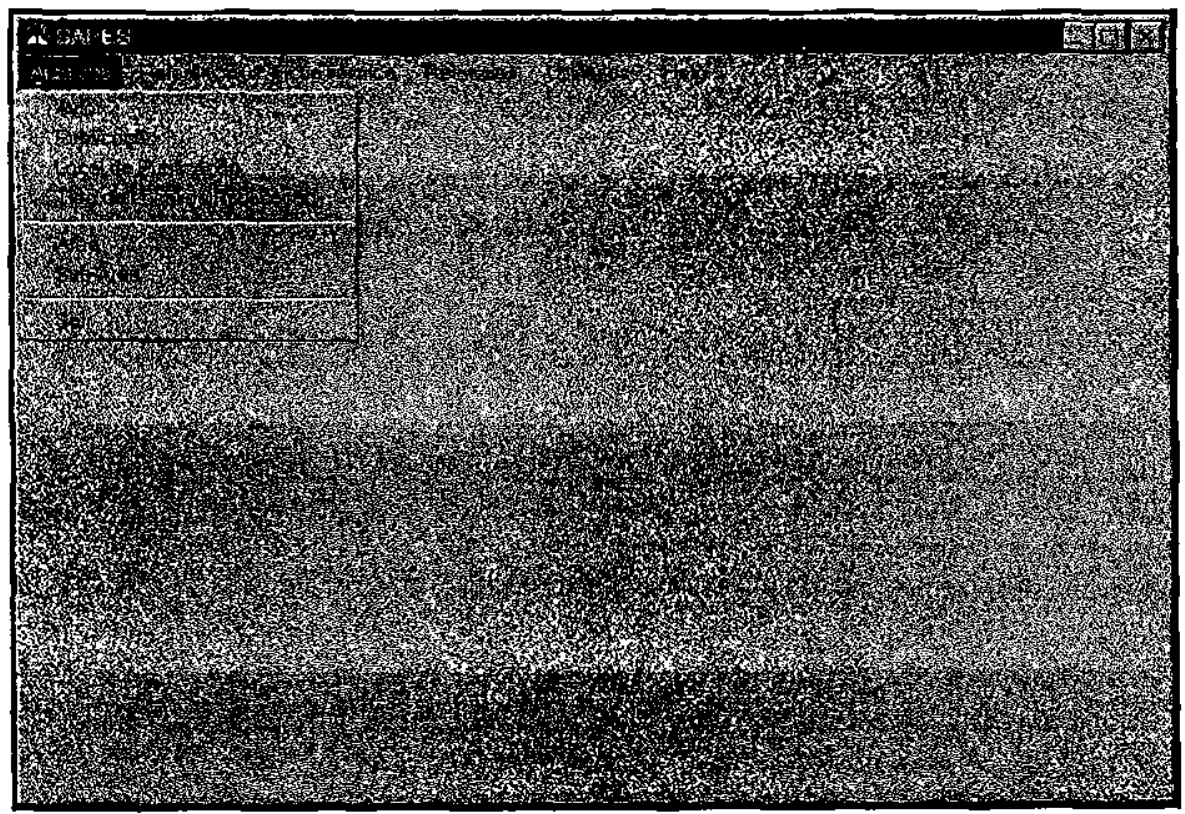

Figura 12. O Sistema SAPES.

\subsubsection{UML}

A UML (Unified Modeling Language) é uma proposta de modelagem de sistemas que engloba o melhor das principais metodologias orientadas a objetos. Seu aparecimento foi motivado principalmente pela falta de uma notação padronizada e eficaz para o desenvolvimento de novos sistemas utilizando a orientação a objetos [FUR98;BAR98]. Além de incorporar características de outras técnicas de modelagem de sistemas, a UML também propõe novos conceitos para modelar qualquer tipo de aplicação. 
$\mathrm{Na}$ verdade, a UML é uma linguagem de modelagem de sistemas, e não uma metodologia. Essa linguagem é usada para especificar, visualizar, documentar e construir artefatos de um sistema. Ou seja, seus principais objetivos são: fornecer uma linguagem de modelagem visual para modelagem de sistemas, ser independente da linguagem de programação e integrar melhores práticas para o desenvolvimento de sistemas [MOR98].

Para atingir essas metas, a UML dispõe de quatro tipos de elementos: estruturais, comportamentais, de agrupamento e de anotação. Os elementos estruturais são as partes estáticas de um modelo, representando elementos que são ou conceituais ou físicos. Os elementos comportamentais são as partes dinâmicas dos modelos da UML. Os elementos de agrupamento são partes organizacionais dos modelos. $\mathrm{E}$, por fim, os elementos de anotação são partes explicativas dos modelos. São os comentários aplicados para descrever, iluminar e remarcar elementos no modelo [CAT99]. Esses elementos são representados pelos vários diagramas propostos pela UML. A maioria dos diagramas é composta por gráficos que contém nós (vértices) conectados por caminhos (arcos).

Os diagramas propostos pela linguagem são nove: diagrama de casos de uso, diagrama de classes, diagrama de objeto, diagrama de estado, diagrama de seqüência, diagrama de colaboração, diagrama de atividade, diagrama de recurso e o diagrama de implantação [Quadro 3].

Quadro 3. Descrição dos Diagramas da UML.

\begin{tabular}{|c|c|}
\hline & \\
\hline Casos de Uso & $\begin{array}{l}\text { descreve os requisitos funcionais do sistema. Em outras palavias, descreve a visão } \\
\text { externa do sistema e suas interações com o mundo exterior, representando uma visão } \\
\text { de alto nivel de funcionalidade. }\end{array}$ \\
\hline Classes & $\begin{array}{l}\text { demonstra a estrutura estática do sistema, representada pelas classes (incluindo seus } \\
\text { atributos e operações), interfaces e relacionamentos entre classes. }\end{array}$ \\
\hline Objetos & $\begin{array}{l}\text { mostra a instanciação das classes do diagrama de classes; ou seja, os objetos. Utilizado } \\
\text { para: representar o perfil do sistema em um dado momento de sua execução e para } \\
\text { modelar estruturas complexas. }\end{array}$ \\
\hline Estados & $\begin{array}{l}\text { mostra os estados em que um objeto pode estar e os eventos que fazem o objeto passar } \\
\text { de um estado para outro. }\end{array}$ \\
\hline Seqüência & $\begin{array}{l}\text { mostra a colaboração dinâmica entre os vários objetos do sistema. Mostra ainda a } \\
\text { interação entre os objetos, seus relacionamentos e as mensagens que podem ser } \\
\text { enviadas entre objetos. }\end{array}$ \\
\hline Colaboração & $\begin{array}{l}\text { estende o diagrama de sequêencia, pois, além de mostrar os objetos, mostra também } \\
\text { seus relacionamentos e as mensagens que enfatizam a organização dos objetos que } \\
\text { trocam mensagens. Neste diagrama, o tempo não é tratado como dimensão separada. }\end{array}$ \\
\hline Atividade & $\begin{array}{l}\text { usado para modelar atividades concorrentes dos estados e mostram o fluxo entre } \\
\text { atividades (ações não-atômicas). }\end{array}$ \\
\hline Recurso & $\begin{array}{l}\text { mostra o sistema pelo seu lado funcional, apresentando a organização de seus módulos } \\
\text { durante sua execução, os recursos (documentos, tabelas) do software e suas } \\
\text { dependências entre si. }\end{array}$ \\
\hline Implantação & $\begin{array}{l}\text { mostra a arquitetura física do hardware o do software no sistema. Mostra, por } \\
\text { exemplo, os atuais computadores e periféricos e também os recursos executáveis e } \\
\text { objetos. }\end{array}$ \\
\hline
\end{tabular}




\subsubsection{Rational Rose 98}

A Rational Rose $98 \AA$ é uma ferramenta que oferece suporte para a modelagem de sistemas orientados a objetos em UML. Desenvolvida pela Rational Software Inc., a ferramenta disponibiliza recursos para a construção, verificação e checagem da consistência dos diagramas propostos pela linguagem.

Além da modelagem, outras características da ferramenta: ambiente iterativo para que múltiplas equipes de desenvolvedores trabalhem em projetos diferentes, integra-se a qualquer controlador de versões, automatiza tarefas como a geração de esqueletos para as classes definidas no modelo e realiza a Engenharia Reversa de projetos já existentes [RAT99].

A adoção dessa ferramenta no estudo baseou-se em critérios de avaliação de ferramentas de modelagem orientadas a objeto. Segundo Furlan, uma ferramenta deve apresentar: suporte aos diagramas da linguagem de modelagem, um repositório comum para armazenar dados do modelo em um único lugar e navegação desse mesmo modelo com rastreamento de um elemento de um diagrama a outro ou expansão da descrição desse elemento [FUR98].

A Rational Rose é uma ferramenta que não exige muitos recursos de hardware e de software. Basicamente são exigidos: sistema operacional Microsoft Windows NT 4.0, Windows 95 ou Windows 98, computador Pentium, $32 \mathrm{Mb}$ de RAM, $100 \mathrm{Mb}$ de espaço em disco e um monitor SVGA.

\subsubsection{Resultados Obtidos}

O estudo forneceu importantes subsídios para a adaptação dos principais componentes do SASHE para a documentação de software. Dentre esses componentes, destacam-se: Nós Terminais, Nós de Contexto, Roteiros e Elos.

Os Nós Terminais são componentes aos quais são relacionados arquivos de mídia. $\mathrm{O}$ estudo mostrou que esse componente é bastante interessante na documentação de software pois pode estar associado a um documento de software. Observou-se que as operações realizadas com os nós terminais quando esses estão associados a arquivos de Ensino também podem ser realizadas se os nós terminais estiverem associados a documentos de software, independentemente se esse documento for um texto, áudio, vídeo ou imagem. Por exemplo, a operação de inserção do nó terminal pode ser normalmente realizada quando esse está 
associado: a uma imagem, representando um modelo do software; a um áudio, contendo explicações de uso narradas pelo proprietário do software; ou um texto, com informações sobre a operação do software.

Os Nós de Contexto agrupam sob um mesmo tema nós terminais e até outros nós de contexto. Sob o enfoque da Engenharia de Software, o nó de contexto é o componente cujo conceito recorda o conceito de uma etapa do ciclo de vida do software.

Uma etapa do desenvolvimento do software reúne documentos que descrevem um aspecto particular do software. Por exemplo, a etapa de Análise reúne documentos que descrevem os requisitos do software; a etapa de Testes reúne documentos que descrevem os testes realizados com o software. Nota-se que as etapas em um ciclo de vida de software agrupam documentos sob um mesmo tema comum. Assim, o nó de contexto assumiria o papel de uma etapa, no qual estão agrupados nós terminais (documentos de software) ou outras subfases (nós de contexto).

Roteiro é uma seqüência de nós terminais apresentados ao estudante durante a navegação dos hiperdocumentos. Associando documentos de software a nós terminais, o roteiro seria igualmente útil na apresentação desses documentos.

$O$ roteiro permitiria, por exemplo, o engenheiro de software organizar os documentos de software de acordo com a ordem cronológica de produção dos documentos. Dessa forma, a visualização do roteiro pode proporcionar um maior entendimento do software e do contexto dos hiperdocumentos de software sob uma determinada ótica.

No entanto, para que esse entendimento ocorra de maneira apropriada é preciso que as estratégias de navegação do roteiro relacionadas a botões dispostos na barra de controle estejam igualmente adequadas à navegação de hiperdocumentos de software.

A criação de Elos entre hiperdocumentos é seguramente o recurso com maior aplicabilidade em outros domínios, inclusive a Engenharia de Software. Como se trata de um recurso bastante genérico, não há necessidade de alterações em suas características, podendo comportar-se da mesma maneira como implementada hoje. Uma possível adaptação seria relacionar diferentes partes de um mesmo hiperdocumento, o que seria bastante útil na leitura de hiperdocumentos de software extensos.

$\mathrm{Na}$ realidade, os documentos de uma etapa formam a documentação a respeito do software. Por conseguinte, o recurso do SASHE cujo conceito de documentação é a aplicação final, pois é formada por conjunto de hiperdocumentos definidos no módulo de Autoria.

A figura abaixo ilustra a aplicação hipermídia criada [Figura 13]. Na figura podem ser observadas as representações de Nós de Contexto e de Roteiro. 


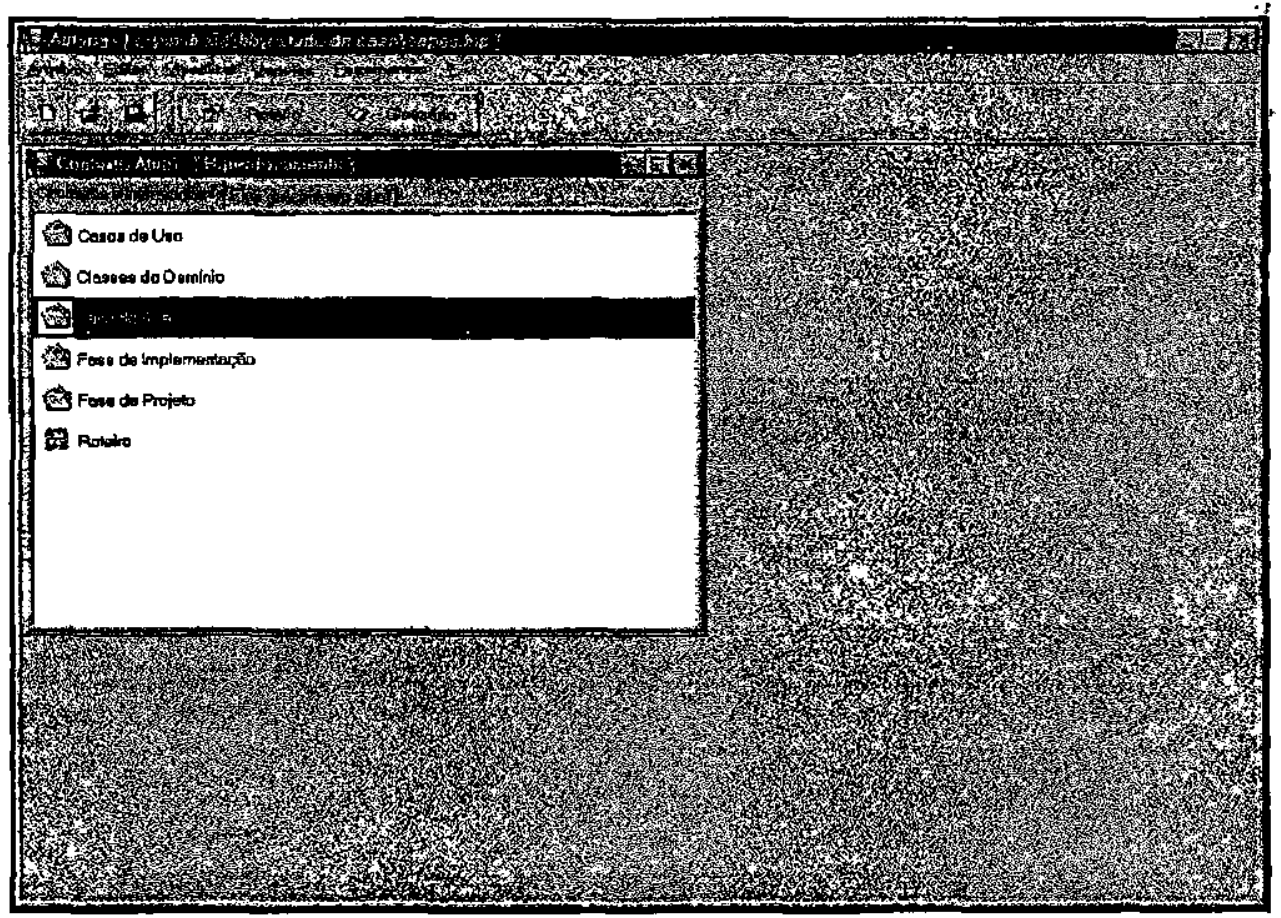

Figura 13. Aplicação no SASHE formada por Hipendocumentos de Software.

Concluindo, o objetivo proposto para o estudo foi alcançado. A criação da aplicação hipermídia sobre o SAPES proporcionou maior compreensão a respeito do comportamento do SASHE no desenvolvimento e na navegação de hiperdocumentos de software. Além disso, permitiu associar os conceitos dos principais componentes do sistema a conceitos da Engenharia de Software; em especial, aos conceitos da documentação de sof̣tware.

\subsection{Considerações Finais}

Sob o ponto de vista da reutilização de software, os resultados dos estudos anteriores apontam três situações em que recursos do SASHE podem ser reusados: nas suas próprias atualizações, em sistemas pertencentes ao domínio Ensino e em sistemas pertencentes a outros domínios de informação. $\mathrm{O}$ reuso de recursos entre sistemas pertencentes a outros domínios diferentes é provavelmente o tipo de reutilização mais custosa pois pode envolver a adaptação do componente às caracteristicas do domínio.

Existem muitos aspectos que precisam ser considerados no reuso de recursos do SASHE. Tais aspectos podem ser divididos em aspectos motivadores e aspectos inibidores, conforme mostrado no [Quadro 4]. É importante lembrar que esses aspectos precisam ser 
levados em consideração para que o resultado final da reutilização do SASHE, em qualquer situação, seja satisfatório.

O principal resultado do estudo apresentado na Seção 3.3. foi constatar que existem recursos no SASHE aplicáveis em outros domínios de informação. Entretanto, essa atividade deve ser bem planejada, pois um reuso de recursos mal-realizado pode acarretar em sérios transtornos como diminuir a qualidade do software no qual os recursos foram incorporados. Outros beneficios alcançados com o estudo foram: um maior entendimento do funcionamento, limites e possibilidades do SASHE, em vista das inúmeras aplicações desenvolvidas; e uma maior compreensão da relação "domínio-reuso-hipermídia".

Quadro 4. Aspectos Motivadores e Aspectos Inibidores do Reuso do SASHE.

\begin{tabular}{|c|c|}
\hline 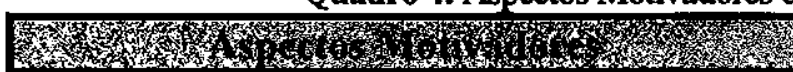 & Yin \\
\hline $\begin{array}{l}\text { Uma grande quantidade de recursos do } \\
\text { SASHE pode ser reusada, inclusive para } \\
\text { outros domínios de informações. No entanto, } \\
\text { para que essa tarefa seja bem-sucedida, } \\
\text { alguns recursos precisam soffer alterações. }\end{array}$ & $\begin{array}{l}\text { A falta de uma maior documentação técnica } \\
\text { sobre a construção e a operação da atual } \\
\text { versão do sistema. Assim, a principal fonte } \\
\text { de informação disponível sobre a atual } \\
\text { versão do sistema é o seu próprio código } \\
\text { fonte e sua interface. }\end{array}$ \\
\hline $\begin{array}{l}\text { O ambiente foi implementado em linguagem } \\
\text { orientada a objetos. As linguagens orientadas } \\
\text { a objetos são potencialmente propícias ao } \\
\text { reuso de recursos. Além disso, proporcionam } \\
\text { umá economia de tempo e esforço no } \\
\text { desenvolvimento de atualizações do software } \\
\text { [WIR90; PRE95b]. }\end{array}$ & $\begin{array}{l}\text { SASHE não foi construído pensando-se em } \\
\text { uma futura reutilização de seus recursos. } \\
\text { Durante o desenvolvimento do sistema, não } \\
\text { foi construído um repositório de recursos } \\
\text { para que esses fossem armazenados e } \\
\text { pudessem ser reusados posteriormente. }\end{array}$ \\
\hline $\begin{array}{l}\text { A disponibilidade de documentação sobre a } \\
\text { primeira versão. Feltrim realizou a a } \\
\text { Engenharia Reversa da versão } 1.0 \text { do SASHE } \\
\text { [FEL99]. Os documentos gerados neste } \\
\text { trabalho podem servir de base e orientação } \\
\text { para um maior esclarecimento do sistema. }\end{array}$ & $\begin{array}{l}\text { O sistema ainda apresenta problemas de } \\
\text { usabilidade, por exemplo: falta de maior } \\
\text { intercâmbio entre os módulos de autoria e de } \\
\text { navegação, impossibilidade de reversão das } \\
\text { ações dos usuários e ausência de facilidades } \\
\text { de ajuda sensíveis ao contexto. }\end{array}$ \\
\hline $\begin{array}{l}\text { O suporte proporcionado pelo Modelo de } \\
\text { Contextos Aninhados [CAS91]. Seu reuso é } \\
\text { viável, pois proporciona a organização das } \\
\text { informações independentemente do dominio }\end{array}$ & $\begin{array}{l}\text { O SASHE apresenta recursos que não foram } \\
\text { totalmente implementados tais como o } \\
\text { recurso de browser gráfico a a definição de } \\
\text { exercicios. }\end{array}$ \\
\hline
\end{tabular}

Por outro lado, o estudo descrito na Seção 3.4. possibilitou maior esclarecimento sobre a possibilidade de utilizar recursos do SASHE no contexto da documentação de software. Verificou-se que muitos recursos possuem alta aplicabilidade no contexto, assistindo em atividades essenciais como a autoria e principalmente a navegação de hiperdocumentos de software. 
Dentre os benefícios extraídos com esse estudo, pode-se citar: aquisição de conhecimento sobre a UML e a ferramenta Rational Rose, uma melhor compreensão do SASHE e embasamento necessário para a construção de um sistema de documentação de software utilizando os recursos identificados no estudo anterior.

Em suma, este capítulo foi dedicado ao sistema SASHE. O sistema foi abordado em três perspectivas: sua revisão bibliográfica, a investigação da possibilidade de reuso de seus recursos e sua aplicação no desenvolvimento de hiperdocumentos de software.

As investigações a respeito do SASHE foram importantes haja visto que neste trabalho é apresentado o protótipo de um sistema hipermídia para produção de hiperdocumentos de software. Nesse protótipo, estão incorporados muitos dos recursos anteriormente identificados. Segundo a classificação de Prieto-Diaz [PRI93], o reuso dos recursos proposto neste trabalho possui o seguinte perfil:

- Conforme Substância: reuso de elementos abstratos (reuso de idéias e conceitos);

- Conforme Escopo: reuso para o domínio da Documentação de Software (reuso horizontal);

- Conforme Modo: reuso realizado por uma única pessoa (reuso oportunista);

- Conforme Técnica: reuso de blocos de recursos (reuso por composição);

- Conforme Intenção: reuso com pequenas alterações nos recursos (reuso caixa branca com modificação);

- Conforme Produto: reuso de elementos físicos (reuso de especificação, projeto, arquitetura e textos);

Os resultados das investigações deste capitulo foram bastante elucidativos para as demais atividades descritas no decorrer deste trabalho. O protótipo de um sistema hipermídia de documentação de software construído a partir de recursos do SASHE é apresentado no capítulo seguinte. 



\section{Capitulo 4}

\section{O Sistema SASHDoc}

\subsection{Consideraçōes Iniciais}

Os sistemas hipermídia são ferramentas para a criação, manipulação e navegação de aplicações hipermídia. Nos últimos anos, os sistemas hipermídia sofreram uma rápida expansão impulsionada por características como flexibilidade no acesso à informação aliada à capacidade alternativa de organização de documentos. Tais características tornaram esses sistemas bastante atrativos como programas de recuperação de informação [NIE95].

Uma aplicação hipermídia é o produto processado pelo sistema hipermídia. Em suma, uma aplicação hipermídia corresponde a um conjunto de hiperdocumentos interligados que abordam um ou mais contextos de informação.

A autoria de uma aplicação hipermídia é um processo no qual são realizadas tarefas como o planejamento, projeto e implementação da aplicação. Para que o usuário alcance uma maior efetividade na autoria da aplicação, recomenda-se que os sistemas hipermídia apresentem características tais como [SHN88]: funções de edição, disponibilidade de listas de nomes de links, índice e sinônimos, funções de formatação, funções de busca e substituição de nós, controle de cores, capacidade de alternar entre a autoria e a navegação, capacidade de exportar arquivos para outros sistemas, operabilidade em uma rede local e a integração com outros softwares/hardwares.

Por outro lado, a navegação de uma aplicação hipermídia consiste na exploração das informações presentes nos hiperdocumentos. Para se obter uma navegação mais efetiva da aplicação, recomenda-se o emprego de mecanismos navegacionais tais como [SHN88; NIE95]: pesquisa por palavra-chave, "backtrack" (navegação orientada sempre para o nó anterior já visitado), "history lists" (navegação que permite acesso a qualquer nó 
anteriormente visitado) e "bookmarks" (navegação por nós selecionados anteriormente visitados).

Algumas dessas características, tanto para a autoria quanto para a navegação de aplicações hipermídia, foram empregadas no sistema SASHDoc - Sistema de Autoria e Suporte Hipermídia para Documentação de Software. O SASHDoc consiste de um protótipo de um sistema de autoria e navegação de aplicações hipermídia formadas por documentos de software. As conclusões obtidas com os estudos acerca do sistema SASHE e da documentação de software proporcionaram o embasamento necessário para a formulação do sistema SASHDoc. Nesse sistema foram adaptadas características e funcionalidades atualmente presentes no SASHE de modo que atendessem à tarefa de criação de documentos de software.

Conforme visto, a navegação é a atividade responsável pela recuperação e exploração das informações presentes nos hiperdocumentos. Da navegação depende a assimilação do conteúdo dessas informações, bem como a satisfação da busca de informações pelo usuário. Por isso, consideramos importante que os mecanismos navegacionais empregados na navegação de hiperdocumentos estejam de acordo com o domínio ao qual as informações estão relacionadas. A análise dos mecanismos navegacionais do SASHE indicou que alguns desses tais como "Está Fácil" e "Está Dificil" não estavam adequados para a navegação de informações que retratassem o ciclo de vida de um software. Haja visto que foram prioritariamente projetados para a navegação de hiperdocumentos do domínio Ensino.

Assim, foi realizado um breve estudo sobre os mecanismos navegacionais apresentados por um browser comum, o Microsoft Internet Explorer 5.0, com o objetivo de identificar mecanismos que possam ser empregados na navegação de (hiper)documentos de software. Na seção seguinte esse estudo é apresentado em detalhes. Na Seção 4.3. é apresentado o sistema SASHDoc, protótipo de sistema hipermidia de autoria e navegação de documentos de software que fundamenta-se nos conceitos do MCA, nas estratégias de navegação do SASHE e nas estratégia de navegação de documentos de software derivadas dos estudos realizados. Uma análise da mudança de domínio do SASHE para o SASHDoc é apresentada na Seção 4.4. Por fim, as considerações finais do capítulo.

\subsection{Estudo de Caso 2: Hiperdocumentos de Software}

A Internet é um ambiente favorável à documentação de software por possibilitar fácil acesso e distribuição de informações em hiperdocumentos de software [GOL99]. Nesse 
sentido, nos últimos anos vários sistemas foram desenvolvidos para a criação de hiperdocumentos de software que atendam às características desse ambiente [JAV95;BRA98a;RAJ99]. Por exemplo, JavaDoc é uma ferramenta capaz de gerar automaticamente a documentação de programas Java em formato HTML de modo a serem navegados em browsers [JAV95]; DynaDoc gera documentos hipertexto dinâmicos a partir do código fonte de um sistema [BRA98a]; e, por último, PAS é um sistema de Engenharia Reversa que também gera documentos de software no formato hipertexto [RAJ99].

Esses sistemas caracterizam-se por empregar browsers comerciais como o Netscape Navigator e o Internet Explorer na busca, exploração e recuperação de informações em hiperdocumentos de software. Essas pesquisas consideram que certos mecanismos como o "backtracking" - retorno ao hiperdocumento anteriormente navegado - podem ser úteis na assimilação de informações em hiperdocumentos de software.

Contudo, a navegação de hiperdocumentos de software em browsers não se reserva apenas aos recursos disponibilizados pelos próprios browsers. A navegação também pode ser realizada por meio da exploração dos links presentes nos próprios hiperdocumentos. Nesse caso, o recurso navegacional é disponibilizado pelo hiperdocumento e não pelo browser. Então, pode-se dizer que a navegação de hiperdocumentos de software pode ser realizada sob duas formas genéricas em um browser: por meio dos recursos oferecidos pelo browser e por meio dos recursos disponibilizados pelo próprio hiperdocumento.

Se por um lado o principal recurso navegacional oferecido por hiperdocumentos são os links, quais são os recursos que os browsers podem oferecer para a navegação de hiperdocumentos de software? Para responder essa questão, um estudo foi realizado utilizando-se os recursos disponibilizados pelos atuais browsers na navegação de hiperdocumentos de software de forma a identificar esses recursos. Além disso, avaliar a aplicabilidade desses recursos em um sistema hipermídia de autoria e navegação de documentos de software.

Para tanto, hiperdocumentos de software foram desenvolvidos a partir dos documentos e diagramas do SAPES criados em estudos anteriores. Os hiperdocumentos foram produzidos na ferramenta Macromedia Dreamweaver $2.0 \mathrm{e}$, em seguida, navegados no Microsoft Internet Explorer 5.0 (IE5). Essas tarefas foram realizadas no Laboratório de Engenharia de Software do ICMC e foram utilizados os recursos apresentados no [Quadro 5]. A seguir, são descritas as características principais da ferramenta Macromedia Dreamweaver 2.0 [MAC99] e do browser Internet Explorer 5.0. [MIC00]. 
Quadro 5. Recursos Utilizados no Estudo de Caso 2.

\begin{tabular}{|l|l|l|}
\hline Pational Rose 98 & Pentium $166 \mathrm{MHz}$ & Papel \\
Microsoft Word 97 & $32 \mathrm{Mde}$ RAM & Cartucho para impressão \\
Macromedia Dreamweaver 2.0 & $4.8 \mathrm{~Gb}$ de HD & \\
Microsoft Internet Explorer 5.0 & Impressora HP $695 \mathrm{C}$ & \\
\hline
\end{tabular}

\subsubsection{Macrómedia'Dreamiweaver 2.0}

Macromedia Dreämweaver 2.0 é uma ferramenta para o projeto e confecção de websites. Sua adóção nesse estudo baseou-se principalmente pór apresentar características como a facilidade de uso, eficiência de código HTML gerado, recursos de gerenciamento de websites. Um outro recurso interessante considerado foi o Mapeamento do Site, isto é, a ferramenta permite criar uma representação de alto nível dos elementos que compõem o site. Algumas outras características da ferramenta são [CAS99;MAC99]:

- Projeto visual e gerenciamento de sites;

- Editor de tags que permite rapidamente modificar, adicionar ou remover tags sem deixar de visualizar o projeto;

- Inclui um editor de mapas de imagem;

- Permite adicionar objetos especiais como: datas, email, barra de navegação, caracteres especiais, frames e mídias (Flash e Shockwave);

- Permite importar dados formatados de planilhas ou bancos de dados para tabelas HTML;

- Sincroniza arquivos da versão local e remota do site;

- Integração de aplicativos externos para edição de qualquer tipo de arquivo;

- Permite a criação de templates para que aparência e características sejam reutilizadas.

Os recursos computacionais necessários para a execução da ferramenta são: processador Pentium ou equivalente de $120 \mathrm{MHz}$, sistema operacional Windows $95 / 98$ ou Windows NT 4.0 ou anterior, 32MB de RAM, 20MB de espaço em disco livre, monitor SVGA e CD-ROM [MAC99]. A interface da ferramenta pode ser visualizada na [Figura 14]. 


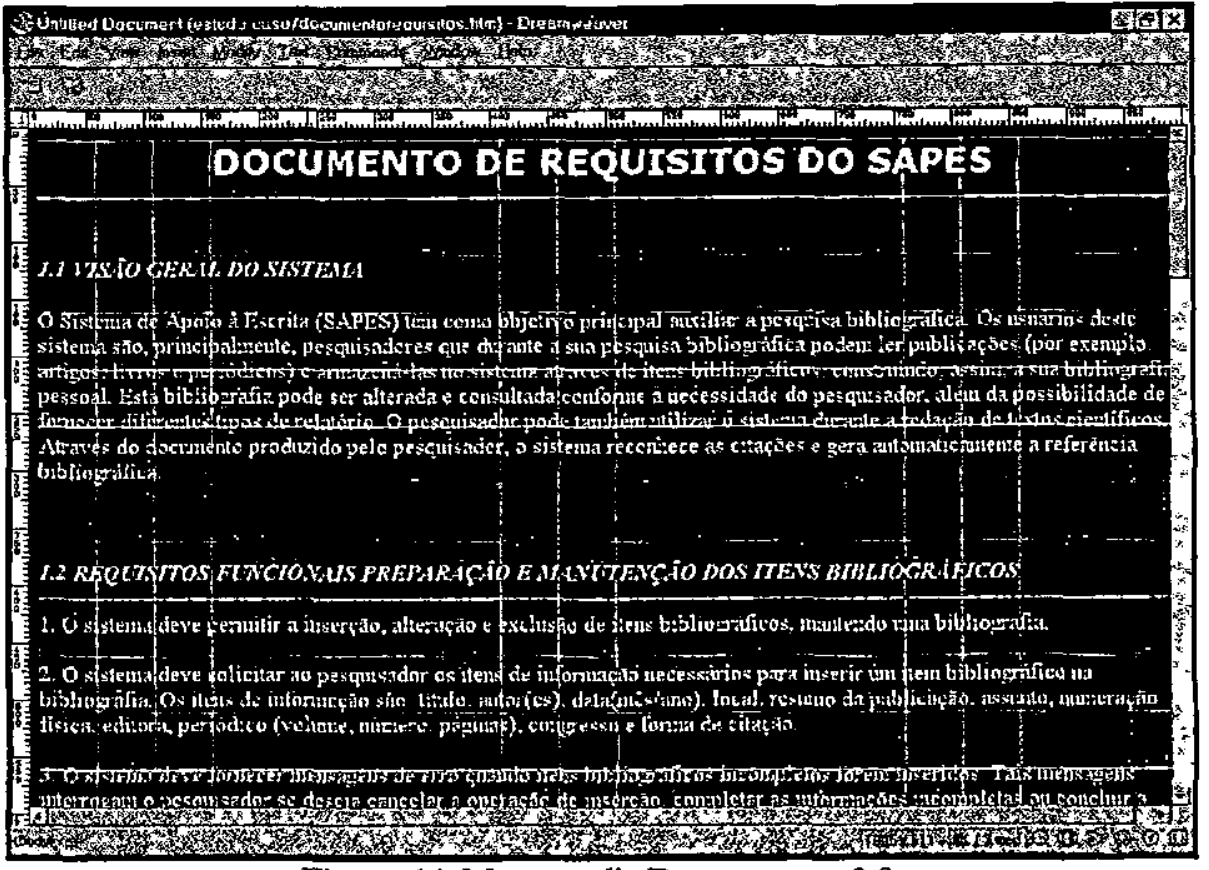

Figura 14. Macromedia Dreamweaver 2.0.

\subsubsection{Microsoft Internet Explorer 5.0}

O Internet Explorer 5 (IE5) é provavelmente o browser mais conhecido atualmente. Sua popularidade pode ser atribuída a características como [MIC00]:

- Facilita a pesquisa por diferentes tipos de informações, utilizando diferentes recursos da web de acordo com a vontade do usuário.

- Para facilitar a localização de sites exibidos recentemente, o usuário tem múltiplas organizações de exibição do Histórico - por data, por site, por freqüência de visitas e por ordem de acesso no dia.

- Os usuários podem digitar ou procurar um URL na barra de endereços e pressionar "Enter" ou clicar no novo botão "Ir".

- Permite criar novas pastas, mover os Favoritos de uma pasta para outra, renomeá-los ou exclúí-los, além de oferecer informações adicionais como URL, número de acessos, data da última visita e se a página está disponível para visualização off-line.

- Ao adicionar um site aos Favoritos, o Internet Explorer reconhece a ordem dos quadros atual, ao invés de simplesmente utilizar a ordem descrita pelo código do quadro mais externo. 
Grande parte dos recursos apresentados pelo IE5 também podem ser encontrados em outros browsers comerciais. Desse modo, a adoção do IE5 nesse estudo de caso não afeta os resultados finais obtidos. A seguir, esses resultados são apresentados.

\subsubsection{Resultados Obtidos}

Em suma, o estudo consistiu em navegar por hiperdocumentos de software utilizando os recursos do IE5. A realização deste exercício permitiu identificar cinco formas (maneiras) básicas de navegação de hiperdocumentos de software em browsers. São elas:

\section{$\underline{I^{\circ} \text { Forma }}$}

A primeira forma corresponde à navegação de hiperdocumentos de software precedentes e subseqüentes. Em outras palavras, assumindo um hiperdocumento de software como ponto de referência, o engenheiro de software pode optar entre retornar a um hiperdocumento de software anterior ou prosseguir para o hiperdocumento seguinte. Normalmente, a navegação é realizada pelo acionamento dos botões "Voltar" e "Avançar" dispostos na interface do browser. A figura abaixo ilustra a navegação entre hiperdocumentos precedentes e subseqüentes [Figura 15].

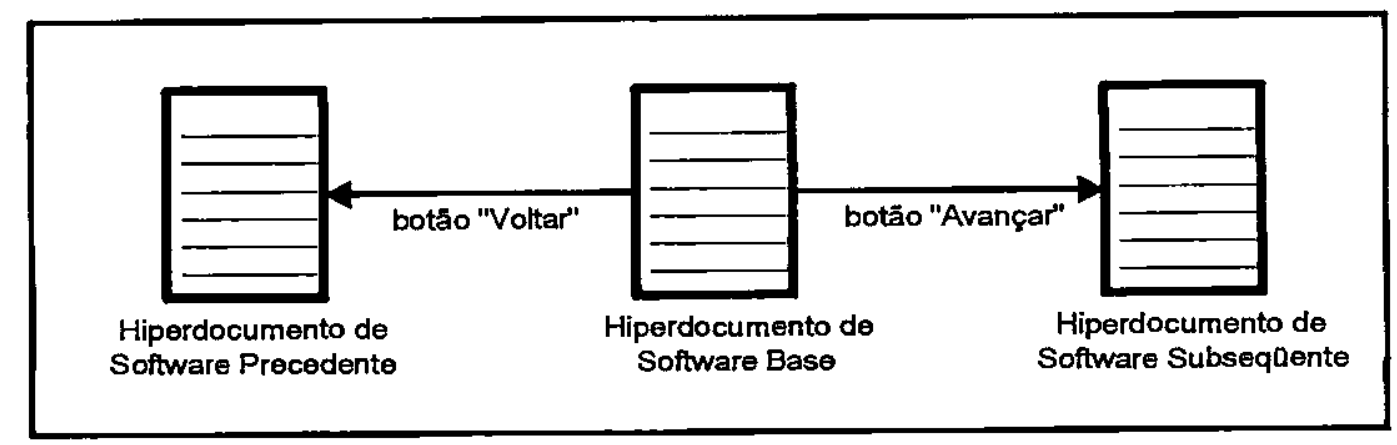

Figura 15. A Navegação entre Hiperdocumentos de Software Precedentes e Subseqüentes.

\section{$\underline{2^{\circ} \text { Forma }}$}

A segunda forma de navegação corresponde à exploração de links. A navegação por links é a forma mais tradicional de navegação de hiperdocumentos [NIE95]. Esse tipo de 
navegação pode ainda ser dividida em duas formas: links entre dois ou mais hiperdocumentos de software ou links entre partes de um mesmo hiperdocumento de software, conforme indicado na [Figura 16].

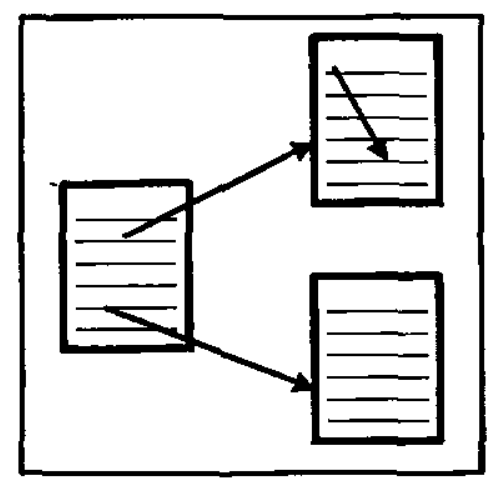

Figura 16. A Navegação por links em Hiperdocumentos de Software.

\section{$\underline{3^{\circ} \text { Forma }}$}

A terceira forma corresponde à navegação pelo Histórico ("history"). O Histórico tem a função de armazenar links para hiperdocumentos de software já navegados. A partir de um link do Histórico, o usuário pode recuperar o hiperdocumento de software correspondente a esse link.

Os links de um Histórico podem ser organizados de várias maneiras. No caso do IE5, os links podem ser ordenados: por data, pelas páginas mais visitadas, pela ordem de visita no dia ou pelas páginas pertencentes a um site.

\section{$\underline{4^{\circ} \text { Forma }}$}

A quarta forma de navegação corresponde ao emprego de mecanismos de busca de informações em hiperdocumentos. A busca de informações em um hiperdocumento pode ser realizada por meio do browser, conforme indicado em destaque na [Figura 17]. Basta o usuário informar a palavra que deseja localizar no conteúdo do hiperdocumento.

A busca por informações também pode ser disponibilizada pelo próprio hiperdocumento. $\mathrm{O}$ hiperdocumento pode apresentar uma caixa de texto onde $\mathrm{O}$ usuário informa a palavra-chave que deseja encontrar. Através do acionamento de um botão procedese a busca por hiperdocumentos de software que contenham tal palavra-chave. 


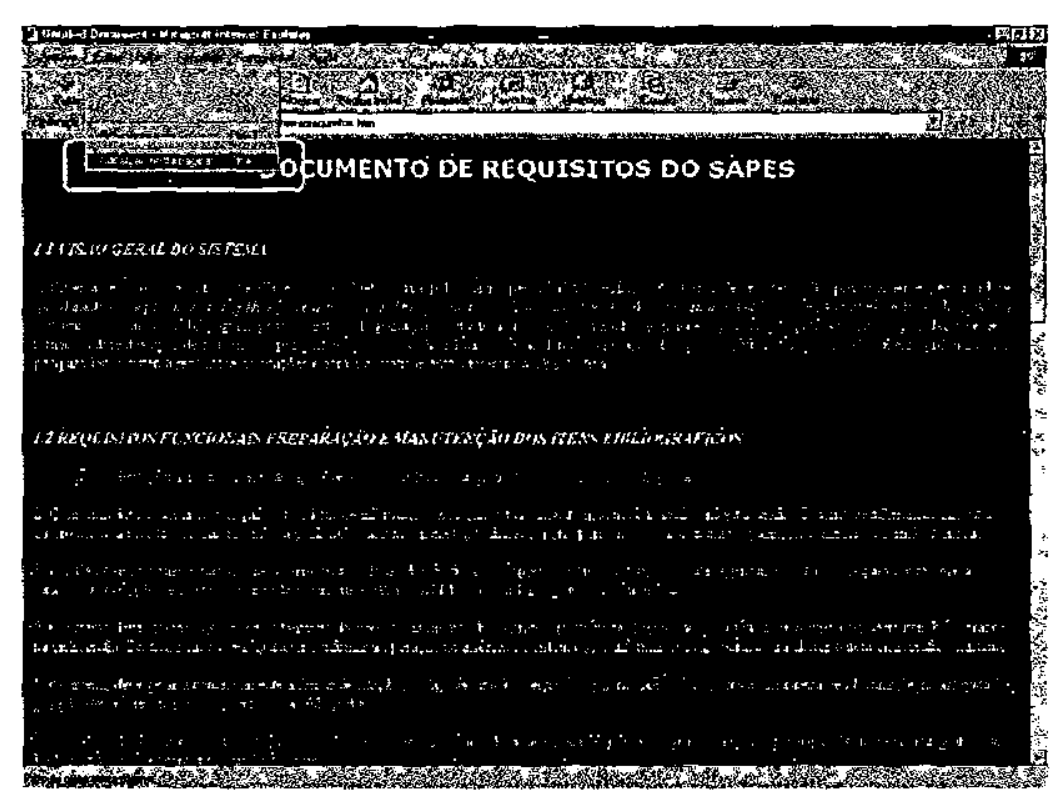

Figura 17. A Navegação por busca de palavras-chaves no Hiperdocumento de Software.

\section{$\underline{5^{\circ} \text { Forma }}$}

A quinta e última forma corresponde à exploração dos links armazenados em "Bookmarks". "Bookmarks" consiste de um repositório cuja função é armazenar links para hiperdocumentos navegados. Difere do Histórico devido o usuário ser capaz de selecionar quais os hiperdocumentos (links) que devem ser armazenados. Um dos fatores que motivam o armazenamento de links em "Bookmarks" é o desejo de futuramente retornar ao hiperdocumento em questão.

Além da identificação dessas cinco formas de navegação de hiperdocumentos de software, observou-se que a navegação dos hiperdocumentos pode ser melhor executada caso exista um roteiro definido para a apresentação dos hiperdocumentos. $O$ roteiro proporcionaria uma ordenação lógica dos hiperdocumentos de software de modo que a assimilação da informação pudesse ser facilitada. Todavia, a navegação do roteiro não deve ser extremamente rígida; ao contrário, deve ser flexível o suficiente para que engenheiros de software com diferentes perfis alcancem seus objetivos.

Observou-se também que a navegação entre partes de um mesmo hiperdocumento de software pode prover maior relacionamento entre as informações que compõem o hiperdocumento. Esse tipo de navegação é útil no relacionamento de mídias distintas como, por exemplo, links entre partes descritivas e imagens localizadas em outro ponto do hiperdocumento.

Como aspecto positivo do uso de um browser como o IE5 na navegação de hiperdocumentos de software é a possibilidade de suporte para hiperdocumentos escritos em 
diferentes linguagens (VRML, DHTML, ASP, PHP, Perl, etc) e que integram tecnologias recentes como Flash e Shockwave. Por outro lado, a generalização dos recursos navegacionais é apontado como aspecto negativo, pois não suprem as necessidades específicas de navegação para hiperdocumentos de software.

A investigação sobre a navegabilidade de hiperdocumentos de software mostrou que uma mesma forma de navegação pode ser oferecida pelo browser ou pelo próprio hiperdocumento de software. Essa consideração pode ser melhor visualizada recorrendo-se ao [Quadro 6].

Quadro 6. Relação da Navegação com os Recursos de Hiperdocumentos e do Browser.

\begin{tabular}{|l|l|l|}
\hline (1) & Navegação entre documentos precedentes e subseqüentes & Hiperdocumento e Browser \\
(2) & Navegação por links & Hiperdocumento \\
(3) & Navegação pelo Histórico & Browser \\
(4) & Navegação através de um mecanismo de busca & Hiperdocumento e Browser \\
(5) & Navegação através de links em "bookmarks" & Browser \\
\hline
\end{tabular}

De acordo com o [Quadro 6], as formas 1, 2 e 4 são possíveis em navegação orientada por recursos oferecidos nos hiperdocumento de software. Por outro lado, browsers oferecem recursos para a navegação de acordo com as formas $1,3,4$ e 5 .

Esse fato revela que certos recursos navegacionais dos atuais browsers comerciais ("Bookmarks", por exemplo) podem ser empregados na navegação de hiperdocumentos de software. A aplicação desses recursos pode ser favorável a um maior entendimento do hiperdocumento e consequentemente do próprio software. Entretanto, os recursos navegacionais oferecidos pelos hiperdocumentos podem ser igualmente úteis, principalmente por possibilitarem um tipo de navegação extremamente flexível (por links).

Os resultados dos estudos apresentados até o momento embasaram a proposição de um sistema hipermidia de autoria e navegação de documentos de software baseado nas características e nos recursos implementados no SASHE. Tal proposta é apresentada a seguir.

\subsection{Descrição Geral do Sistema SASHDoc}

SASHDoc, Sistema de Autoria e Suporte Hipermídia para Documentação de Software, é um protótipo de sistema hipermídia para a produção de documentos de software. O sistema 
é formado por dois módulos principais: o módulo de autoria, destinado à confecção dos documentos de software, e o módulo de navegação, destinado à exploração das informações que compõem os documentos de software.

O usuário principal do sistema é o engenheiro de software; contudo, o sistema pode ser utilizado por qualquer pessoa que manipule documentos de software como o usuário final, que navega pelo manual de operação do sistema, ou o gerente do projeto de software, que manipula os documentos do planejamento do software.

No sistema, uma documentação de software é formada por um ou mais documentos de software. $O$ documento de software pode ser um texto, uma imagem, um áudio, um vídeo ou até mesmo um arquivo executável. Os documentos, em geral, podem estar distribuídos em etapas que representam as fases do ciclo de vida do software. A documentação, as etapas e os documentos de software são caracterizados por um conjunto de propriedades.

É permitido criar relacionamentos (elos) unidirecionais entre documentos de software. Os elos são criados por meio do relacionamento entre âncoras presentes nos documentos. Uma âncora representa um fragmento do conteúdo de um documento de software.

Os documentos de software dispostos numa ordenação lógica formam um roteiro. $O$ roteiro é construído no módulo de autoria e navegado pelo usuário final no módulo de navegação. A navegação de um roteiro é realizada por meio de estratégias associadas a botões dispostos numa barra de controle na interface do módulo de navegação.

Como outras funcionalidades do sistema, pode-se citar:

- Controlar as versões dos documentos de software produzidos;

- Cadastrar os usuários do sistema;

- Alternar facilmente entre os módulos de autoria e navegação;

- Visualizar ("Preview") o roteiro;

- Armazenar palavras-chave em um Glossário;

- Armazenar referências da documentação em uma Bibliografia;

- Refazer ou desfazer ações do usuário;

- Editar a posição dos documentos no roteiro;

- Criar mais de um roteiro para uma mesma documentação;

- Integrar a interface com outras ferramentas de edição dos documentos de software;

- Oferecer independência da metodologia de desenvolvimento do software;

- Disponibilizar mecanismos de busca e recuperação de informação;

- Possibilitar diferentes visões do software; 
- Estabelecer relacionamento entre documentos;

- Suporte de um banco de dados e de um modelo hipertexto;

- Disponibilizar de modelos de documentos (Templates);

- Oferecer suporte a diferentes tipos de mídia (texto, áudio, vídeo e imagem);

- Disponibilizar interface WYSIWYG (What You See Is What You Get);

- Possibilitar o usuário fazer anotações, esclarecimentos e recomendações sobre o software;

- Disponibilizar recursos navegacionais como histórico e "bookmarks";

- Disponibilizar mecanismos de gerenciamento e manutenção das informações;

- Disponibilizar mecanismos de checagem de consistências entre os documentos (nós);

O sistema SASHDoc é suportado pelo Modelo de Contextos Aninhados (MCA) [CAS91]. Relembrando, o MCA é um modelo conceitual hipermídia baseado nos conceitos de nós e elos sobre o qual o SASHE está implementado.

Em vista da quantidade de recursos que o sistema SASHDoc apresenta, a seguir serão mostrados apenas aqueles considerados com maior relevância para este trabalho

\subsubsection{Interfaces}

O sistema possui três interfaces principais: a Interface de Abertura, Interface do Módulo de Autoria e Interface do Módulo de Navegação.

A Interface de Abertura é a primeira interface a ser apresentada na execução do sistema [Figura 18]. Nessa interface estão disponibilizadas as tarefas de validação do usuário do sistema e de seleção do módulo de trabalho. $\mathrm{O}$ acesso aos módulos do sistema somente deve ser permitido a usuários previamente cadastrados.

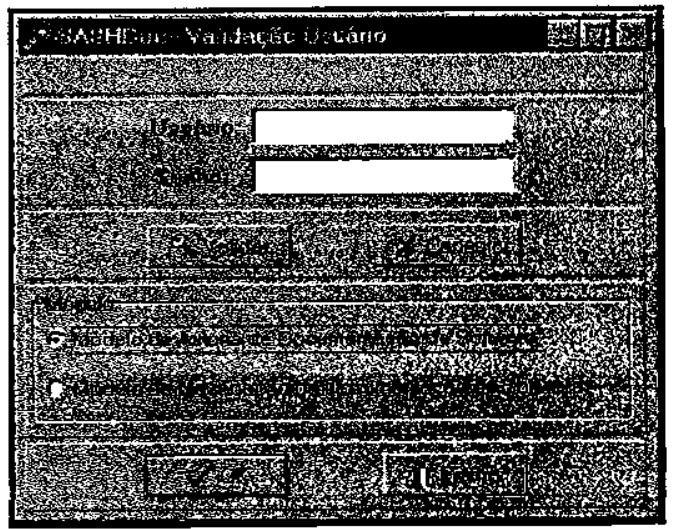

Figura 18. Interface de Abertura do SASHDoc. 
A Interface do Módulo de Autoria disponibiliza as tarefas de criação de uma documentação de software [Figura 19]. Resumidamente, a partir desta interface o engenheiro de software pode: cadastrar (criar, editar e excluir) etapas do ciclo de vida, manipular documentos de software, relacionar documentos de software, criar roteiros navegacionais, alternar para o módulo de navegação, etc.

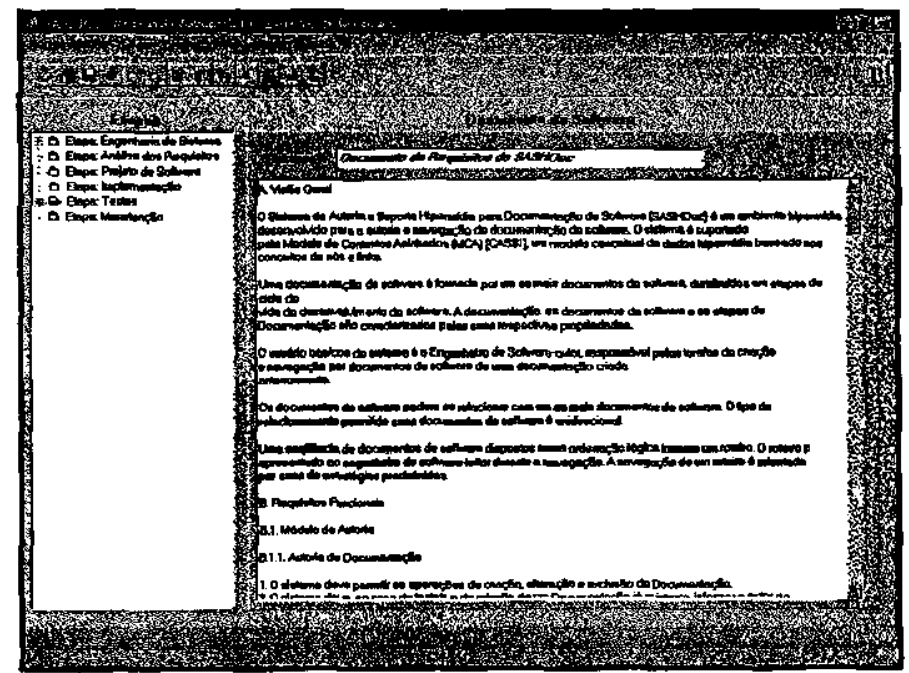

Figura 19. Interface do Módulo de Autoria do SASHDoc.

A Interface do Módulo de Navegação disponibiliza um conjunto de botões dispostos em uma barra de controle para a navegação da documentação [Figura 20]. Esses botões estão associados a estratégias orientadas ao domínio e, em certos casos, baseadas nas propriedades dos documentos da aplicação. Na próxima seção são discutidas as propriedades dos documentos de software projetadas para o SASHDoc.

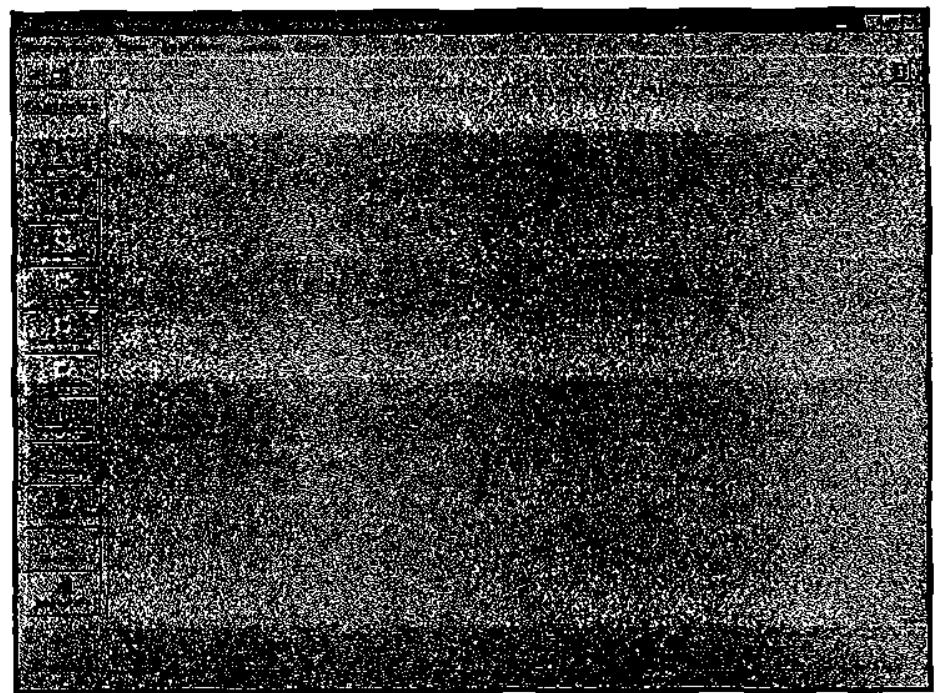

Tigura 20. Interface do Módulo de Navegąąo do SASHDoc 


\subsubsection{Propriedades dos Documentos de Software}

Os documentos de software do SASHDoc são caracterizados por um conjunto de propriedades. O objetivo dessas propriedades é classificar os documentos de software de modo a auxiliar seu entendimento, proceder ao controle de suas versões e auxiliar na recuperação e navegação dos documentos. Do ponto de vista da exploração de informações nos hiperdocumentos, as propriedades consideradas mais importantes são: abstração, visibilidade, formalidade e funcionalidade. Essas propriedades foram elaboradas principalmente a partir dos trabalhos de: [CHI90;TIL92;ALL97].

\section{a) $\underline{\text { Abstração }}$}

Para minimizar a complexidade do mundo real, as pessoas procuram estabelecer uma visão simplificada dos objetos ou das partes que formam esse mundo. Dessa forma conseguem administrar a complexidade e entender melhor os seus elementos. Esse processo de simplificação pode ser chamado de abstração [CUR89;QUI98].

Segundo o dicionário Oxford, abstração é o "princípio de ignorar os aspectos de um assunto não relevantes para o propósito em questão, tornando possível uma concentração maior nos assuntos principais." [OXF86]. Abstração enfatiza aqueles aspectos que em um determinado momento são relevantes para atender um propósito estabelecido. Muito embora se saiba que no contexto existem muitos outros elementos, simplesmente opta-se por não considerá-los no momento. [COA91]

A abstração é um conceito também aplicado na Ciência da Computação. Por exemplo, existe a abstração de procedimento que é uma forma de abstração utilizada por analistas de requisitos para dividir um processo maior em subpassos ou subfunções a fim de minimizar sua complexidade. Também existe a abstração de dados, uma forma de organização de pensamento e de especificação das responsabilidades dos elementos informacionais que formam o sistema [COA91].

O ciclo de vida de desenvolvimento do software também está relacionado com a abstração do software [CHI90;PRE97]. Segundo Pressman, cada passo no processo de Engenharia de Software é refinado em níveis de abstração da evolução do software [PRE97]. De acordo com Chikofsky e Cross, a abstração se relaciona com as atividades do ciclo de vida segundo os conceitos [CHI90]: 
- Nível de Abstração: quanto mais próximo o projeto estiver do nível de implementação, menor será o nível de abstração do projeto. Por outro lado, quanto mais próximo o projeto estiver da fase de especificação dos requisitos do sistema, maior será o nível de abstração do mesmo.

- Grau de Abstração: dentro de uma mesma etapa (ou fase) do ciclo de vida do software, se as informações forem pouco detalhadas, diz-se que é alto o grau de abstração, já se as informações forem muito detalhadas, diz-se que é baixo o grau de abstração.

Como se percebe, a abstração é diretamente proporcional a uma visualização simplificada do software [COS97]. Nas fases iniciais do ciclo, o software é declarado em termos amplos usando-se a linguagem do domínio a que o software pertence. Nessas fases são considerados aqueles aspectos relevantes para o entendimento do software. Esse tipo de visão do software é também conhecido como visão top-down. Já nas fases finais do ciclo, o software é visto na forma de uma aplicação final. Essa etapa corresponde às fases de implementação, teste e manutenção do software. Esse tipo de visão do software é conhecido como visão bottom-up.

Considerando que cada etapa do ciclo de vida exige a produção de documentos, inferese que os documentos também são acometidos por diferentes graus de abstração. Por exemplo, se o documento retrata os passos iniciais do ciclo de vida do software, conseqüentemente seu nível de abstração é alto e o seu grau de abstração é baixo. Ou seja, uma maior quantidade de detalhes sobre o software é disponibilizada ao engenheiro de software. Por outro lado, se o documento retrata as etapas finais do ciclo de vida, o seu nível de abstração é baixo e o seu grau de abstração é alto. Em outras palavras, uma menor quantidade de detalhes sobre o software é descrita no documento.

Levando-se em conta a relação de abstração-detalhamento e sua importância para o processo de desenvolvimento e de documentação do software foi definida a propriedade Abstração para documentos de software no SASHDoc cujo fundamento baseia-se especificamente no nível de detalhamento do conteúdo do documento acerca do software. Desse modo, o documento de software pode ser classificado em três tipos:

- Documento com alto grau de abstração. nessa classe, o software é retratado no documento em linhas gerais. São traçados apenas os aspectos gerais, os elementos e requisitos principais.

- Documento com grau médio de abstração: nessa classe, o documento descreve o software em uma quantidade maior de detalhes. $O$ objetivo do documento é prover um melhor 
entendimento do software, em complemento do entendimento prévio adquirido em documentos de maior abstração.

- Documento com baixo grau de abstração: nessa classe, o documento descreve o software em riqueza de detalhes. As informações anteriormente apresentadas de forma genérica são expandidas.

A abstração possui estreita relação com o detalhamento do software descrito no conteúdo do documento. $\mathrm{Na}$ realidade, o que o engenheiro de software pretende ao produzir um documento é reduzir a complexidade com que visualiza o software. Um documento detalhado é necessário quando se encontra em um estágio mais avançado do desenvolvimento do software. Da mesma forma, muito pouco ajuda um documento que descreva o software superficialmente quando se inicia a implementação. Por estas razões, há de se considerar o detalhamento do software; mas no momento apropriado.

A figura abaixo apresenta a relação nível versus grau de abstração presentes em documentos de software durante as três principais etapas do ciclo de vida do software análise de requisitos, projeto e implementação [Figura 21]. Os documentos são representados por quadradinhos pretos inseridos em cada etapa do ciclo de vida.

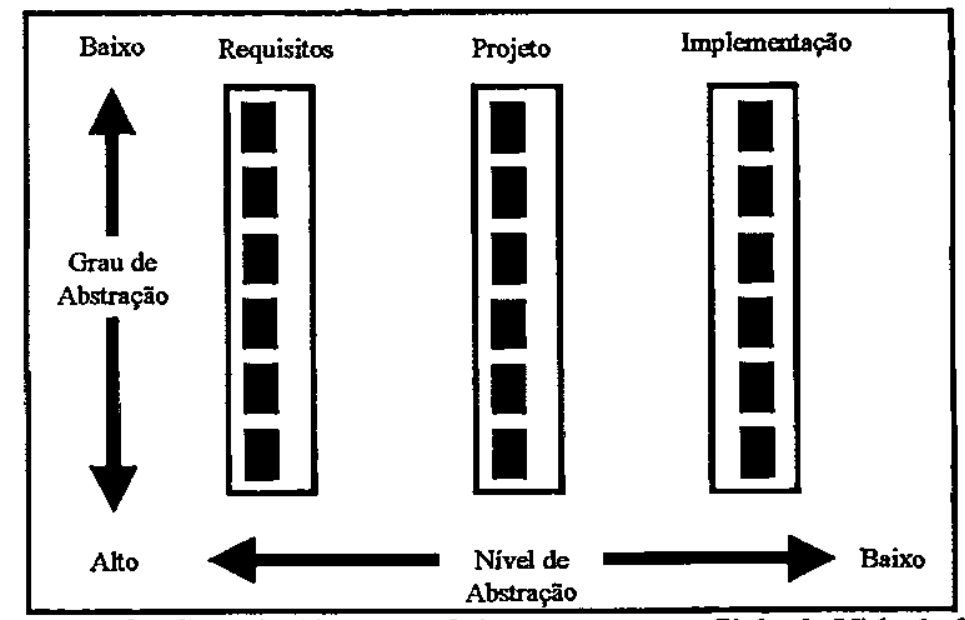

Figura 21. Nível e Grau de Abstração de Documentos no Ciclo de Vida do Software.

Contudo, não é tarefá fácil atribuir o nível de detalhamento do documento com relação ao software. Essa atribuição pode estar diretamente relacionada com a experiência do engenheiro de software no desenvolvimento de software. Nos casos em que o engenheiro não possui a experiência necessária, é possível basear-se simplesmente na etapa do ciclo de vida a qual o documento descreve. Ou seja, nas fases iniciais do ciclo, menos detalhes do software são necessários; nas fases finais são exigidos maiores detalhes acerca do software. 


\section{b) $\underline{\text { Visibilidade }}$}

As visões (ou visibilidade) de software têm o objetivo de apresentar as características do software sob diferentes pontos de vista. A focalização do software sob ângulos distintos visa, principalmente, facilitar a sua compreensão pelo engenheiro de software ou pela equipe de desenvolvimento, de forma que consigam obter o entendimento adequado do software [COS97].

Uma visão representa, entre outras coisas, um estado particular do software. Esse estado pode ser traduzido na forma de uma representação gráfica ou na forma de uma descrição textual. A organização das visões organizadas numa seqüência lógica pode servir para formar a documentação final do software, ou para formar um "guided tour" com fins tutoriais, ou até mesmo para focalizar aqueles componentes que precisam ser melhor analisados e entendidos [TIL92;ALL97].

Conforme visto no Capítulo Dois, Rigi é uma ferramenta de documentação de software que aplica o conceito de visões [ALL97]. A ferramenta produz documentos a partir de um processo de engenharia reversa desses sistemas; as visões extraidas deste processo auxiliam na: tomada de decisões pelo engenheiro de software focalizando, por exemplo, os pontos problemáticos do software que requerem mais esforço de reconstrução; recuperação de informações relevantes a respeito do software, onde as visões assumem um papel tutorial; e incentivo à compreensão do software, reduzindo o nível de complexidade do software por meio de inúmeros gráficos e modelos produzidos.

São inúmeros os aspectos através dos quais o software pode ser visualizado. Por exemplo, de acordo com a UML, o software pode ser visualizado pelos seus aspectos funcionais (que tratam da estrutura estática e das interações dinâmicas do software), pelos aspectos não-funcionais (que tratam dos requisitos de tempo, confiabilidade, desenvolvimento), pelos aspectos organizacionais (que tratam da organização do trabalho e do mapeamento dos módulos), pelos aspectos procedurais (que tratam da descrição da implementação dos módulos e suas dependências) e, por fím, pelos seus aspectos concorrentes (que tratam da divisão do software em processos e processadores) [FOW97;RAT99].

De acordo com a [Figura 22], Harandi e Ning classificam as visões obtidas do software em quatro categorias [HAR90]: 
- Visão em nivel-implementacional: abstrai características da linguagem de programação e características específicas da implementação. Por exemplo, informações a respeito da sintaxe e da semântica da linguagem e informações da implementação.

- Visão em nivel-estrutural: abstrai detalhes da linguagem de programação para revelar sua estrutura a partir de diferentes perspectivas. $O$ resultado é uma representação explícita das dependências entre os componentes do sistema.

- Visão em nivel-funcional: abstrai a função de um componente. Essa visão relaciona partes do programa às suas funções. Essa visão relaciona as partes do programa às suas funções procurando revelar as relações lógicas entre elas.

- Visão em nível-de-dominio: abstrai o contexto em que o sistema está operando. Em outras palavras, o motivo para o sistema ser desenvolvido.

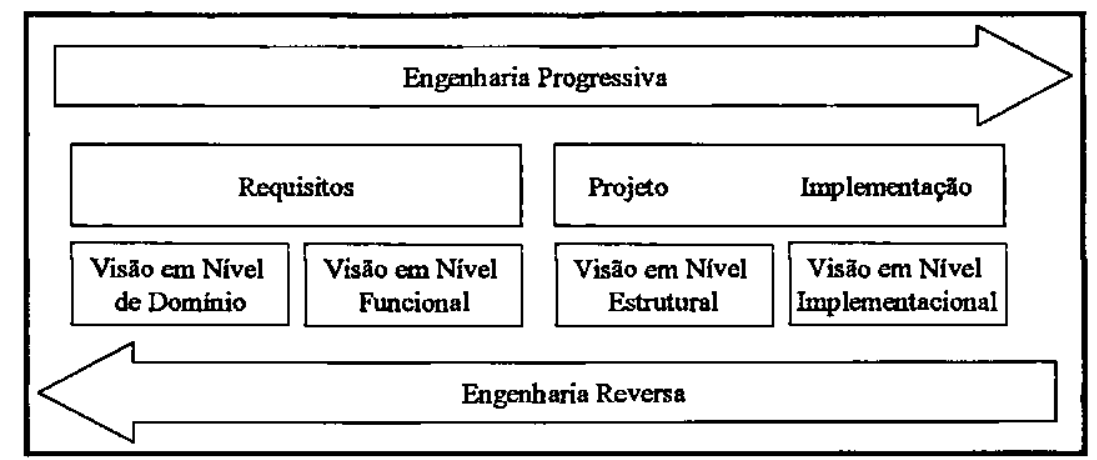

Figura 22. Visualizações de Software no Ciclo de Desenvolvimento [COS97].

Essas categorias de visões de software significam que são considerados os diferentes tipos de leitores de documentos e usuários do software. Ou seja, as visões presentes nos documentos são produzidas de forma que atendam a distintos interesses de leitura e exploração de informação, permitindo que os leitores consigam recuperar eficientemente as informações desejadas [FEL99].

Conforme visto, a visibilidade é uma "estratégia" que pode acarretar em muitos beneficios para o engenheiro de software. Entretanto, é preciso tomar cuidado com o tipo e a quantidade de informação apresentada ao leitor do documento. De forma a estabelecer esse controle no SASHDoc, os documentos que apresentam visões podem ser classifícados de acordo com o conteúdo informacional que apresenta a respeito do software, ou seja, de acordo com a visibilidade do software. Assim, os documentos são classificados em:

- Documento com visibilidade funcional externa: o documento com essa visão descreve a funcionalidade do software desempenhada pelos seus agentes externos. Agentes externos 
são os produtores ou consumidores da informação do software (hardware, pessoa ou mesmo outro software).

- Documento com visibilidade funcional interna: o documento descreve o software sob o ponto de vista interno: sua estrutura estática (classes, objetos, e relacionamentos), as colaborações entre objetos (quando estes enviarem mensagens uns aos outros para realizarem as funções do software) e a concorrência entre os objetos.

- Documento com visibilidade modular: o documento descreve os módulos do software e suas.dependências internas e externas.

- Documento com visibilidade organizacional: $\mathrm{O}$ documento mostra a organização física do software: seus computadores, periféricos e como eles se conectam entre si.

Entretanto, para os documentos que apresentam visões do software deve-se cuidar da quantidade de informação apresentada. A visibilidade da informação deve ser controlada para que a representação do software seja compreensivel ao leitor. Para estabelecer esse controle, Coad e Yordon propõem niveis de controle cuja função é estabelecer a apresentação das informações ao leitor sob diferentes niveis de abstração, respeitando as características daquele leitor [COA95].

\section{c) Formalidade}

Documentos de software são comumente escritos em uma linguagem natural. $O$ objetivo da linguagem natural é facilitar a escrita, a leitura e o entendimento do documento pelo engenheiro de software. No entanto, para engenheiros mais experientes, os documentos também podem ser escritos em uma linguagem cuja sintaxe e semântica sejam definidas de maneira mais formal [SOM96].

Uma linguagem formal é fundamentada basicamente por técnicas formais. As técnicas formais são baseadas em notações matemáticas e/ou em lógica formal (notação formal) para a descrição das propriedades de um sistema. Sua utilização pode resultar na redução erros e ambigüidades do sistema e dos documentos de software [GHE91;SOM96;GOU99].

A quantidade de notações formais é um importante aspecto para o documento de software. Ghezzi, por exemplo, apresentou o nível de formalidade de documentos como um critério para classificação de ferramentas e ambientes de software [GHE91]. No contexto da documentação de software, nível de formalidade pode ser entendido como a quantidade de notação formal presente em um documento. 
Os engenheiros de software normalmente se utilizam das técnicas formais nas etapas iniciais do ciclo de vida [PRE95a]. Esse fato ocorre devido às técnicas formais incentivarem um maior rigor na especificação dos requisitos do software; com isso, evita-se problemas ao longo do processo de desenvolvimento do software como, por exemplo, a falta de consistência. Em vista de seus beneficios, as técnicas formais também passaram a ser aplicadas nas demais etapas do ciclo de vida.

Nas fases iniciais do ciclo de vida do software, o engenheiro de software tende a utilizar notações formais nos documentos em quantidade maior. Nas fases finais do ciclo, os documentos têm uma preocupação maior com claro entendimento do software e com sua implementação. Nesse sentido, uma quantidade menor de notação formal é utilizada, uma vez que a própria linguagem de programação já possui sintaxe e semântica (formalismos) bem definidas.

Tendo em vista a forte tendência do uso de técnicas formais em documentação de software, definiu-se a propriedade Formalidade para documentos de software no SASHDoc. Essa propriedade classifica o documento de acordo com a quantidade de notaçōes matemáticas e lógicas formais presentes no documento. Assim, um documento é classificado em três tipos:

- Documento com alto nivel de formalidade: o documento apresenta ampla quantidade de notações formais.

- Documento com nível médio de formalidade: o documento apresenta uma quantidade relativa de notação formal. Estima-se que em torno de cinqüenta por cento dos documentos esteja redigido em notação formal.

- Documento com baixo nível de formalidade: o documento não apresenta o uso de notações formais a descrição do software.

Muito embora o uso de notação formal tenha proliferado nos últimos anos, ainda assim encontra resistências por grande parte dos engenheiros de software. Justifica-se que as notações formais não proporcionam uma leitura fácil e agradável ao leitor. Uma alternativa para facilitar o entendimento de documentos é a utilização de uma linguagem natural em conjunto com as notaçōes formais [PRE97]. A utilização de uma linguagem natural proveria um mecanismo para reforçar o entendimento do sistema pelo engenheiro de software. 


\section{d) Funcionalidade}

A documentação sobre um software não é formada somente pelos documentos que descrevem formalmente o software. Outros tipos de documentos também podem ser importantes para o engenheiro de software pois podem proporcionar uma visão diferente sobre um determinado aspecto do software [RAJ99].

Esses documentos podem fornecer: (1) mais esclarecimento do software e do ambiente em que está inserido; (2) mais detalhes de uma etapa do ciclo de vida; ou (3) registro dos acontecimentos ocorridos durante o desenvolvimento do software de modo que sirva como histórico para novos projetos. Normalmente são redigidos em paralelo com uma atividade ou etapa do desenvolvimento do software.

Sendo assim, um documento de software produzido no SASHDoc pode ser classificado em quatro tipos:

- Documento de Software: são aqueles documentos normalmente exigidos durante a construção de um software (documento de requisitos, de projeto, de testes, etc). Esses documentos retratam o software segundo o nível de abstração da etapa do ciclo de vida. Geralmente utiliza-se de linguagem técnica e formal

- Nota do Documento: esse documento contém as informações consideradas "extras" em um documento de software. Ou seja, visa complementar um documento já produzido. As informações possuem cunho informativo, ilustrativo ou explicativo a respeito do software. A linguagem utilizada é técnica e impessoal.

- Nota da Etapa: esse documento registra informações sobre uma determinada etapa do ciclo de vida do desenvolvimento do software. Similarmente à nota anterior, suas informações também podem ter cunho informativo, ilustrativo ou explicativo e a linguagem utilizada é técnica e impessoal.

- Nota do Autor: esse documento apresenta anotações e observações pessoais do engenheiro de software a respeito do processo de desenvolvimento ou do próprio software. Caracteriza-se pela linguagem informal e pessoal utilizada.

Abstração, Formalidade, Visibilidade e Funcionalidade são as principais propriedades de documentos de software no sistema SASHDoc. Com os valores atribuídos às duas primeiras foram definidas estratégias que visam atender os interesses navegacionais do engenheiro de software. Essas estratégias são apresentadas a seguir. 


\subsubsection{Estratégias Navegacionais}

Todos os botões da barra de controle do módulo de navegação estão associados à funcionalidades para a exploração das informações presentes nos documentos de software integrantes do roteiro. No entanto, aos botões Mais Abstração, Menos Abstração, Mais Formalidade e Menos Formalidade são associadas estratégias especiais.

Os botões Mais Abstração e Menos Abstração remetem estratégias de apresentação de documentos de software relacionados a um documento em questão. Ou seja, os documentos a serem apresentados são julgados de acordo com um maior ou menor grau de abstração, respectivamente [Figura 23].

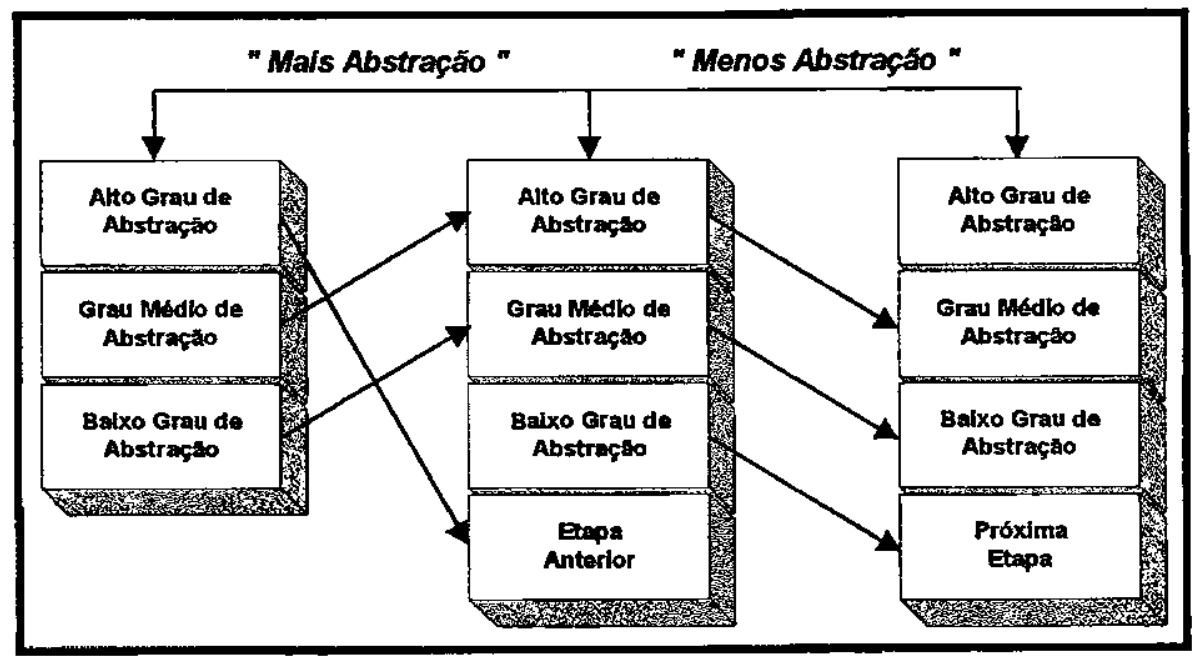

Figura 23. Estratégia Navegacional para os botões "Mais Abstração" e "Menos Abstração".

A estratégia pode ser resumida assim: durante a navegação do roteiro, o usuário se encontra em um documento de software com a respectiva propriedade abstração de valor "grau médio de abstração". Caso o usuário deseje um documento com informações mais abstratas, deve-se pressionar o botão Mais Abstração; nesse caso, há uma busca na mesma etapa por um documento com a propriedade abstração de valor "alto grau de abstração". Por outro lado, caso o usuário deseje um documento com informações menos abstratas, deve-se pressionar o botão Menos Abstração; nesse caso, há uma busca na mesma etapa por um documento com a propriedade abstração de valor "baixo grau de abstração".

É possível acontecer que na etapa não exista um documento de software com maior ou menor grau de abstração. Neste caso, se o usuário optar por um documento com informações 
mais abstratas, ocorre uma busca por um documento de software com valor "alto grau de abstração", só que na etapa anterior. Se a opção for por um documento com informações menos abstratas, a busca ocorre por um documento com valor "baixo grau de abstração", contudo, a busca ocorre na etapa seguinte.

Aos botões Mais Formalidade e Menos Formalidade, a estratégia de apresentação de documentos de software está relacionado com a propriedade Formalidade. Os documentos são julgados de acordo com um maior ou menor nível de formalidade, respectivamente [Figura 24].

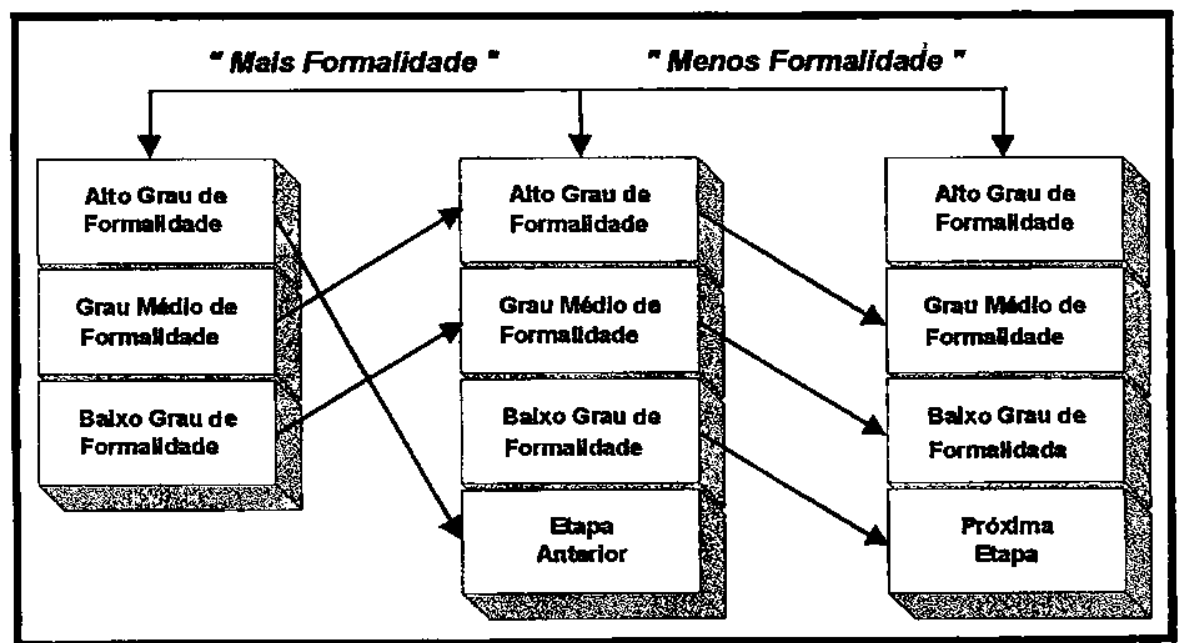

Figura 24. Estratégia Navegacional para os botões "Mais Formalidade" e "Menos Formalidade".

A estratégia pode ser resumida assim: durante a navegação do roteiro, o usuário se encontra em um documento de software com a respectiva propriedade formalidade de valor "nível médio de formalidade". Caso o usuário deseje um documento com uma maior quantidade de notações formais, deve-se pressionar o botão Mais Formalidade; nesse caso, há uma busca na mesma etapa por um documento com a propriedade abstração de valor "alto nível de formalidade". Por outro lado, caso o usuário deseje um documento com uma quantidade menor de notações formais, deve-se pressionar o botão Menos Formalidade; nesse caso, há uma busca na etapa por um documento com a propriedade abstração de valor "baixo nível de formalidade".

É possível acontecer que na etapa não exista um documento de software com maior ou menor nível de formalidade. Nesse caso, se o usuário optar por um documento mais formal, ocorre uma busca por um documento de software com valor "alto nível de formalidade", contudo, a busca ocorre na etapa anterior. Se a opção for por um documento com informações 
menos formal, a busca ocorre por um documento com valor "baixo nível de formạlidade", só que na etapa seguinte.

\subsubsection{Roteiros Dinâmicos}

Relembrando, de acordo com a "Visibilidade", documentos de software podem ser classificados como: documento com visibilidade funcional externa, o qual descreve a funcionalidade do software desempenhada pelos seus agentes externos; documento com visibilidade funcional interna, o qual descreve o software sob o ponto de vista interno; documento com visibilidade modular, o qual descreve os módulos do software e suas dependências internas e externas; e documento com visibilidade organizacional, o qual mostra a organização fisica do sistema.

Utilizando-se do valor de visibilidade fornecido pelo usuário, o sistema SASHDoc pode gerar um roteiro navegacional somente com documentos de software com aquele valor. Em outras palavras, o sistema pode gerar automaticamente um roteiro com documentos de software com propriedade funcional externa, por exemplo. Com isso, basta o usuário informar que o tipo de visibilidade desejada é a funcional externa. A ordem dos documentos do software no roteiro respeita a data de criação do documento de software. Caso a ordenação dos documentos não esteja de acordo com os objetivos do usuário, é possível reposicionar os documentos do roteiro. Esse tipo de roteiro gerado automaticamente é denominado de Roteiro

\section{Dinâmico.}

O recurso Roteiros Dinâmicos possui como principais vantagens a economia no tempo e no esforço da construção de um roteiro, e a possibilidade de fornecer uma visão particular acerca de um determinado elemento do software, descrito nos vários documentos que compõem a documentação.

\subsection{Análise da Mudança de Domínio do SASHE para SASHDoc}

Os principais elementos dos sistemas SASHE e SASHDoc estão retratados em seus respectivos diagramas de classes. Sob essa perspectiva, ao se confrontar os diagramas de classe dos dois sistemas, é possivel observar a correspondência existente entre os elementos de ambos os sistemas como identificar onde houve o reaproveitamento de componentes. 
Os diagramas de classes do SASHE e do SASHDoc representam as principais atividades de ambos os sistemas: respectivamente, autoria/navegação de aplicações hipermídia para Ensino e autoria/navegação de aplicações hipermídia para documentação de software. Ambos diagramas foram criados com o auxilio da ferramenta Rational Rose, sendo aquele primeiro adaptado de [FEL99].

Nos diagramas dos sistemas são encontrados três tipos de relacionamentos entre classes: (1) relacionamento do tipo associação binária, que ocorre quando há duas classes diretamente envolvidas na associação; (2) relacionamento do tipo agregação por composição, que é uma agregação na qual uma classe representa o "todo" de um conjunto de classes, que formam as "partes" deste "todo"; e (3) relacionamento do tipo herança com disjunção, que ocorre quando classes derivadas ocorrem de maneira mutuamente exclusiva para uma mesma ocorrência da superclasse.

No diagrama de classes do SASHE para a atividade de autoria pode-se encontrar [Figura 25]:

- 16 classes,

- 2 relacionamentos do tipo associação binária;

- 3 relacionamentos do tipo agregação por composição;

- e 10 relacionamentos do tipo herança com disjunção.

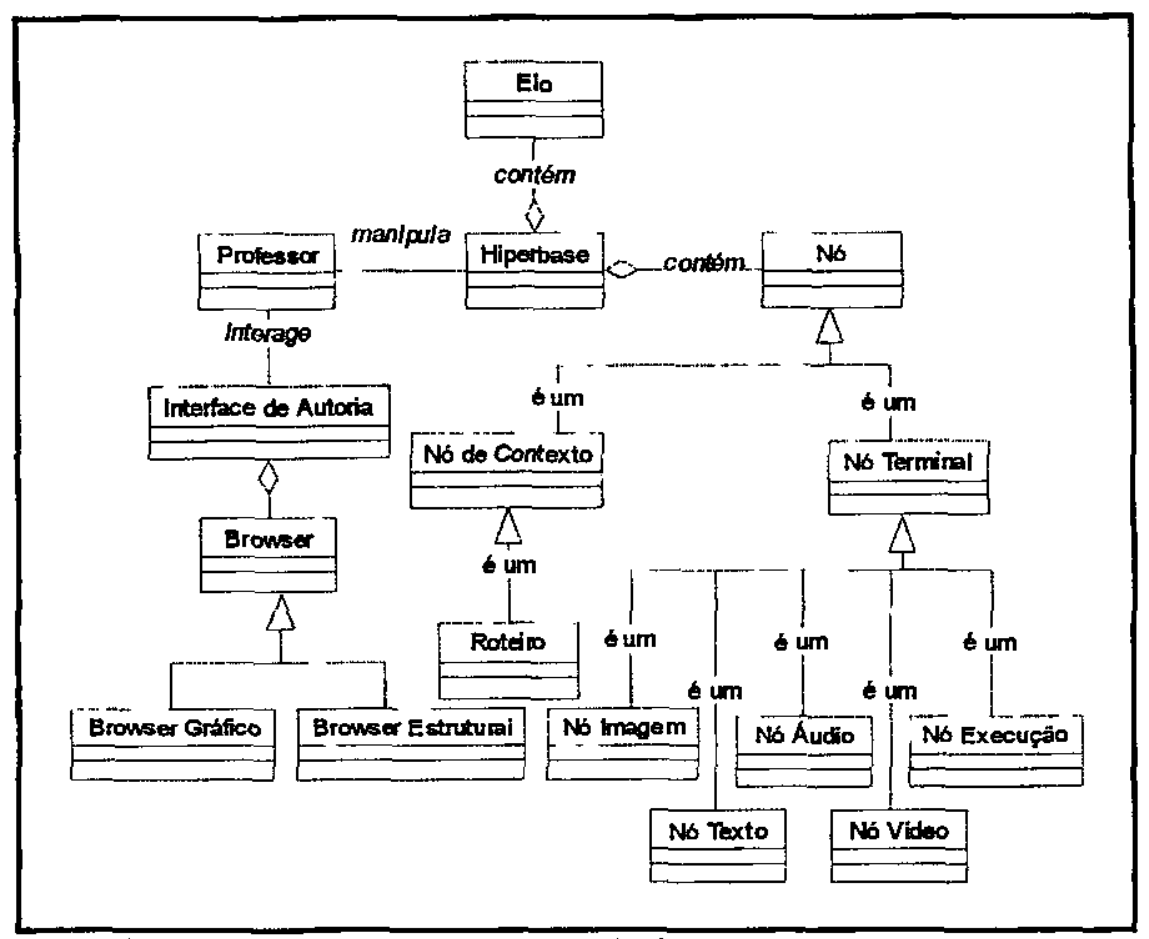

Figura 25. Diagrama de Classes do SASHE para Autoria [FEL99].

O diagrama de classes do SASHE para a atividade de navegação possui [Figura 26]: 
- 10 classes;

- 2 relacionamentos do tipo associação binária;

- 5 relacionamentos do tipo agregação por composição;

- e 2 relacionamentos do tipo herança com disjunção.

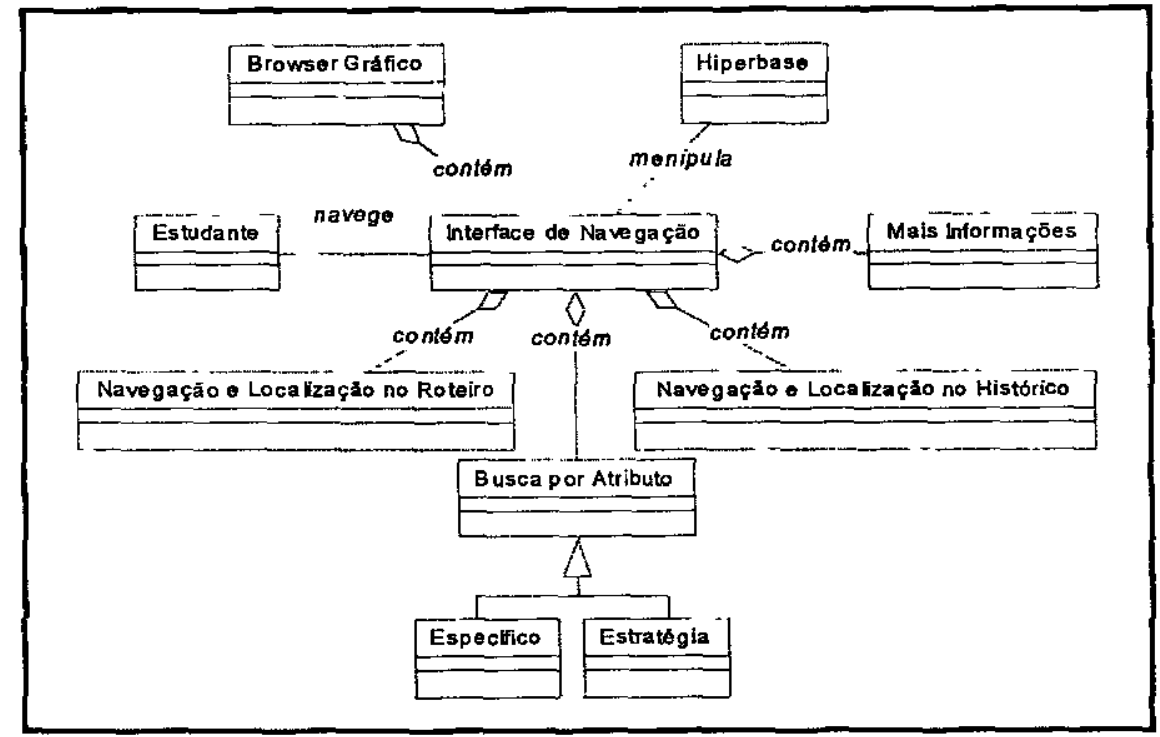

Figura 26. Diagrama de Classes do SASHE para Navegação [FEL99].

O diagrama de classes do SASHDoc para a atividade de autoria possui [Figura 27]:

- 19 classes;

- 6 relacionamentos do tipo associação binária;

- 6 relacionamentos do tipo agregação por composição;

- e 7 relacionamentos do tipo herança com disjunção.



Figura 27. Diagrama de Classes do SASHDoc para Autoria. 
O diagrama de classes do SASHDoc para a atividade de navegação das aplicações hipermídia possui [Figura 28]:

- 10 classes;

- 2 relacionamentos do tipo associação binária;

- 5 relacionamentos do tipo agregação por composição;

- e 2 relacionamentos do tipo herança com disjunção.

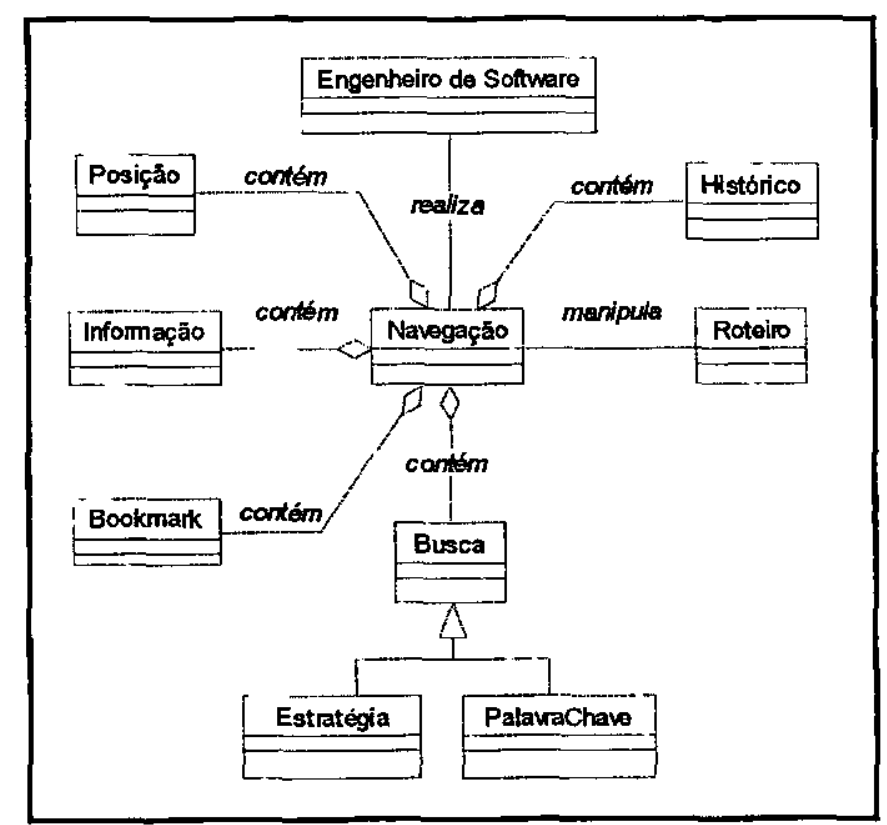

Figur2 28. Diagrama de Classes do SASHHoc para Navegação.

Considerando classes como componentes de software, ao analisar os diagramas de classes do SASHE e do SASHDoc constatou-se quatro tipos de classes:

A) Classes pertencentes ao SASHE incorporados no SASHDoc com alterações para adequar ao novo domínio

Verificou-se que várias classes do SASHE foram utilizadas na construção do sistema SASHDoc [Quadro 7] . Tais classes foram reutilizadas com alterações de pequeno, médio ou grande porte para poderem se adequar ao contexto do novo sistema, a documentação de software. 
Quadro 7. Correspondência entre as Classes Alteradas na Mudança de Domínio.

SASHE

\begin{tabular}{|l|} 
Professor \\
\hline
\end{tabular}

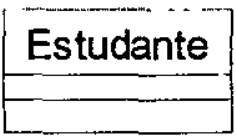

Hiperbase

-

Nó Terminal

Nó de Contexto

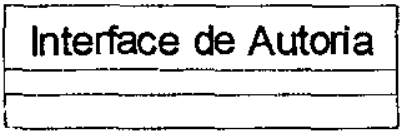

Interface de Navegação

-

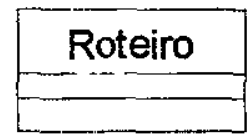

\section{Estratégia}

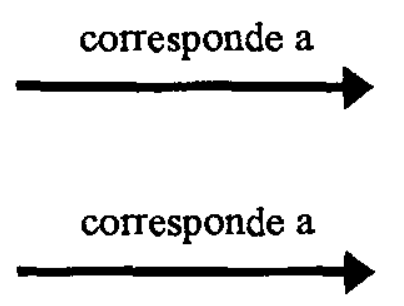

corresponde a

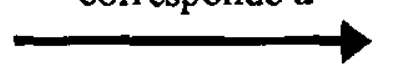

corresponde a
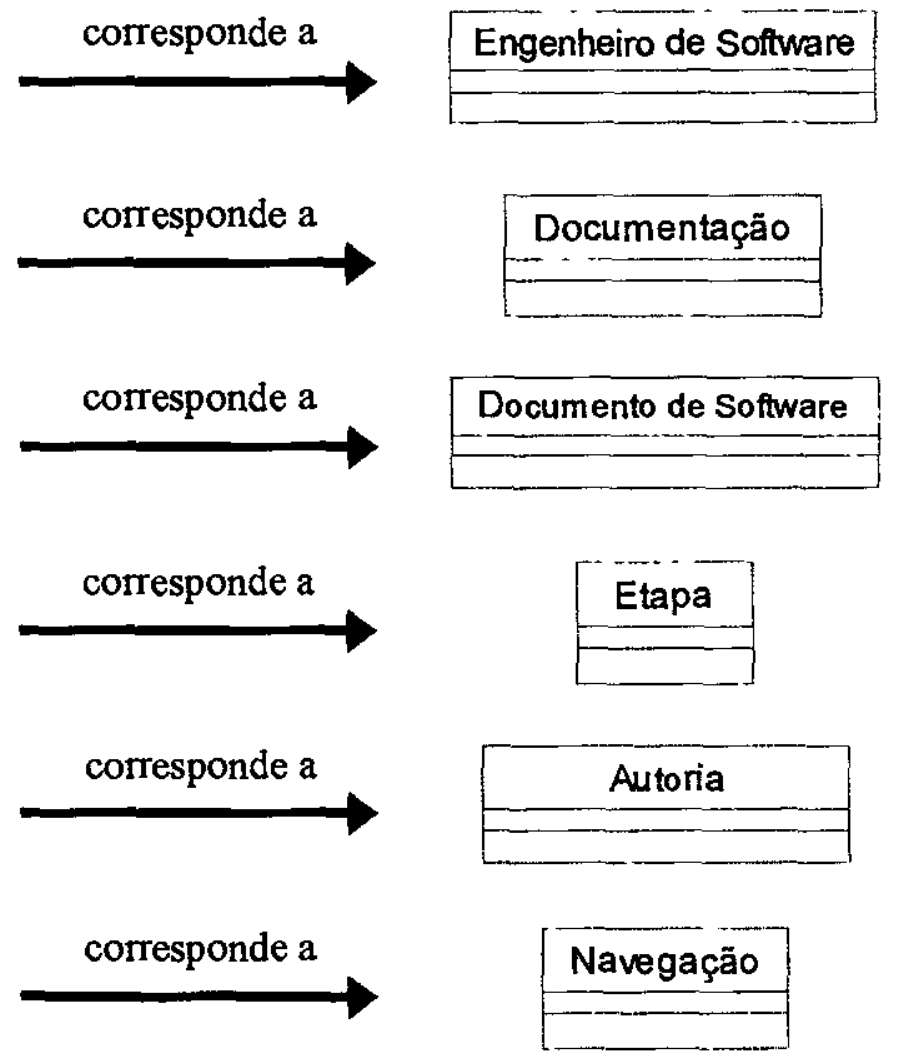

corresponde a
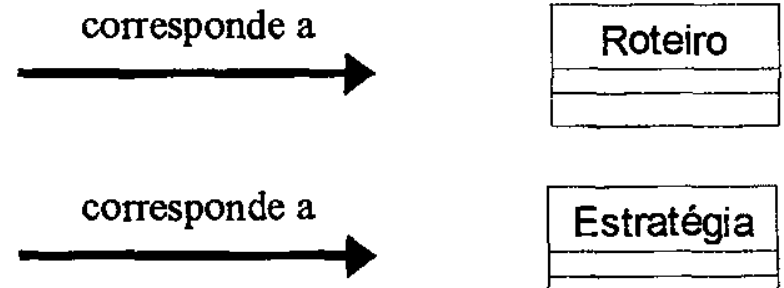

\section{Estratégia}

B) Classes do SASHE incorporados no SASHDoc sem alterações para adequar-se ao novo domínio

Ao contrário do que se previa, constatou-se o reaproveitamento de muitos elementos do SASHE no SASHDoc sem que tivessem sofrido alterações para se adequar à documentação de software [Quadro 8]. Observando esse fato mais atentamente, percebeu-se que a maioria das classes está diretamente relacionada com a tarefa de apresentação de informações; mais 
especificamente com a apresentação das informações que compõem a estrutura da aplicação durante a autoria e com a apresentação do conteúdo da aplicação durante a navegação.

Quadro 8. Correspondência entre as Classes Não-Alteradas na Mudança de Domínio.

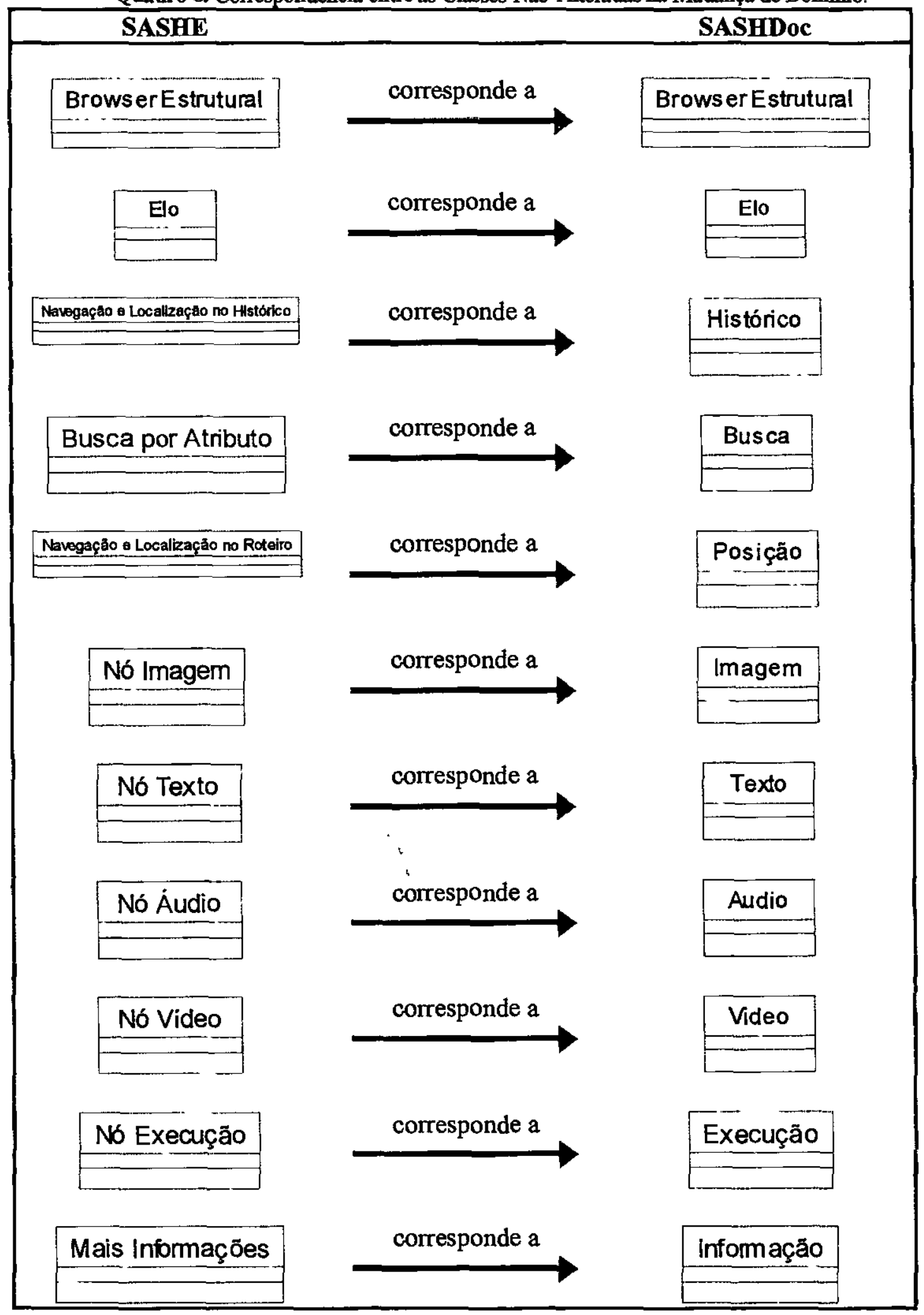




\section{C) Classes do SASHDoc não existentes no.SASHE}

Poucas classes foram acrescidas no sistema SASHDoc [Quadro 9]. Preferencialmente, essas classes apresentam características e operações relacionadas à tarefa de documentação de software, mas não significa que sua aplicação em outros domínios não possa ser viável.

Quadro 9. Classes Construidas para o SASHDoc.

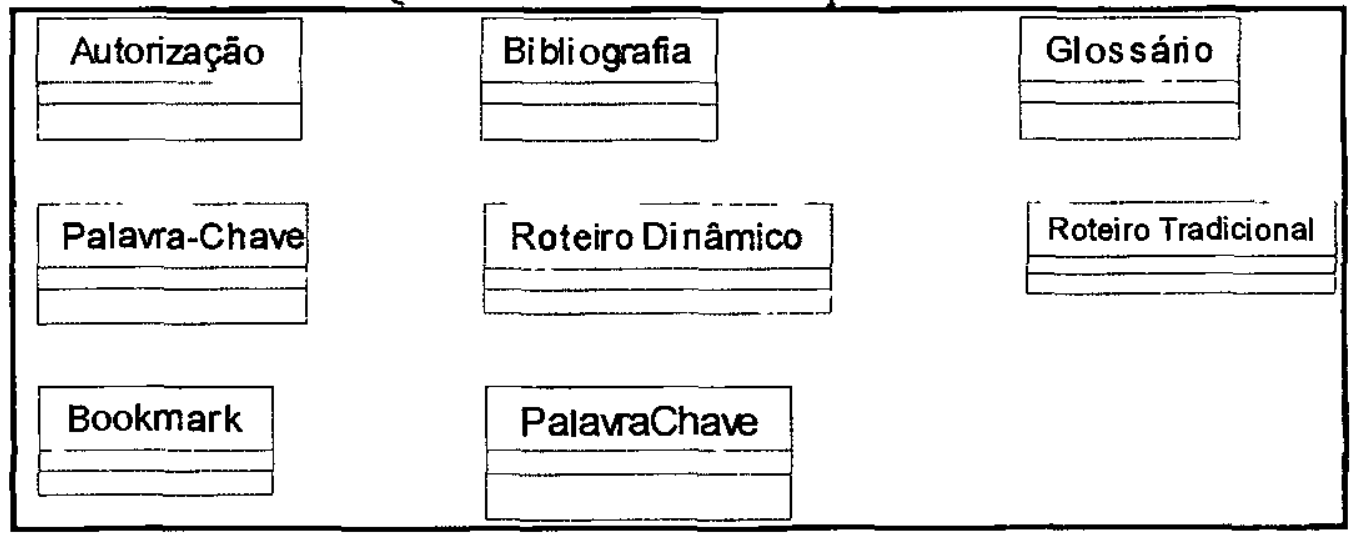

D) Classes do SASHE que não aproveitados no SASHDoc

Observou-se que poucos componentes do SASHE não foram incorporados ao SASHDoc [Quadro 10]. Esse fato pode sugerir que tais elementos não são aplicáveis na documentação de software ou mesmo que são aplicáveis especificamente ao domínio de Ensino.

Quadro 10. Classes do SASHE não-Aproveitadas no SASHDoc.

\begin{tabular}{|l|l|l|}
\hline Es pecífico & \\
\hline & & \\
\hline & & \\
\hline
\end{tabular}

Durante o estudo com os diagramas e das correspondências entre classes dos dois sistemas foi possível identificar que houve um grande reaproveitamento de recursos do SASHE. Esse fato pode significar: a) que o SASHDoc está fortemente baseado no SASHE, visto que reutiliza grande parte dos componentes desse último; b) e que o SASHE apresenta um grande número de componentes com alta aplicabilidade em outros domínios. 
A partir desse aprendizado, é possível propor uma classificação de componentes de sistemas pertencentes a um processo de mudança de domínio de software. Nesse caso, também considerando alterações como necessárias à adequação dos componentes ao domínio do software produto. Assim, tem-se:

- Componentes do software base reutilizados sem alterações no software alvo.

- Componentes do software base reutilizados com alterações no software alvo.

- Componentes do software alvo não existente no software base.

- Componentes do software base não reutilizados no software alvo.

Em linhas gerais, o desenvolvimento do SASHDoc exemplifica uma prática da mudança de domínio de software. Possivelmente, muitos elementos do SASHE poderiam ser aplicados em outros domínios, além da Engenharia de Software. Por isso, é importante que a atividade de mudança de domínio de software defina claramente os componentes de modo que possam ser reaproveitados em outros softwares, do mesmo ou de domínio diferente.

\subsection{Consideraçōes Finais}

Neste capitulo foi apresentado o produto da mudança de domínio do SASHE: o sistema SASHDoc. Para a formulação do sistema, porém, foram necessários maiores estudos sobre hiperdocumentos de software. Assim, hiperdocumentos com informações sobre um software desenvolvido no ICMC foram criados e em seguida navegados por meio dos recursos apresentados pelo browser Internet Explorer 5.0. Essa tarefa visou proporcionar um maior esclarecimento sobre o aspecto navegacional de hiperdocumentos de software. Importantes resultados foram obtidos como a identificação de recursos para navegação de hiperdocumentos de software.

Com embasamento adquirido nessa atividade e em estudos preliminares apresentados foi possível elaborar o Documento de Requisitos do SASHDoc. Nesse documento estão descritos as principais informações e recursos do sistema. Esse documento pode ser visualizado no apêndice $B$.

Ao percorrer tal documento nota-se que os recursos do SASHDoc estão fortemente baseados nos recursos apresentados pelo sistema SASHE. Esse fato é verdadeiro visto que os seguintes recursos do SASHE estão incorporados no SASHDoc: 
Construção de Nós de Contexto - Construção de Nós Terminais - Visualização de Nó Terminal - Construção de Elos - Construção de Roteiros - Visualização pelo Browser Estrutural - Disponibilização de Informações de Ajuda - Navegação por Tópicos Navegação por Histórico - Localização no Roteiro - Navegação pelo Contexto - Busca por Documentos Relacionados - Navegação pela Bibliografia - Construção de Glossário

Do mesmo modo, pelo documento é possivel perceber que SASHDoc contempla grande parte dos requisitos propostos por [CAB94]. Relembrando, esses requisitos evidenciam uma adequação de um sistema hipertexto para a produção de documentos de software [Quadro 11]. Percebe-se que os requisitos 7 e 9 não são atendidos pelo SASHDoc pois considerou-se que não comprometem a construção de uma documentação de software adequada e também porque exigiam maiores estudos que escapam ao propósito principal do trabalho.

Quadro 11. Requisitos propostos por [CAB94] atendidos pelo SASHDoc.
\begin{tabular}{|l|c|}
\hline 1. Configurável & $\mathrm{x}$ \\
\hline 1. Consistência & $\mathrm{x}$ \\
\hline 3. Controle de versões & $\mathrm{x}$ (3) \\
\hline 4. Geração de documentação impressa & $\mathrm{x}$ \\
\hline 5. Informações complementares & $\mathrm{x}$ \\
\hline 6. Relacionamento de documento & $\mathrm{x}$ \\
\hline 7. Suporte a ambiente distribuido & - \\
\hline 8. Suporte a ambiente multiprojeto & $\mathrm{x}$ \\
\hline 9. Suporte a trabalho cooperativo & - \\
\hline 10. Visões & $\mathrm{x}$ \\
\hline
\end{tabular}

Outro ponto importante refere-se ao fato do SASHDoc ser um protótipo. Considerou-se que não seria necessário desenvolver totalmente o sistema para que os objetivos deste trabalho fossem atingidos. Logicamente, caso o sistema seja implementado por completo, tornar-se-á uma interessante ferramenta de autoria e navegação de hiperdocumentos de software.

Em meio à edificação do SASHDoc, importantes aspectos da mudança de domínio de software foram observados. Por exemplo, observou-se que fatores como a familiaridade com o domínio e a experiência em Engenharia de Software foram imprescindíveis para a compreensão de informações sobre documentação de software. Sob esse enfoque, no capítulo seguinte são discutidos mais profundamente os elementos que afetam a mudança de domínio de software. 


$$
\text { . }
$$




\section{Capitulo 5}

\section{A Mudança de Dominio de Software}

\subsection{Considerações Iniciais}

No decorrer deste trabalho foram observados vários aspectos importantes a respeito da mudança de domínio de software. Observou-se, por exemplo, que é necessário um Planejamento das atividades para que essas possam convergir adequadamente para a meta de se obter o software no novo domínio. Outra constatação foi a importância do conhecimento do domínio alvo de modo que recursos de um software de outro domínio possam ser empregados na solução de problemas daquele domínio.

Essas e outras conclusões foram derivadas considerando-se a influência dos fatores de familiaridade e de experiência do engenheiro de software na mudança de domínio do SASHE. Mais especificamente, a familiaridade com os domínios Engenharia de Software e Documentação de Software, e a experiência com o sistema SASHE e com o desenvolvimento de software. Esses fatores foram muito importantes para a mudança de domínio do SASHE pois auxiliaram na realização das tarefas de mudança de domínio e a definição do sistema SASHDoc.

Em vista da relevância desses fatores - familiaridade e experiência, as conclusões foram transformadas em um conjunto de assertivas para a mudança de domínio de software. Essas assertivas visam compor uma base de informações para a realização de futuros exercícios de mudança de domínio de software. Vale lembrar que essas assertivas foram derivadas da mudança de domínio realizada sobre o SASHE; obviamente, são necessários mais estudos como este para que as assertivas sejam validadas e consolidadas. Assim, na Seção 5.2. essas assertivas são apresentadas e discutidas. $\mathrm{Na}$ Seção 5.3. são apresentados alguns aspectos e 
práticas favoráveis à mudança de domínio de software também identificados no decorrer do trabalho. Por fim, as considerações finais do capítulo.

\subsection{Assertivas sobre Mudança de Domínio de Software}

As assertivas relacionadas a seguir foram concluídas a partir da observação da influência da familiaridade e da experiência do engenheiro de software na mudança de domínio.

\subsection{1. "A Familiaridade com o Dominio Alvo e a Experiência com o Software Base Facilitam a Mudança de Dominio de Software".}

Para se adquirir mais conhecimento sobre o SASHE e seus recursos, inúmeras aplicações foram construídas. As aplicações tiveram principalmente a temática da Documentação de Software. Em outras palavras, no SASHE foram desenvolvidas aplicações formadas por hiperdocumentos de software.

A simulação do SASHE na produção de documentos de software foi bastante importante na definição do sistema SASHDoc. Simulação já é um reconhecido recurso que possibilita especificar o comportamento de forma que produtos conhecidos possam ser integrados e utilizados de formas e maneiras diferentes [ADE85;SOU93].

A atividade de simulação do SASHE na produção de documentos de software possibilitou identificar as funcionalidades do sistema que poderiam ser aplicadas na documentação de software. Recordando o capitulo três, identificou-se que Nós Terminais, Nós de Contexto, Roteiros e Elos poderiam ser aplicados, bastando certas adaptações para o domínio da documentação de software. Posteriormente, esses recursos foram definidos e incorporados no sistema SASHDoc.

Analisando esse comportamento, percebeu-se também que: quanto mais o software é desconhecido, mais experimentações são necessárias para se conhecer seus recursos; e à medida que mais aplicações são construídas, melhor é a identificação de recursos aplicáveis em outros domínios. As experimentações, de fato, proporcionaram mais conhecimento das capacidades e possibilidades do SASHE. E principalmente, permitiu se realizar a mudança de domínio do sistema e a construção do protótipo do sistema SASHDoc com maior segurança. 
Assim, a prática com o software foi mais favorável ao entendimento do software para a mudança de domínio do que simplesmente a leitura da documentação do software .

\subsection{2. "A Familiaridade com o Domínio Alvo Facilita o Ciclo de Vida de} Software no Dominio".

Adelson e Soloway, em [ADE85], perceberam que a familiaridade com o domínio da aplicação influi diretamente na construção de um modelo mental do sistema. Modelo Mental de um sistema pode ser definido como "o modelo que as pessoas têm de si próprias, dos outros, do meio ambiente, e das coisas com as quais interagem. As pessoas formam modelos mentais através da experiência, do treinamento e da instrução." [NOR85]. O modelo mental permite escolher um caminho particular de pensamento sobre o problema e gerar melhores representações desse problema [ADE85].

O estudo realizado sobre "Documentação de Software" possibilitou a identificação dos aspectos relevantes do domínio tais como a necessidade de um maior relacionamento entre documentos de software e a necessidade de controle das várias versões de documentos produzidos. Essa familiaridade foi importante principalmente na etapa de análise de requisitos do sistema SASHDoc.

A familiaridade com a Documentação de Software foi importante na elaboração dos requisitos de um sistema de documentação de software que vise solucionar problemas inerentes do domínio por meio da aplicação da tecnologia hipermídia. Esses requisitos foram então traduzidos para o Documento de Requisitos do Sistema SASHDoc ${ }^{2}$. Nesse documento são descritos as informações, os requisitos de desempenho, as restrições e outros dados relevantes que compõem os requisitos do software.

A partir desse documento foram construídas as representações do sistema e refinadas até se alcançar uma representação considerada adequada (vide Capítulo Quatro). Por exemplo, um dos vários diagramas criados foi o Diagrama de Casos de Uso do Sistema SASHDoc [Figura 29]. Esse diagrama representa como o engenheiro de software enxerga o sistema externamente, em função de suas funcionalidades e recursos [FUR98].

Portanto, tanto a familiaridade com o domínio Engenharia de Software quanto com a Documentação de Software proporcionaram que os "modelos mentais" do engenheiro de software acerca do sistema fossem convertidos em produtos do ciclo de vida de desenvolvimento: um documento de especificação de software com requisitos claros e bem

${ }^{2}$ O Documento de Requisitos do Sistema SASHDoc pode ser visualizado no Apêndice B. 
definidos para um sistema hipermídia de documentação de software e representações do sistema enfatizando diferentes aspectos do sistema - estáticos e dinâmicos - até resultar em uma representação que satisfaça às necessidades de entendimento do sistema. Possivelmente um engenheiro de software com maior familiaridade com o domínio (e experiência em desenvolvimento de software) pode criar variações melhores dessas representações.

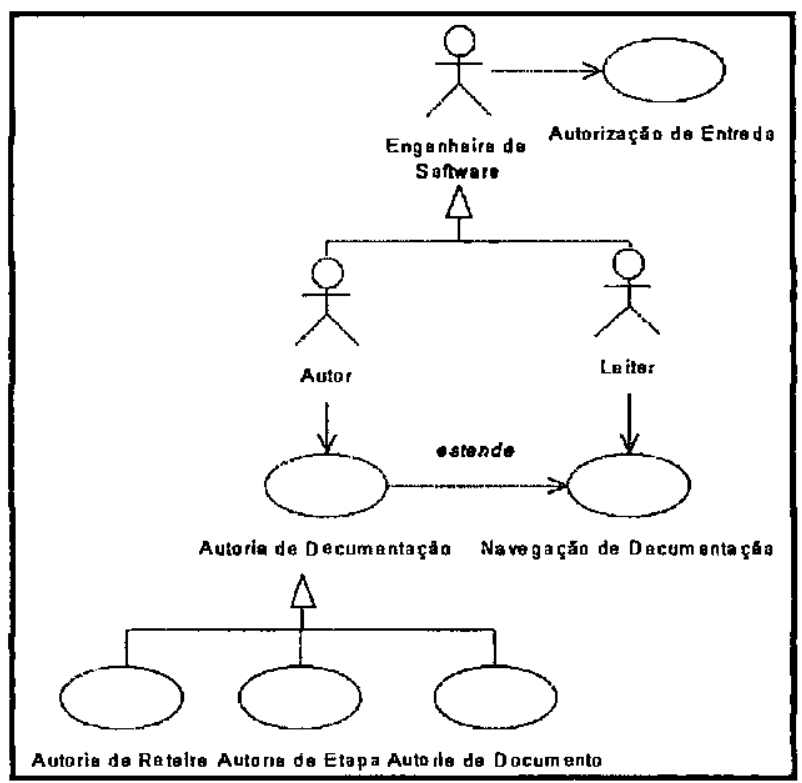

Figura 29. Diagrama de Casos de Uso do Sistema SASHDoc.

\subsection{3. "A Familiaridade com o Domínio Auxilia na Avaliação de Softwares Desenvolvidos para Solucionar Problemas do Domínio".}

A necessidade de criar melhores hiperdocumentos de software estimulou o estudo de mecanismos que asseguram maior qualidade às informações em documentos de software e mecanismos que avaliam a estrutura hipertextual dos hiperdocumentos de software. Os trabalhos de Blanqui [BLA97] e de Campos [CAM94] foram importantes nesse sentido.

Blanqui identificou um conjunto de critérios que avaliam a documentação de software sob o ponto de vista qualitativo e sob o ponto de vista lógico [BLA97]. Para se tornarem aplicáveis, esses critérios foram convertidos em dezenove questões de "SIM" ou "NÃO" de forma que o engenheiro de software assinale se o critério é atendido pelo documento de software.

Já no trabalho de Campos foi elaborado um conjunto de critérios para avaliação de sistemas hipertexto/hipermídia educacionais na perspectiva dos usuários autores e dos 
usuários leitores dos hiperdocumentos criados com esses sistemas [CAM94]. Assim como no trabalho de Blanqui, esses critérios foram convertidos em questionários que verificam se os sistemas atendem ao critério de qualidade e em que grau esse critério é atendido.

A familiaridade com os domínios de Engenharia de Software e Hipermídia permitiram integrar o conhecimento adquirido com o estudo desses trabalhos de modo que as avaliações fossem aplicadas a hiperdocumentos de software. Assim, como produto foram gerados dois checklists: o primeiro visa avaliar o conteúdo das informações dos hiperdocumentos de software e o segundo avaliar a estrutura hipertexto dos hiperdocumentos. Esses checklists são mostrados na [Figura 30] e [Figura 31], respectivamente.

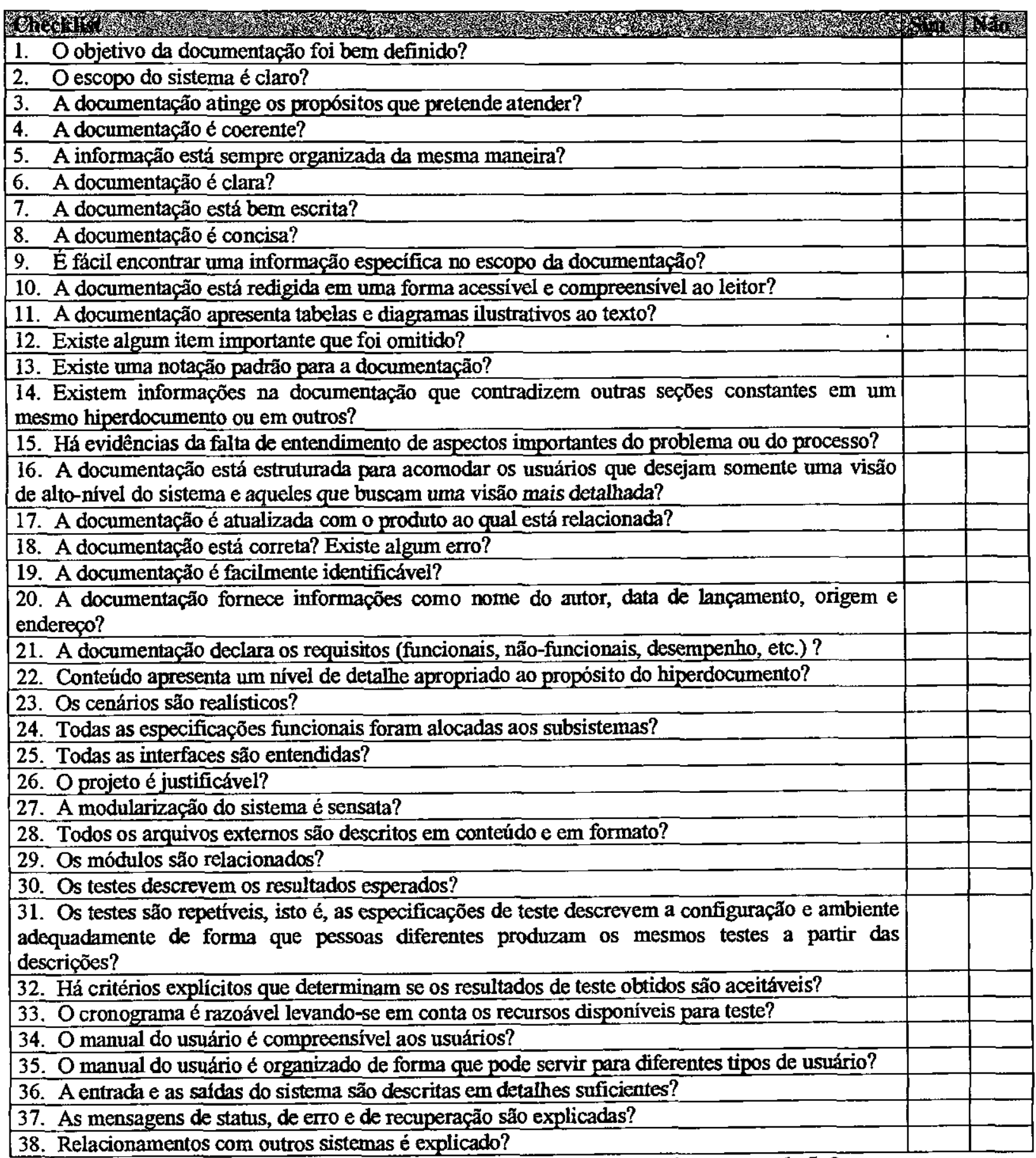

Figura 30. Checklist para Avaliação do Conteúdo de Hiperdocumentos de Software. 
Em síntese, o primeiro checklist extende a avaliação de Blanqui e o segundo adapta a avaliação de sistemas hipermídia educacionais para o contexto de hiperdocumentos de software. É importante lembrar que os checklists não objetivam realizar uma avaliação exaustiva e precisa de hiperdocumentos de software, mas sim identificar pontos fortes e problemáticos dos hiperdocumentos.

\begin{tabular}{|c|c|c|}
\hline \multicolumn{3}{|c|}{ Fof } \\
\hline 1. Todos os nós especificados e projetados estão implementados? & & \\
\hline 2. Todas as ligaç̃es especificadas e projetadas estão implementadas? & & \\
\hline 3. É fácil de se entender a estrutura do hiperdocumento? & & \\
\hline 4. Os conteúdos dos nós são acessados com facilidade? & & \\
\hline $\begin{array}{l}\text { 5. Existem mapas, indices ou outros mecanismos que facilitam a localização dos relacionamentos } \\
\text { entre os nós do hiperdocumento? }\end{array}$ & & \\
\hline 6. Os nós são modulares? & & \\
\hline 7. Os nós enfocam apenas um tópico? & & \\
\hline 8. Todos os nós presentes na especificação e projeto estão implementados? & & \\
\hline 9. Todas as ligaccões presentes na especificação e projeto estão implementadas? & & \\
\hline 10. As informacốes imprescindfveis ao alcance dos objetivos do projeto estâo implementadas? & & \\
\hline 11. Os conteúdos dos nós são apresentados com facilidade? & & \\
\hline 12. A estrutura do hiperdocumento é de fácil compreensão? & & \\
\hline 13. O hiperdocumento pode ter seu conteúdo atualizado? & & \\
\hline $\begin{array}{l}\text { 14. Ao usar o hiperdocumento pela primeira vez, o leitor rapidamente entende as opções de } \\
\text { navegação? }\end{array}$ & & \\
\hline $\begin{array}{l}\text { 15. E assegurado ao leitor a navegação apenas por nós relevantes para o seu conhecimento e } \\
\text { interesse? }\end{array}$ & & \\
\hline 16. O hiperdocumento tem interface com outras facilidades do ambiente computacional? & & \\
\hline 17. O vocabulário utilizado no hiperdocumento está adequado ao usuário leitor? & & \\
\hline 18. O hiperdocumento é compreensivel e familiar, durante todo o tempo de leitura? & & \\
\hline 19. O hiperdocumento possui elementos motivadores para estimular o leitor? & & \\
\hline 20. O hiperdocumento permite ao leitor uma navegação livre pelos nós e ligacões? & & \\
\hline 21. O uso de ilustrações é adequado ao conteúdo do hiperdocumento? & & \\
\hline 22. O uso de marcas especiais no hiperdocumento favorece a identificação de nós e ligacôes? & & \\
\hline 23. Os recursos sonoros utilizados são adequados ao conteúdo do hiperdocumento? & & \\
\hline 24. Os textos apresentados no hiperdocumento são adequados para 1 & & \\
\hline
\end{tabular}
Figura 31. Checklist para verificacão da Estrutura de Hiperdocumentos de Software.

\subsection{4. "A Familiaridade com o Domínio Auxilia na Identificação de}

\section{Caracteristicas do Dominio no Software".}

Durante a mudança de domínio do SASHE foram identificados componentes no sistema que são exclusivos do domínio Ensino. Essa identificação foi possível por meio de atividades como: a exploração da interface e recursos do software e a leitura da documentação disponível em [HAB99], [FEL99] e [PAN99].

No módulo de Autoria, aos nós terminais são associados arquivos cujo conteúdo (texto, áudio, vídeo, imagem ou arquivo executável) são caracterizados por atributos como 
Nome, Arquivo, Palavras-Chave, Função Didática e Dificuldade. Analisando esses atributos, notou-se que os dois últimos atributos somente assumem valores relativos ao domínio Ensino.

Dificuldade identifica o grau de dificuldade do nó terminal. Os valores assumidos por esse atributo são "Fácil", "Regular" e "Dificil". Função Didática identifica a função do nó terminal na aplicação. As funções (valores) disponiveis são "Ajuda", "Bibliografia", "Definição", "Exemplo", "Exercício", "Introdução", "Motivação" e "Resumo". Entende-se que os valores assumidos por esses atributos somente possuem significado em aplicações com fins didáticos.

Dificuldade e Função Didática também podem ser encontradas na caracterização dos roteiros. Relembrando, os atributos de um roteiro são: Assunto, Função Didática, Dificuldade e Palavras-Chave. Assim como ocorre com os nós terminais, Função Didática e Dificuldade foram considerados exclusivamente pertencentes ao domínio Ensino, pois os valores que podem assumir são os mesmos disponiveis para seus correspondentes nos nós terminais, acrescentando somente o valor "TODAS" em ambos os casos.

Outras evidências do domínio Ensino nesse módulo são os textos e mensagens apresentadas ao usuário: Selecione o nó até onde o aprendiz poderá navegar, exibido durante a definição da liberdade de navegação do nó; e os valores dos atributos Função Didática e Dificuldade atribuídos a um nó exibidos durante o posicionamento do ponteiro do mouse em cima do nó situado na janela de contextos.

Já no módulo de Navegação foram identificadas estratégias associadas aos botões da interface como exclusivamente voltadas ao domínio Ensino. Mais especificamente, àquelas associadas aos botões Está Fácil, Está Difícil e Exercícios.

Verificou-se que os botões Está Fácil e Está Dificil remetem estratégias de apresentação de nós de acordo com o valor do atributo Função Didática do nó. Por sua vez, o botão Exercícios disponibiliza os exercícios que estão relacionados com o tema da hiperbase que está sendo apresentada. A busca por exercícios se dá no contexto do nó atual e sua existência depende de sua definição durante o trabalho de autoria.

Por fim, os textos e mensagens que evidenciam o domínio Ensino nesse módulo são: Não há nada mais difícil Avance aos tópicos seguintes, exibida quando o autor deseja visitar um nó "mais dificil”; Não há nada mais fácil. Retorne aos tópicos anteriores, exibida quando o autor deseja visitar um nó "mais fácil"; e Não existe nenhum exercício, exibida quando o autor clica no botão "Exercício" e não existe nenhum exercício vinculado.

Portanto, mesmo com a pouca familiaridade com o domínio Ensino foi possível identificar ao todo doze componentes voltados ao domínio: cinco mensagens informativas ao usuário, duas propriedades de nós terminais, duas propriedades de roteiro e três estratégias de 
navegação. No caso de uma maior familiaridade com o domínio, possivelmente demais componentes poderiam ser identificados.

\subsection{5. “A Experiência com o Software Permite Visualizar a Aplicação de seus Recursos em Outros Domínios".}

De acordo com [SOU93], "quando lidamos com a funcionalidade de um aplicativo, lidamos com o que pode ser feito com o aplicativo, com o conjunto de possíveis produtos, $\mathrm{e}$ com os propósitos para os quais o aplicativo é útil para o usuário". Como o software está relacionado a um domínio, as suas funcionalidades foram projetadas para executar tarefas dentro desse domínio.

Com sua constante manipulação, a experiência adquirida com o software permitiu visualizar a aplicação de suas funcionalidades na solução de problemas de outros domínios de conhecimento. A experiência prática na construção de inúmeras aplicações hipermídia no SASHE permitiu a observação de alguns domínios nos quais seus recursos (Recursos Independentes de Domínio) poderiam ser utilizados:

- Direito: "Construção de Glossário" pode ser empregado no armazenamento de termos técnicos relacionados a processos jurídicos.

- Odontologia: "Navegação por Tópicos" pode ser empregado na navegação de documentos que compõem a documentação ortodôntica de cada paciente.

- Medicina: "Construção de Elos" pode ser empregado no relacionamento de documentos de auxílio ao diagnóstico de doenças.

- Agricultura: "Construção de Nós de Contexto" pode ser empregado para agrupar documentos relacionados a uma determinada técnica de manuseio de solo.

- Engenharia Elétrica: "Construção de Nó Terminal" pode ser empregado na associação de nós a documentos sobre manutenção de disjuntores elétricos.

- Turismo: "Construção de Roteiros" pode ser empregado na criação de roteiros turísticos sobre um determinado pais, estado ou município.

- Arqueologia: "Navegação por Histórico" pode ser empregado na recuperação de documentos outrora navegados sobre, por exemplo, "A Vida e os Costumes dos Homens Primitivos". 
- Serviço Social: "Busca por Documentos Relacionados" pode ser empregado na navegação de documentos técnicos para o treinamento de agentes de saúde.

Esses são apenas alguns exemplos de domínios onde os recursos do SASHE poderiam ser bem-sucedidos. Certamente, uma maior familiaridade com os domínios (Direito, Turismo, etc.) proporcionaria a identificação de outros recursos do software que poderiam ser aplicados. Nesse sentido, uma maior interação com especialistas de outras áreas é interessante.

Do mesmo modo, um engenheiro de software mais experiente poderia identificar outros recursos do SASHE que poderiam ser aplicados em outras atividades da Engenharia de Software. Por exemplo, interagindo com demais membros do Grupo de Engenharia de Software do ICMC foi possivel observar que certos recursos poderiam ser empregados na navegação de aplicações sobre Qualidade de Software.

Outra maneira de identificação de outros recursos para utilização em outros domínios é através de reuniões formais e informais entre desenvolvedores, especialistas e usuários. É importante, contudo, que essas reuniões sigam uma abordagem de grupo que estimule e facilite a comunicação entre seus membros [PRE95a;SOM96].

\subsection{6. "A Experiência com o Software Proporciona Identificar Questões de Usabilidade no Software".}

Essa conclusão também foi constatada a partir de inúmeras aplicações desenvolvidas no SASHE. A experiência e a familiaridade com o sistema permitiram relacionar um conjunto de sugestões para a sua melhoria e aperfeiçoamento. Algumas das sugestões são ${ }^{3}$ :

- Disponibilizar recursos de "Fechar Hiperbase" e "Imprimir" no menu principal;

- Disponibilizar mensagens somente em um idioma (preferencialmente em português);

- Disponibilizar botões para as funcionalidades do menu pop-up ativado a partir da janelas de Contextos Aninhados;

- Disponibilizar help e outros recursos de ajuda como: referência de consulta na Internet e help sensitivo a contexto;

- Informar ao usuário que ao clicar duas vezes em nós de informação ou do tipo trilha, esses

${ }^{3} O$ conjunto completo das sugestões para o SASHE é apresentado no Apêndice A. 
serão editados. No caso de nós de contextos; estes são expandidos;

- Disponibilizar mais mecanismos de fechamento de janelas além do botão no canto superior direito da janela ("X");

- Disponibilizar recursos para alternar entre os módulos de autoria e de navegação sem que seja necessário reiniciar o sistema;

- Possibilitar a criação de mais de um roteiro de navegação assim como proporcionar maiores recursos para sua edição como, por exemplo, alterar a posição dos itens do roteiro;

- Possibilitar a seleção de hiperbases sem qué seja preciso reinicializar o módulo do navegação;

Póde-se dizer então que á experiência com o software pode ajudar a melhorar sua qualidade. Ao se realizar uma pesquisa com usuários do editor de texto Microsoft Word®, por exemplo, certamente esses apontariam vantagens e desvantagens do software. Com isso, desenvolvedores podem aperfeiçoar o software de modo que os pontos positivos sejam reforçados e os problèmas eliminados.

Uma outra maneira de se rèduzir problemas em um software é por mèio da realização de avaliações de usabilidade tal como a Avaliação Heurística [BAR93;CO095]. Esse tipo de avaliação é um ótimo método para encontrar problemas na usabilidade do software a partir da verificação de aspectos (heurísticas) tais como a flexibilidade, consistência, documentação, etc. do software [MOL90].

\subsection{7. "A Experiência em Projetos Anteriores no Domínio Alvo Auxilia} na Mudança de Domínio de Software".

Conforme visto anteriormente, na literatura são encontradas poucas experiências práticas acerca de Reuso Horizontal. Acredita-se que quanto maior o número de trabalhos nesse contexto forem realizados, uma maior quantidade de informações estará disponível sobre os aspectos e elementos que influem em uma mudança de domínio de software; assim, com base nessas informações, possivelmente melhores trabalhos poderão ser realizados futuramente.

Em outras palavras, existe uma falta de Padrões de Software para a mudança de domínio. Padrőes de Software são princípios de projeto úteis no desenvolvimento de software 
pois descrevem soluções para uma mesma classe de problemas [GAL96]. Nos casos em que o engenheiro de software confronta-se com novos problemas, esse pode recorrer aos padrões na busca de soluções implementadas anteriormente para resolver problemas similares.

Por exemplo, o processo de desenvolvimento de software orientado a objetos pode ser facilitado pelo uso de padrões de projeto. Os padrões proporcionam um vocabulário comum para a comunicação entre desenvolvedores de modo a facilitar a criação de abstrações em um nível superior ao de classes e instâncias. O tempo exigido para o aprendizado de uma biblioteca de padrões pelo engenheiro de software é reduzido, ajudando um inexperiente a agir como um especialista [GAM93;BRA98a].

Gall, em [GAL96], afirma que o uso de padrões promove um considerável aumento de produtividade no desenvolvimento e manutenção de software. Para a mudança de domínio, os padrões pode ser igualmente benéficos pois fornecem exemplos de soluções a serem seguidas, copiadas e refinadas para a solução de novos problemas.

Como não foram encontrados Padrões para sistemas de documentação de software, neste trabalho foram seguidos exemplos de pesquisas sobre sistemas hipermidia de documentação de software (vide Capitulo Dois). Com base nas informaç̃̃es dessas pesquisas, foi possível criar o projeto de um sistema semelhante, o SASHDoc. Caso houvesse uma maior experiência em projetos de sistemas de documentação de software, provavelmente o SASHDoc teria sido projetado sob uma outra ótica.

Por fim, a experiência adquirida nessa atividade certamente proporciona um maior embasamento para o novos projetos de sistemas de documentação de software. Do mesmo modo, proporcionou maior esclarecimento acerca do emprego de características e recursos do SASHDoc em softwares pertencentes a outros domínios.

\subsection{Auxiliando a Mudança de Domínio de Software}

A experiência prática em desenvolvimento de software permitiu identificar algumas tarefas importantes para a atividade de mudança de domínio de software. Dentre essas: Planejamento, Automatização, Apoio da Gerência, Comunicação entre Engenheiro de Software e o Cliente, Revisões Técnicas, Análise de Domínio, Gerenciamento de Configuração e Modelos de Ciclo de Vida de Software Orientados a Componentes.

O Planejamento é fundamental para a mudança de domínio de software (e qualquer outra atividade) uma vez que define as metas a serem alcançadas e delineia as etapas necessárias para o alcance dessas metas. Essas informações precisam ser claras e objetivas em 
um documento formal de modo a evitar incertezas, ambigüidades ou inconsistências na realização do trabalho.

O uso de ferramentas na mudança de domínio de software, assim como no desenvolvimento tradicional de software, pode trazer beneficios tal como o auxílio na documentação [STA95]. Por outro lado, também pode gerar mais despesas e exigir requisitos extensos e mais exatos. A Automatização da atividade deve ser cuidadosamente avaliada pois pode fazer com que bons projetos produzam excelentes resultados e também fazer com que projetos ruins resultem em um produto ainda pior.

No âmbito organizacional é importante ter o respaldo da gerência para a realização das atividades necessárias para a mudança de domínio de software. É preciso que a gerência participe do processo para assim evitar problemas que normalmente surgem pelo desenvolvimento e a implantação de novos sistemas como [STA95]: (a) temor de que o funcionário perca seu emprego, poder ou influência na organização; (b) crença de que o sistema proposto criará mais trabalho do que eliminará; (c) relutância em trabalhar com o "pessoal de computadores"; (d) preocupação com que o sistema proposto altere a estrutura da organização para pior; (e) crença de que existem outros problemas mais urgentes do que os resolvidos pelo sistema proposto, ou de que o sistema está sendo desenvolvido por pessoas: pouco familiarizadas com "o modo como as coisas devem ser feitas"; e (f) falta de disposição para aprender novos procedimentos ou técnicas. Grande parte desses problemas podem ser evitados com o apoio dos'gerentes e da alta administração.

Diálogos com as pessoas que fazem parte do domínio também podem ser úteis na aquisição de um maior entendimento do software. Uma boa Comunicação realizada por meio de entrevistas e reuniões formais pode conduzir ao claro estabelecimento dos objetivos a serem atingidos. Por outro lado, uma comunicação ineficiente pode ser a origem de problemas na especificação de requisitos e na acomodação de mudanças no software. Por isso, aconselha-se uma abordagem de grupo para a aquisição de.informações sobre o software e o domínio [PRE95a].

As Revisões Técnicas podem ser empregadas para apontar melhorias necessárias ao software em virtude de problemas surgidos no desenvolvimento ou na adaptação do software ao novo domínio. Tambẹ́m podem auxiliar na identificação de partes do software que não precisam de melhorias. Sendo assim, o engenheiro de software pode se beneficiar das Revisões Técnicas de modo a centralizar seus esforços em áreas do software que requerem melhorias e nas áreas que requerem grandes alterações para se adaptar a um novo domínio.

A Análise de Domínio é uma tarefa benéfica para a mudança de domínio pois proporciona ao engenheiro de software um maior conhecimento sobre o domínio. Esse 
conhecimento é adquirido por meio da realização de atividades como a identificação e documentação de aspectos comuns e diferentes em softwares pertencentes ao domínio. Esses aspectos são registrados em documentos nos quais são descritos: (a) os termos mais importantes do domínio e seus relacionamentos; (b) caracterizações detalhadas dos sistemas do domínio; (c) atributos importantes dos sistemas no domínio, e a maneira pela qual os sistemas são iguais ou diferentes com relação a esses atributos e (d) atributos comuns e variáveis dos novos sistemas no domínio. Além dessas, a criação de Recursos Reusáveis como requerimentos, planos, projeto, prazos, codificação e documentação, e a criação de um Repositório no qual esses recursos podem ser encontrados para serem reutilizados em novos produtos também são consideradas atividades benéficas [BRA98a].

O Gerenciamento de Configuração de Software é uma prática incontestável em qualquer desenvolvimento de software. Também pode ser útil na mudança de domínio de software contribuindo na identificação, controle e documentação das mudanças atribuidas ao software.

Como a mudança de domínio de software pode resultar no desenvolvimento de um novo software reutilizando componentes de outro, os Modelos de Ciclo de Vida de Software baseados no reuso de componentes de software podem ser mais adequados em vista das características da atividade. Por exemplo:

- Modelo de Ciclo de Vida de Software Cleanroom: esse modelo aborda um desenvolvimento incremental do software onde cada componente do software é desenvolvido e testado separadamente [KAN95].

- Modelo de Ciclo de Vida de Software Reuso. esse modelo baseia-se na montagem de um protótipo rápido do software usando componentes já existentes. O modelo é suportado pelo desenvolvimento orientado a objetos permitindo o reuso de classes de objetos assim como as operações sobre essas classes. As vantagens do modelo são os ganhos na produtividade e na qualidade do software além de encorajar a maturidade do processo de seu desenvolvimento. Por outro lado, exige muita infra-estrutura de suporte [McC95;FOO98].

- Modelo de Ciclo de Vida de Software Incremental. Esse modelo baseia-se na construção de módulos funcionais do software que aos poucos são disponibilizados. $O$ desenvolvimento do software é feito em dois estágios: a criação de uma arquitetura do software para que cada módulo possa ser incorporado individualmente, e o projeto, implementação e integração de cada módulo na arquitetura [JOH99]. 
No entanto, o desenvolvimento de software orientado a componentes está sujeito a problemas com a busca, seleção e a adaptação no reuso desses componentes. A dificuldade quanto à localização está associada à inexistência de mecanismos de busca que permitam potenciais usuários selecionar os componentes desejados. A dificuldade de seleção está associada às deficiências nos mecanismos de descrição de componentes ao especificar o que os componentes fazem e como interagem. Por fim, a dificuldade na adaptação está associada à compatibilidade de componentes originalmente incompativeis [SIL99].

\subsection{Considerações Finais}

Uma reflexão maior de todo o trabalho desenvolvido foi apresentada neste capitulo. Relatou-se uma série de conclusões a respeito da influência da familiaridade e da experiência do engenheiro de software com os domínios e os softwares (respectivamente) envolvidos na mudança de domínio.

Embora possam ser tomadas várias conclusões sobre a mudança de domínio de software realizada neste trabalho, considera-se a mais importante como sendo a mudança de domínio de software uma solução prática que pode reduzir o tempo exigido para o desenvolvimento de software por enfatizar a reutilização de componentes.

Porém, conforme sentido neste trabalho, a mudança de domínio exige muito esforço do engenheiro de software. Em especial, nas fases de definição, pois os objetivos e as tarefas mal estabelecidos podem resultar, ao final, um produto diferente do esperado.

No próximo capítulo são finalmente apresentadas as conclusões finais do trabalho assim como as contribuições e trabalhos futuros que podem ser desenvolvidos a partir deste. 


\section{Capitulo 6}

\section{Conclusões}

\subsection{Conclusões Finais}

A reutilização de componentes entre softwares é uma atividade que pode acarretar em beneficios como a redução no tempo e no esforço exigidos no desenvolvimento de software. Todavia, relatos sobre experiências práticas relacionadas com a reutilização de componentes de software entre domínios (Mudança de Domínio de Software) são incomuns, possivelmente por exigirem esforços distintos do engenheiro de software. No entanto, a familiaridade e a experiência do engenheiro de software podem proporcionar um suporte desejável à realização do processo.

Sendo assim, este trabalho investigou a mudança de domínio de software sob o ponto de vista da familiaridade com o domínio e a experiência com o software. Em vista dos indicativos da possibilidade de aplicação de componentes do SASHE em outros domínios, neste trabalho foi descrito um estudo no qual componentes desse sistema foram reutilizados em um sistema hipermídia de documentação de software (SASHDoc) pertencente ao domínio de Engenharia de Software.

Para tanto, foram também realizados estudos com o objetivo de definir o sistema SASHDoc. Dentre esses, pode-se citar: (1) o estudo de atuais ferramentas hipermídia de documentação de software, que possibilitou a identificação de recursos imprescindíveis em ferramentas com tal propósito; e (2) estudos de caso com o SASHE, os quais propiciaram um embasamento teórico e prático do sistema de modo a auxiliar na identificação de seus componentes reutilizáveis. 
Confirmando as expectativas de [NUN97a], no sistema SASHDoc foi possível reutilizar inúmeros componentes do SASHE relacionados tanto com a atividade de autoria quanto com a de navegação de aplicações hipermídia (neste caso, aplicações hipermídia compostas por documentos de software). Embora alguns componentes não tenham sido aproveitados para documentação de software, percebeu-se que os componentes categorizados como "independentes de domínio" podem ser aplicados a outros domínios de informação além do Ensino e da Engenharia de Software.

Os estudos que resultaram na proposta do sistema SASHDoc possibilitaram também obter conclusões sobre como a familiaridade e a experiência do engenheiro de software influenciam na mudança de domínio de um software. Essas conclusões foram refinadas até se chegar em um conjunto de assertivas que podem orientar o engenheiro de software na definição e na realização de tarefas para a mudança de domínio de software de modo que direcionem para um resultado final em conformidade com os novos objetivos de domínio pretendidos.

No decorrer do trabalho foram encontrados obstáculos. O maior destes foi, sem dúvida, a escassez na literatura de estudos e experiências sobre a mudança de domínio de software. Essa carência dificultou a elaboração objetiva das atividades propícias à mudança de domínio do SASHE e conseqüente definição do SASHDoc. Mas esse obstáculo foi superado com estudos sobre manutenção adaptativa de software, além de se empregar muita criatividade.

Por outro lado, um aspecto que favoreceu a mudança de domínio do sistema foi o suporte do Modelo de Contextos Aninhados implementado no SASHE. Como o modelo proporciona a organização de informações independentemente do domínio, sua adaptação para o SASHDoc foi bastante natural de modo que pôde ser empregado diretamente no tratamento da documentação de software.

Uma contribuição obtida com a realização do trabalho foi a constante manipulação do sistema SASHE que permitiu relacionar os pontos positivos e negativos do sistema, de modo que os negativos possam ser reavaliados nas versões futuras do sistema e os positivos sirvam de referência para outros softwares. Outro resultado relevante foi a definição do sistema SASHDoc, cuja proposta supre deficiências encontradas nas ferramentas hipermídia de documentação de software revisadas neste trabalho.

Por fim, os objetivos pretendidos para o trabalho foram alcançados. Relevantes informações quanto à mudança de domínio de software estão agora disponíveis como fonte de consulta para futuros trabalhos que envolvam a reutilização de componentes entre softwares de diferentes domínios. 


\subsection{Trabalhos Futuros}

Como linhas de pesquisa em continuidade a este trabalho, pode-se citar:

- Validação do SASHE. Avaliação e validação do sistema para solucionar problemas encontrados em sua manipulação (vide Apêndice $A$ ).

- Generalização do SASHE. Adaptação do sistema para a autoria e navegação de aplicações em qualquer domínio de informação.

- Implementação do SASHDoc. Transformação do SASHDoc de protótipo em um sistema funcional, assim como estender o conjunto de suas características e recursos.

- Definição de Repositório de Componentes. Criação de um repositório de componentes para - SASHE e para o SASHDoc de modo que seus componentes possam ser armazenados, classificados e reutilizados em versões futuras de ambos sistemas ou mesmo em outros softwares.

- Avaliação de Hiperdocumentos de Software. Definição de mecanismos para avaliação estrutural e de conteúdo de hiperdocumentos de software.

- Discutir especificamente a "Mudança de Domínio de Software". Realização de novas experiências práticas sobre mudança de domínio de software de modo a estudar o tema sob novas perspectivas. 



\section{Referências}

\section{Bibliográficas}

[ADE85] ADELSON, B., SOLOWAY, E. The Role of Domain Experience in Software Design. IEEE Transactions on Software Engineering, v.SE-11, n.11, p.1351-1360, 1985.

[ALL97] ALLISON, W., CARRINGTON, D., JONES, T., STEWART-ZERBA, L., WELSH, J. Visualising Software Documents in a Generic Development Environment. [online]. [12/12/1999]. Disponivel na Internet: $<$ http://svrc.it.uq.edu.au/Publications/Technical_reports_1997.html >.

[BAR93] BARFIELD, L. The User Interface: Concepts and Design. Workingham: AddisonWesley Publishing Company, 1993, 353p.

[BAR98] BARROS, P. Linguagem de Modelagem Unificada em Português. [online]. [30/08/1999]. Disponivel na Internet: <http://www.eribeiro.com.br/pablo/uml/>.

[BAS94] BASILI, V., PERRICONE, B.T. Software Errors and Complexity: An Empirical Investigation. Communications of the ACM, v.27, n.1, p.42-52, 1994.

[BIG88] BIGELOW, J. Hypertext and CASE. IEEE Software, v.2, n.5, p.23-27, 1988.

[BLA97] BLANQUI, F. A Document-centered Approach for An Open CASE Environment Framework Connected with the World Wide-Web. Software Engineering Notes, v.22, n.2, p.58-64, 1997.

[BOA96] BOARETTO, JR., H. Ensino Apoiado por Computador Aplicado a Ferramentas Gráficas Gerenciais. São Carlos, 1996. 159p. Dissertação (Mestrado) - Escola de Engenharia de São Carlos, Universidade de São Paulo.

[BRA98a] BRAGA, C.O., STAA, A., LEITE, J.C.P., MOREIRA, M. DynaDoc: A Dynamic Hypertext Documentation Generation Tool for Software Systems. [online]. [13/12/1999]. Disponivel na Intemet: $<$ www.ics.uci.edu/pub/kanderso/htf5/papers/dynadoc/>.

[BRA98b] BRAGA, C.O., STAA, A., LEITE, J.C.S.P. Documentu: A Flexible Architecture for Documentation Production Based on a Reverse-Engineering Strategy. Software Maintenance: Research and Practice, n.10, p.279-303, May 1998. 
[BRA98c] BRAGA, R.T.V. Padrões de Software a partir da Engenharia Reversa de Sistemas Legados. São Carlos, 1998. 129p. Dissertação (Mestrado) - Instituto de Ciências Matemáticas e de Computação, Universidade de São Paulo.

[CAB94] CABRAL, R.S., MEIRA, S.L. Id: Um Sistema de Hipertexto Configurável e Orientado a Objetos para Integrar os Documentos do Software. In: Simpósio Brasileiro de Engenharia de Software, VIII., Curitiba. Anais, 1994. p.283-296.

[CAM88] CAMPBELL, B., GOODMAN, J.M. HAM: A General Purpose Hypertext Abstract Machine. Communications of the ACM, v.31, n.7, p.856-861, July 1988.

[CAM94] CAMPOS, F.C.A. Hipermídia na Educação: Paradigmas e Avaliação da Qualidade. Rio de Janeiro, 1994. 140p. Dissertação (Mestrado), Universidade Federal do Rio de Janeiro.

[CAS91] CASANOVA, M.A. The Nested Context Model for Hyperdocuments. In: Hypertext'91, San Antonio, Texas. Proceedings, 1991. p.193-201.

[CAS99] CASTELLAN, R.G., FORTES, R.P.M. Descobrindo o Ambiente Macromedia Dreamweaver 2.0. São Carlos, Instituto de Ciências Matemáticas e de Computação, Universidade de São Paulo, 1999. (Notas do ICMC-USP, n.43, 38p).

[CAT99] CASTRO, J.F.B. Introdução à Unified Modeling Language. Minicurso apresentado no XII SBES, Outubro 1999.

[CEN98] CENEVIVA, R., SANCHES, R. Implementação do Sistema SAPES. In: Simpósio de Iniciação Científica da Universidade de São Paulo, 6., São Carlos. Anais, 1998. p.254.

[CHI90] CHIKOFSKY, E.J., CROSS, J.H. Reverse Engineering and Design Recovery: a Taxonomy. IEEE Software, p.13-17, Janeiro 1990.

[COA91] COAD, P.; YOURDON, E. Análise Baseada em Objetos. Rio de Janeiro: Campus, 1991. 233p.

[COL98] COLLAUD, G. A Hypertext Environment For Linear Optimisation. [online]. [05/03/99]. Decision Support Systems, v.23, n.2, p.111-131, 1998.. Disponivel na Internet: $<$ http://webofscience.fapesp.br $>$.

[COL99] COLANZI, T.E., MASIERO, P.C., MALDONADO, J.C. Especificação do SAPES com o Prodes/UML. Relatórios Técnicos do ICMC-USP, n.99, Dezembro 1999.

[CO095] COOPER, A. About Face: The Essentials of User Interface Design. Foster City: IDG Books, 1995. 580p.

[COS97] COSTA, R.M. Fusion-RE/: Um Método de Engenharia Reversa para Auxiliar à Manutenção de Software. São Carlos, 1997. 112p. Dissertação (Mestrado), Instituto de Ciências Matemáticas e de Computação, Universidade de São Paulo.

[CUR89] CURTIS, B., SHEPPARD, S., BAILEY, E., BOEHM-DAVIS, D. Experimental Evaluation of Software Documentation Formats. The Journal of Systems and Software, v.9, n.2., p.167-207, 1989.

[CYB92] CYBULSKI, J.L.; REED, K. A Hypertext Based Software Engineering Environment. IEEE Software, v.9, n.2, p.62-68, 1992. 
[DRO97] DRORI, O. Hypertext Implications for CASE Environments. Software Engineering Notes, v.22, n.4, p.35-38, 1997.

[FEL99] FELTRIM, V.D. Apoio à Documentação de Engenharia Reversa de Software por meio de Hipertextos. São Carlos, 1999. 116p. Dissertação (Mestrado) - Instituto de Ciências Matemáticas e de Computação, Universidade de São Paulo.

[FER92] FERRANS, J.C., HURST, D.W., SENNETT, B.M., CONNOT, W., J, P.; KAJKA, P. HyperWeb: A Framework for Hypermedia-Based Environments. In: Symposium of Software Development Environment, 5, Tyson's Corner, USA. Anais, 1992. p.110 .

[FER99] FERNANDES, D.B. Metodologia Dinâmica para o Desenvolvimento de Sistemas Versáteis. São Paulo: Érica, 1999. 129p.

[FO098] FOOTE, B. A Fractal Model of the Lifecycle of Reusable Objects. [online]. [22/11/1999]. Disponivel na Internet: $<$ http://www.laputan.org/frameworks/fractal.html>.

[FOW97] FOWLER, M. UML Distilled: Applying the Standard Object Modeling Language. Reading: Addison-Wesley, 1997. 179p.

[FRA96] FRAKES, W., TERRY, C. Software Reuse: Metrics and Models. ACM Computing Surveys, v.28, n.2, p.415-435, 1996.

[FRE97] FRENCH, J.C., KNIGHT, J.C., POWELL, A.L. Applying Hypertext Structures to Software Documentation. Information Processing \& Management, v.33, n.2, p.219-231, 1997.

[FUR98] FURLAN, J.D. Modelagem de Objetos através da UML. São Paulo: .Makron Books, 1998. 344p.

[GAL96] GALL, H., KLÖSH, R., MTTTERMEIR, R. Application Pattems in ReEngineering: Identifying and Using Reusable Concepts. Intemational Conference on Information Processing and Management of Uncertainty in Knowledge-Based Systems, 6., Granada, Spain. Anais, 1996. p.1099-1106.

[GAM93] GAMMA, E., JOHNSON, R., VLISSIDES, J. Design Pattems - Abstraction and Reuse of Object-Oriented Design. Lecture Notes in Computer Science, v.707, p.406-431, 1993.

[GAR90] GARG, P.K., SCACCHI, W. A Hypertext System to Manage Software Life Cycle Documents. IEEE Software, v.7, n.3, p.90-98, 1990.

[GAR96] GARCIA, O., MIRALLES, M., SANCHO, J., VALL, O., SANZ, F. Generation of Hypermedia Documents for Medical Education. [online]. M.D. Computing, v.13, n.6, p.578-83, 1996. [05/03/99]. Disponivel na Intemet: $<$ http://www4.ncbi.nlm.nih.gov/PubMed/>.

[GAS98] GASKA, M. The Unification of Reuse, Open Systems and Concurrent Engineering Concepts in an Architeture Framework. [online]. [16/08/1999]. Disponível em $\langle$ http://www.umcs.maine.edu/ ftp/wirs/wirs8/papers/gaska/gaska.html>.

[GHE91] GHEZZI, C., JAZAYERI, M., MANDRIOLI, D. N. Fundamentals of Software Engineering. Englewood Cliffs: Prentice Hall, 1991. 574p. 
[GIL98] GILLHAM, D. Using Hypertext to Facilitate Nurse Education. [online]. Computer Nurse, v.16, n.2, p.95-8, 1998. [05/03/99]. Disponivel na Internet: $<$ http://www4.ncbi.nlm.nih.gov/PubMed/>.

[GOL99] GOLDMANN, S., KOTTING, B. Software Engineering over the Internet. IEEE Internet Computing, v.3, n.4, p. 93-94, 1999.

[GOU99] GOULART, L.V.T., PÔRTO, I.J. Especificação Formal. [online]. [25/08/1999]. Disponivel na Internet: $\langle$ http://www.inf.ufrgs.br/gpesquisa/tf/portugues/ensino/espform.html $>$.

[HAB99] HABER, R.R. Uma Ferramenta de Importação de Documentos HTML para um Ambiente de Ensino. São Carlos, 1999. 104 p. Dissertação (Mestrado) - Instituto de Ciências Matemáticas e de Computą̧ão, Universidade de São Paulo.

[HAR90] HARANDI, M.T., NING, J.Q. Knowledge-Based Program Analysis. IEEE Software, v.7, n.1, p.74-81, 1990.

[HOR86a] HOROWITZ, E., WILLIAMSON, R.C. SODOS:A Software Document Support Environment - Its Definition. IEEE Transactions on Software Engineering, v. 12, n.8, p.849-859, 1986.

[HOR86b] HOROWITZ, E., WILLIAMSON, R.C. SODOS:A Software Document Support Environment - Its Use. IEEE Transactions on Software Engineering, v.12, n.11, p.1076-1087, 1986.

[IER96] IERUSALIMSCHY, R.; FIGUEIREDO, L.; CELES, W. Lua - An Extensible Extension Language. Software: Practice \& Experience, v.26, n.6, p.635-652, 1996.

[JAV95] JAVADOC Tool HomePage. [online]. [18/01/2000]. Disponivel na Internet: $\langle$ http://java.sun.com/products/jdk/javadoc/>.

[JEN98] JENKINSON J., WILSON-PAUWELS, L., JEWETT, M.A., WOOLRIDGE, N. Development of a Hypermedia Program Designed to Assist Patients with Localized Prostate Cancer in Making Treatment Decisions. [online] Journal of Biocommunity, v.25, n.2, p.2-11, 1998. [05/03/99]. Disponível na Internet: $<$ http://www4.ncbi.nlm.nih.gov/PubMed/>.

[JOH98] JOHNSON, D.B., TAIRA, R.K., ZHOU, W., GOLDIN, J.G.; ABERLE, D.R. Hyperad: Augmenting and Visualizing Free Text Radiology Reports. [online]. Radiographics, v.18, n.2, p.507-15, 1998. (abstract) [05/03/99]. Disponivel na Internet: 〈http://webofscience.fapesp.br>.

[JOH99] JOHNSON, R.B. Incremental Model. [online]. [02/09/1999]. Disponivel em $\langle$ http://st-www.cs.uiuc.edu/users/johnson/senior-project/incremental.html >.

[KAH91] KAHLE, B.; MEDLAR, A. A Information System for Corporate Users: Wide Area Information Servers. Online Magazine, v. 15, n.5, p.56-60, 1991.

[KAN95] KAN, S.H. Metrics and Models in Software Quality Engineering. Reading: Addison-Wesley, 1995.344p.

[KRU92] KRUEGER, C.W. Software Reuse. ACM Computing Surveys, v.24, n.2, p.131-183, 1992. 
[LAB99] LABORATÓRIO Nacional de Computação. Normas e Padrões de Documentação de Software. [online]. [06/04/1999]. Disponivel na Internet: <www.lncc.br/docum.html>.

[LAL96] LALLE, C. A Hypermedia System for Parasite Identification. [online]. International Journal of Biomedical Computing, v.41, n.3, p. 175-80, 1996. (abstract) [05/03/99]. Disponivel na Internet: <http://webofscience.fapesp.br>

[LEI95] LEITE, J., CERQUEIRA, P. Recovering Business Rules from Structure Analysis Specifications. In: Working Conference in Reverse Engineering, IEEE Computer Society Press, 2., Canada. Proceedings, 1995. p.13-21.

[LEW98] LEWIS, K.A., BARDON, K.S. A Computer-based Informal Environmental Management System for Agriculture. [online]. Environmental Modelling \& Software, v. 13 n.2, p. 123-137, 1998. [05/03/99]. Disponivel na Internet: $<$ http://webofscience.fapesp.br $>$

[LIN98] LINDVALL, M., SANDAHL, K. How Well do Experienced Software Developers Predict Software Change?. The Journal of Systems and Software, n.43, p.19-27, 1998.

[LUC97] LUCENA, C. et al. AulaNet: Um Ambiente para Desenvolvimento e Mamutenção de Cursos na WWW. Monografias em Ciência da Computação, Departamento de Informática - Pontificia Universidade do Rio de Janeiro, 1997.

[MAC99] MACROMEDIA Inc. Macromedia Dreamweaver. [online]. [10/03/2000]. Disponível em <www.macromedia.com $>$.

[MAL99] MALDONADO, J.C., CEREDA, R.D. Instruções para Documentação de Programas. [online]. [30/03/2000]. Disponível na Internet: $<$ http://tapioca.icmsc.sc.usp.br/ cursos/sce182/docprog.html>.

[McC95] McCLURE, C. Model-Driven Software Reuse Practing Reuse Information Engineering Style. [online]. [22/11/1999]. Disponivel na Internet: $<$ http://www.reusability.com/papers2.html $>$.

[MIC00] MICROSOFT Corporation. Guia de Migração: Do Netscape Communicator para o Microsoft Internet Explorer 5. [online] [22/05/2000]. Disponivel na Internet: $<$ http://www.microsoft.com/brasil/ie50/ie50_doc.htm>.

[MIC99] MICHAELIS Moderno Dicionário da Língua Portuguesa. [online]. [12/10/1999]. Disponivel na Internet: $<$ http://www.uol.com.br/michaelis $/>$.

[MOL90] MOLICH, R., NIELSEN, J. Improving a Human-Computer Dialogue. Communications of the ACM, v.33, n.3, p.338-348, 1990.

[MOR95] MOREIRA, E.S. NUNES, M.G.V., PIMENTEL, M.G.C. Design Issues for a Distributed Hypermedia Tutoring System (HyDTS). In: International Conference on Computer Applications in Industry, Cairo, Egypt. Proceedings, 1995. p.108113.

[MOR98] MORRIS, S., SPANOUDAKIS, G. Introducing the Unified Modeling Language. Tutorial in Conference on Advanced Information Systems Engineering (CaiSE'98), Pise, Italy, 1998. 
[MUN99] MUNSON, E. The Software Concordance: Bringing Hypermedia to Software Development Environments. In: Simpósio Brasileiro de Sistemas Multimídia e Hipermídia, V, Goiânia. Anais, 1999, p.1-12.

[NEI98] NEILSON A.I., KUMAR, B., MACLEOD, I.A. Hybrid Environment for Standards Processing. [online]. Journal of Computing in Civil Engineering, v. 12, n.4, p.195207, 1998. [05/03/99]. Disponivel na Internet: <http://webofscience.fapesp.br>

[NG99] NG, E.H., SARSHAR, M., POUNTNEY, D. Domain Oriented Reuse. [online]. [26/08/1999]. Disponível na Internet: $<$ http://www.cms.livjm.ac.uk/www/homepage/cmseng/p5.htm>.

[NIE95] NIELSEN, J. Multimedia and Hypertext: The Internet and Beyond. California: AP Professional, 1995, 480p.

[NOG92] NOGUEIRA, A.C. Hipermidia na Construção de um Conhecimento: Seres Vivos e Meio Ambiente. São Paulo, 1992. 207p. Tese (Doutorado) - Escola de Comunicações e Artes, Universidade de São Paulo.

[NOR85] NORMAN, D.A.; DRAPER, S.W. Software Engineering for User Interfaces. IEEE Transactions on Software Engineering, v.SE-1 1, n.3, p.252-258, 1985.

[NUN96] NUNES, M.G.V., VIEIRA, F.M.C., HASEGAWA, R. Hip/Windows: Um Ambiente de Autoria de Hiperbases Multimidia. São Carlos, Instituto de Ciências Matemáticas e de Computação, Universidade de São Paulo, 1996. (Relatórios Técnicos do ICMC-USP, n.38, 34p).

[NUN97a] NUNES, M.G.V., HASEGAWA, R., VIEIRA, F.M.C., SANTOS, G.H.R, FORTES, R.P.M. SASHE: Sistema de Autoria e Suporte Hipermidia para Ensino. São Carlos, Instituto de Ciências Matemáticas e de Computação, Universidade de São Paulo, 1997. (Notas do ICMC-USP, n.33, 22p).

[NUN97b] NUNES, M.G.V., FORTES, R.P.M. Roteiros em Aplicações no Ensino: A Questão do Controle do Leitor. In: Workshop em Sistemas Multimídia e Hipermídia, III, São Carlos. Anais, 1997, p. 15-27.

[NUN97c] NUNES, M.G.V., FORTES, R.P.M., NICOLETTI, M.C: Flexible Guided-Tours in Hypertexts: A Way of Controlling the User in Learning Applications In: World Multiconference on Systemics, Cybernetics and Informatics: SCI'97/ISAS'97. Caracas-Venezuela. Proceedings, 1997. p.184-191.

[OXF86] OXFORD Dicionário de Computação, Oxford University Press, 1986.

[PAN99] PANSANATO, L.T.E. EHDM: Um método para o Projeto de Aplicações Hipermídia para Ensino. São Carlos, 1999. 104p. Dissertação (Mestrado) Instituto de Ciências Matemáticas e de Computação, Universidade de São Paulo.

[PAR94] PARNAS, D.L., MADEY, J., IGLEWSKI, M. Precise Documentation of WellStructured Programs. IEEE Transactions on Software Engineering, v.20, n.12, p.948-976, 1994.

[PHO97] PHOHA, V. A. Standard for Software Documentation. IEEE Computer, v.30, n.10, p.97-98, 1997.

[PRE95a] PRESSMAN, R. Engenharia de Software. São Paulo: Makron Books, 1995. 1056p. 
[PRE95b] PREE, W. Designing Patterns for Object-Oriented Software Development. Workingham: Addison-Wesley, 1995.

[PRE97] PRESSMAN, R. Software Engineering: A Practitioner's Approach. New York, McGraw-Hill, 1997. 852p.

[PRI91] PRIETO-DIAZ, R. Implementing Faceted Classification for Software Reuse. Communications of the $A C M, \mathrm{v} .34, \mathrm{n} .5, \mathrm{p} .88-97,1991$.

[PRI93] PRIETO-DIAZ, R. Status Report: Software Reusability. IEEE Software, v. 10, n.3, p.61-66, 1993.

[QU198] QUINAIA, M.A. Diretrizes para Reengenharia de Software com Características de Software Legado. São Carlos, 1998. 79p. Dissertação (Mestrado) - Instituto de Ciências Matemáticas e de Computação, Universidade de São Paulo.

[RAJ99] RAJLICH, V., VARADARAJAN, S. Using the Web for Software Annotations. International Journal of Software Engineering and Knowledge Engineering, n.9, v.1, p.55-72, 1999.

[RAT99] RATTONAL Software Corporation. [online]. [06/08/1999]. Disponivel na Internet: $<$ www.rational.com>.

[SAM97] SAMETINGER, J. Software Engineering with Reusable Components. Berlim, Springer -Verlag, 1997. 280p.

[SAN97] SANTOS, G.H.R. Sistemas Hipermidia para o Ensino: Estendendo as Facilidades para o Tutor e o Estudante. São Carlos, 1997. 63p. Dissertação (Mestrado) Instituto de Ciências Matemáticas e de Computação, Universidade de São Paulo.

[SHN88] SHNEIDERMAN, B. Reflections on Authoring, Editing, and Managing Hypertext. Technical Report n.CS-TR-2160, University of Maryland, December 1988. [06/12/1999]. Disponível na Internet: $<$ http://www.cs.umd.edu/Dienst/UI/2.0/Search>.

[SHU88] SHU, N.C. Visual Programming. New York: Van Nostrand Reinhold Company, 1988. 315p.

[SIL99] SILVA, R.P. Suporte ao Desenvolvimento e Uso de Frameworks e Componentes. Porto Alegre, 1999. 250p. Tese (Doutorado) - Instituto de Informática, Universidade Federal do Rio Grande do Sul.

[SOA95a] SOARES, L.F.G et al. HyperProp: Uma Visão Geral. In: Workshop em Sistemas Hipermídia Distribuídos, I, São Carlos. Anais, 1995, p.1-12.

[SOA95b] SOARES, L.F.G., RODRIGUEZ, N.L.R., CASANOVA, M.A. NCM: A Conceptual Model for Hyperdocuments. In: Workshop em Sistemas Hipermidia Distribuidos, I, São Carlos. Anais, 1995, p.40-46.

[SOM96] SOMMERVILLE, I. Software Engineering. Harlow: Addison-Wesley, 1996. 729p.

[SOU93] SOUSA, M.S.L. Design Cooperativo: O Papel do Designer e do Usuário na Construção de Interfaces. São Carlos, 1993. 139p. Dissertação (Mestrado) Instituto de Ciências Matemáticas e de Computação, Universidade de São Paulo.

[SPR98] SPRECKELSEN, C., SPITZER, K. Formalising and Acquiring Model-based Hypertext in Medicine: An Integrative Approach. [online]. Methods of Information 
in Medicine, v. 37, n.3, p. 239-246, 1998. [05/03/99]. Disponível na Internet: $<$ http://webofscience.fapesp.br $>$.

[STA95] STAIR, R. Principios de Sistemas de Informação: Uma Abordagem Gerencial. Rio de Janeiro: LTC, 1998. 45 lp.

[TA95] TA, A., HYBERTSON, W. A Domain Framework: A Basis for Enhancing Reuse Among Domains. [online]. [16/08/1999]. Disponivel na Internet: $<\mathrm{ftp} / /$ gandalf.umcs.maine.edu/pub/WIRS/wirs7/proceedings/txt/hybertson.txt>.

[TEI76] TEICHROEW, D., HERSHEY III, E.A. A Computer-Aided Technique for Structured Documentation. Data Base, v.8, n.1, p.7-9, 1976.

[TH098] THOMSON, A.J., ALLEN, E., MORRISON, D. Forest Tree Disease Diagnosis Over the World Wide Web. [online]. Computers and Electronics in Agriculture, v.21, n.1, p.19-31, 1998. [05/03/99]. Disponivel na Internet: $<$ http://webofscience.fapesp.br>.

[TIL92] TILLEY, S.R., MÜLLER, H.A., ORGUN, M.A. Documenting Software System with Views. In: International Conference on Systems Documentation, 10., Canada. Proceedings, 1992. p.211-219.

[TRA95] TRACZ, W. Confessions of a Used Program Salesman. Reading: Addison-Wesley, 1995. 233p.

[VAS98] VASIL'EV, A.G., KRYAZHIMSKII, F.V., LIKHTERMAN, A.D., SALNIKOV, A.A. Principles of Organization and Function of the ECOINFORM Information Retrieval System for the Urals and Western Siberia. [online]. Russian Journal of Ecology, v. 29 , n.6, p. $422-424,1998$. [05/03/99]. Disponível na Internet: $<$ http://webofscience.fapesp.br>.

[WIR90] WIRFS-BROCK, R., WILKERSON, B., WIENER, L. Designing Object-Oriented Software. Englewoods Cliffs: Prentice Hall, 1990. 341p. 


\section{Apêndice A \\ Sugestões para Melhoria do SASHE 2.0}

Seguem abaixo sugestões para a melhoria e aperfeiçoamento da atual versão do sistema SASHE.

- Disponibilizar botões para as funcionalidades do menu pop-up ativado a partir da janelas de Contextos Aninhados;

- Disponibilizar help e outros recursos de ajuda como: referência de consulta na Internet e help sensitivo a contexto;

- Informar ao usuário que ao clicar duas vezes em nós de informação ou do tipo trilha, estes são editados. No caso de nós de contextos, estes são expandidos;

- Disponibilizar mais mecanismos de fechamento de janelas além do botão no canto superior direito da janela ("X");

- Disponibilizar uma caixa de diálogo questionando se o usuário deseja salvar as modificações na hiperbase ao encerrar o sistema;

- Disponibilizar um botão de "Cancelar" na janela "Alterar Liberdade" visto que somente apresenta o botão "OK";

- Fornecer mensagens mais claras de término de navegação;

- Corrigir o erro que origina a mensagem List index out of bounds (-1) surgida quando cria-se um elo não válido ou quando deseja-se visualizar o conteúdo de um nó onde nenhum contexto ou informação está selecionado;

- Disponibilizar recursos de "Fechar Hiperbase" e "Imprimir" no menu principal; 
- Disponibilizar mensagens somente em um idioma (preferencialmente em português);

- Possibilitar que a funcionalidade ("Janelas"/"Fechar Todas") também feche a janela de "Glossário";

- Disponibilizar recursos para alternar entre os módulos de autoria e de navegação sem que seja necessário reiniciar o sistema;

- Possibilitar a criação de mais de um roteiro de navegação assim como proporcionar maiores recursos para sua edição como, por exemplo, alterar a posição dos itens do roteiro;

- Possibilitar a seleção de hiperbases sem que seja preciso reinicializar o módulo de navegação;

- Fornecer templates de aplicações para usuários iniciantes;

- Facilitar a inserção de figuras dentro de um arquivo texto;

- Redefinir os procedimentos para a criação de elos entre nós;

- Aperfeiçoar a inserção de itens no roteiro tornando essa atividade mais intuitiva ao usuário;

- Disponibilizar o manual e a documentação sobre o SASHE;

- Reprojetar as mensagem "Não há nada mais fácil!" e "Não há nada mais difícill" de modo a tornarem-se mais significativas ao usuário;

- Permitir visualizar a estrutura de toda a hiperbase a partir do contexto atual por meio do Browser Estrutural;

- Permitir fechar a janela de "Nós e Elos" ao invés de simplesmente minimizá-la;

- Permitir alternar o SASHE com outros aplicativos sem que as janelas se sobreponham;

- Fornecer mensagens de erros que orientem na solução desses erros;

- Permitir a inserção de novos formatos de arquivos tais como gif, jpg, mp3, etc;

- Reimplementar os atributos dos elos ("Apresentar origem e destino simultaneamente" e "Apresentar todas as informações do destino") pois não funcionam corretamente;

- Destacar nos hiperdocumentos os links percorridos e os não-percorridos durante a navegação;

- Permitir visualizar um documento no momento de sua inserção no contexto. (o que já ocorre no caso de figuras);

- Disponibilizar uma barra de status para o surgimento de mensagens informativas a respeito das ações executadas pelo usuário;

- Atribuir outras propriedades ao contexto além do nome tais como data de criação do contexto e quantidade de nós inseridos;

- Reprojetar a barra de navegação de hiperbase, pois em certos momentos atrapalha a leitura do documento aberto; 
- Explorar o recurso de representação por ícones em todo o ambiente;

- Possibilidade de estabelecer elos entre partes de um mesmo nó (do tipo texto); 



\section{Apêndice B}

\section{Documento de Requisitos do Sistema SASHDoc}

\section{A. Visão Geral}

O Sistema de Autoria e Suporte Hipermídia para Documentação de Software SASHDoc - é um sistema hipermídia desenvolvido para a autoria e navegação de documentação de software. O sistema é suportado pelo Modelo de Contextos Aninhados, um modelo conceitual de dados hipermídia baseado nos conceitos de nós e links.

Uma Documentação de software é formada por um ou mais documentos de software, distribuídos em etapas do ciclo de vida de desenvolvimento de software. A Documentação, os documentos de software e as etapas da Documentação são caracterizados pelas suas respectivas propriedades.

O principal usuário do sistema é o engenheiro de software. Ao manipular o sistema, o engenheiro de software pode assumir o papel de autor, responsável por criar uma Documentação de software, e o papel de leitor, com a função de navegar por documentos de software.

Os documentos de software podem se relacionar com outros documentos de software por meio de elos. O único tipo de elo permitido entre documentos de software é unidirecional.

Uma seqüência de documentos de software dispostos numa ordenação forma um roteiro. O roteiro é apresentado ao engenheiro de software durante a navegação. A navegação de um roteiro é orientada por meio de estratégias definidas a partir das propriedades dos documentos de software. 


\section{B. REQUISITOS FUnCIONAIS}

\section{B.1. Módulo De AUTORIa}

\section{B.1.1. AUTORIA DE DOCUMENTAÇĀO}

1. O sistema deve permitir as operações de criação, alteração e exclusão de Documentação.

2. O sistema deve, no caso da tentativa de criação de uma Documentaçâo já existente, informar ao engenheiro de software a existência desta Documentaçâo. Se o engenheiro de software confirmar a inserção, o sistema deve informar que tal operação irá alterar a Documentação existente.

3. O sistema deve solicitar ao engenheiro de software valores para as propriedades de Documentação durante a operação de criação de Documentação. As propriedades de Documentação são: título, responsável, data de criação, data de término, objetivos, descrição, metodologia, versão, apêndice, data da última alteração e alterações efetuadas.

4. O sistema deve emitir mensagens de erro quando propriedades de Documentação incompletas forem informadas. Tais mensagens devem interrogar se o engenheiro de software deseja cancelar a criação da Documentação, completar as informações incompletas ou concluir a criação assim mesmo.

5. O sistema não deve permitir a criação de uma Documentação sem que seja atribuído valor à propriedade título. Neste caso, o sistema deve emitir uma mensagem de erro ao engenheiro de software informando-o da necessidade de um título para a Documentaçâo.

6. O sistema deve, no caso de tentativa de alteração dos valores das propriedades de uma Documentação, interrogar se o engenheiro de software confirma a alteração. Se o engenheiro de software confirmar a alteração, o sistema deve emitir mensagem comunicando que a(s) propriedade(s) foi(ram) alterada(s).

7. O sistema deve, no caso de tentativa de exclusão de uma Documentaçâo, interrogar se o engenheiro de software confirma a exclusão. Se o engenheiro de software confirmar a exclusão, o sistema deve emitir mensagem comunicando que toda a Documentação foi excluída.

8. O sistema deve oferecer um mecanismo para o engenheiro de software visualizar toda a estrutura de uma Documentação ou somente parte dela.

9. O sistema deve permitir o engenheiro de software alternar entre os módulos de autoria e de navegação. 
10. O sistema deve permitir o engenheiro de software imprimir de uma vez todos os documentos de software que compõem a Documentação.

11. O sistema deve permitir o engenheiro de software integrar uma Documentação dentro de outra Documentação.

\section{B.1.2. AUTORIA DE ETAPA}

12. O sistema deve permitir a inserção, alteração e a exclusão de etapas em uma Documentação.

13. O sistema deve, no caso da tentativa de inserção de uma etapa existente, informar o engenheiro de software da existência desta etapa. Se o engenheiro de software confirmar a operação de inserção, o sistema deve comunicar que tal operação irá alterar a etapa existente. 14. O sistema deve solicitar ao engenheiro de software valores para as propriedades da etapa durante a inserção de uma etopa. As propriedades de etapa são: título, data de início e data de término e descrição.

15. O sistema deve emitir mensagens de erro quando propriedades de etapa incompletas forem informadas. Tais mensagens devem interrogar o engenheiro de software se deseja cancelar a inserção, completar as informações incompletas ou concluir a inserção assim mesmo.

16. O sistema não deve permitir a inserção de uma etapa sem que seja atribuído valor à propriedade título. Neste caso, o sistema deve emitir uma mensagem de erro ao engenheiro de software informando-o da necessidade de um título para a etapa.

17. O sistema deve permitir a inserção de uma ou mais etapas dentro de uma etapa.

18. O sistema deve, no caso de tentativa de alteração dos valores das propriedades da etapa, interrogar se o engenheiro de software confirma a alteração. Se o engenheiro de software confirmar a alteração, o sistema deve emitir mensagem comunicando que a(s) propriedade(s) foi(foram) alterada(s).

19. O sistema deve, no caso de tentativa de exclusão de uma etapa, verificar se existe ao menos um documento de software dentro da etapa. Caso positivo, o sistema deve interrogar se o engenheiro de software confirma a exclusão da etapa e dos documentos de software contidos nela. Se o engenheiro de software confirmar a operação de exclusão, o sistema deve emitir uma mensagem informando que a etapa e todos seus documentos de software foram excluídos. 


\section{B.1.3. AUTORIA DE DOCUMENTO DE SOFTWARE}

20. O sistema deve permitir a inserção, alteração e a exclusão de documentos de software dentro de uma Documentação.

21. O sistema deve permitir a inserção, alteração e a exclusão de documentos de software dentro de uma etapa.

22. O sistema deve, no caso da tentativa de inserção de um documento de software existente em uma mesma etapa, informar ao engenheiro de software a existência deste documento de software. Se o engenheiro de software confirmar a inserção, o sistema deve informar que tal operação irá alterar o documento de software existente.

23. O sistema deve solicitar ao engenheiro de software valores para as propriedades do documento de software durante a operação de inserção de documento de software. As propriedades de documento de software são: título, data de criação, data de término, responsável, descrição, objetivos, visibilidade, formalidade, abstração, funcionalidade, arquivo, data da última alteração, alterações efetuadas.

24. O sistema deve disponibilizar valores para as propriedades visibilidade, formalidade, abstração e funcionalidade do documento de software. Os valores para a propriedade visibilidade são: funcional externa, funcional interna, modular e organizacional. Os valores para a propriedade nível de formalidade são: baixa, regular, alta. Os valores para a propriedade abstração são: baixo, médio, alto. Os valores para a funcionalidade são: documento de software, nota de documento, nota da etapa e nota do autor.

25. O sistema deve fornecer mensagens de erro quando propriedades de documento de software incompletas forem informadas. Tais mensagens devem interrogar se o engenheiro de software deseja cancelar a inserção, ou completar as informações incompletas ou concluir a inserção assim mesmo.

26. O sistema não deve permitir a inserção de um documento de software sem que seja atribuído valor às propriedades título e arquivo. Neste caso, o sistema deve emitir uma mensagem de erro ao engenheiro de software informando-o da necessidade de valor para o título e para o arquivo de uma etapa.

27. O sistema deve, no caso de tentativa de alteração dos valores das propriedades de documento de software, interrogar se o engenheiro de software confirma a alteração. Se o engenheiro de software confirmar a alteração, o sistema deve emitir mensagem comunicando que a(s) propriedade(s) foi(ram) alterada(s).

28. O sistema deve permitir o engenheiro de software associar, no máximo, cinco palavraschave a cada documento de software. 
29. O sistema deve armazenar as palavras-chave associadas a um documento de software em um glossário geral para o Documentação.

30. O sistema deve, no caso de tentativa de exclusão de documento de software, verificar se existe ao menos um documento de software relacionado com aquele documento de software. Caso positivo, o sistema deve interrogar se o engenheiro de software confirma a exclusão do documento de software e de todos os seus relacionamentos. Se o engenheiro de software confirmar a operação de exclusão, o sistema deve emitir mensagem informando que o documento de software e seus relacionamentos foram excluídos.

31. O sistema deve fornecer mecanismos para a visualização e a edição de documentos de software.

32. O sistema deve permitir o engenheiro de software associar uma bibliografia a um documento de software.

33. O sistema deve permitir o engenheiro de software imprimir individualmente cada documento de software que compõe a Documentação.

\section{B.1.4. AUTORIA DE RELACIONAMENTOS ENTRE DOCUMENTOS DE SOFTWARE}

34. O sistema deve permitir o engenheiro de software criar, alterar e excluir relacionamentos somente unidirecionais entre documentos de software, por meio de elos.

35. O sistema deve solicitar ao engenheiro de software valores para as propriedades do elos durante a operação de criação de elos. As propriedades de elos são: origem, destino, data da última alteração, descrição.

36. O sistema deve permitir o engenheiro de software criar uma ou mais ancoras em um mesmo documento de software.

37. O sistema deve, no caso de tentativa de criação de um relacionamento, interrogar se o engenheiro de software confirma a criação.

38. O sistema deve, no caso de tentativa de alteração de um relacionamento, interrogar se o engenheiro de software confirma a alteração.

39. O sistema deve, no caso de tentativa de exclusão de um relacionamento, interrogar se o engenheiro de software confirma a exclusão.

40. O sistema deve permitir o engenheiro de software criar relacionamento em que o documento de software origem e o documento de software destino do relacionamento sejam apresentados simultaneamente. 
41. O sistema deve permitir o engenheiro de software criar relacionamentos em que todos os documentos de software destino de um documento de software sejam apresentados simultaneamente.

42. O sistema deve permitir o relacionamento de documentos de soffware entre documentações diferentes.

43. O sistema não deve permitir o relacionamento de um documento de software a uma etapa.

\section{B.1.5. AUTORLA DE ROTEIRO}

44. O sistema deve permitir a criação, alteração e a exchusão de um ou mais roteiros em uma Documentação.

45. O sistema deve permitir o engenheiro de software inserir, alterar e excluir documentos de software e etapas em um roteiro.

46. O sistema deve permitir ao engenheiro de software inserir o mesmo documento de software no roteiro mais de uma vez.

47. O sistema deve, no caso da tentativa de criação de um roteiro existente, informar o engenheiro de software da existência deste roteiro. Se o engenheiro de software confirmar a criação, o sistema deve informar que tal operação irá alterar o roteiro existente.

48. O sistema deve solicitar ao engenheiro de software valores para as propriedades de roteiro. As propriedades de roteiro são: título, data de criação, responsável e descrição.

49. O sistema deve, no caso da tentativa de criação de um roteiro existente, informar ao engenheiro de software a existência deste roteiro. Se, neste caso, o engenheiro de software confirmar a operação de inserção, o sistema deve informar que tal operação irá alterar o roteiro existente.

50. O sistema deve, no caso de tentativa de alteração dos valores das propriedades de roteiro, interrogar se o engenheiro de software confirma a alteração. Se o engenheiro de software confirmar a alteração, o sistema deve emitir mensagem comunicando que a(s) propriedade(s) de roteiro foi(foram) alterada(s).

51. O sistema deve, no caso de tentativa de exchusão de roteiro, interrogar se o engenheiro de software confirma a exclusão. Se o engenheiro de software confirmar a operação de exclusão, o sistema deve emitir mensagem informando que o roteiro foi excluído do Documentação.

52. O sistema deve permitir o engenheiro de software definir graus de liberdade de navegação para uma etapa no roteiro.

53. O sistema deve fornecer um "preview" do roteiro. 
54. O sistema deve permitir o engenheiro de software visualizar um documento de software durante a construção do roteiro.

55. O sistema deve permitir o engenheiro de software criar automaticamente um roteiro formado somente com documentos de software com a propriedade visibilidade com valor funcional externa.

56. O sistema deve permitir o engenheiro de software criar automaticamente um roteiro formado somente com documentos de software com a propriedade visibilidade com valor funcional interna.

57. O sistema deve permitir o engenheiro de software criar automaticamente um roteiro formado somente com documentos de software com a propriedade visibilidade com valor modular.

58. O sistema deve permitir o engenheiro de software criar automaticamente um roteiro formado somente com documentos de software com a propriedade visibilidade com valor organizacional.

\section{B.2. MóduLo de NaVEgaçĀo}

59. O sistema deve permitir o engenheiro de software selecionar o roteiro que deseja navegar.

60. O sistema deve fornecer mensagens de início e de término de navegação de um roteiro.

61. O sistema deve permitir o engenheiro de software navegar por um roteiro através de relacionamentos entre documentos de software.

62. O sistema deve informar o engenheiro de software da atual posição do documento de software com relação ao roteiro original.

63. O sistema deve informar o engenheiro de software dos documentos de software já percorridos no roteiro.

64. O sistema deve permitir o engenheiro de software avançar ou retroceder a documentos de software já percorridos.

65. O sistema deve disparar uma busca em todo o roteiro por documentos de software que possuam uma ou mais palavras-chave em comum e apresentar o resultado da busca ao engenheiro de software.

66. O sistema deve fornecer ao engenheiro de software recursos para avançar ou retroceder no roteiro seqüencialmente.

67. O sistema deve permitir o engenheiro de software navegar no roteiro de acordo com o grau de abstração dos documentos de software. 
68. O sistema deve permitir o engenheiro de software navegar no roteiro de acordo com um maior ou menor nível de formalidade dos documentos de software.

69. O sistema deve permitir o engenheiro de software navegar no roteiro de acordo com o grau de visibilidade dos documentos de software.

70. O sistema deve permitir o engenheiro de software navegar no roteiro de acordo com a funcionalidade dos documentos de software.

\section{Requisitos DE QUALIDADE}

\section{C.1. Segurança}

71. O sistema não deve permitir acesso ao sistema por engenheiros de softwares não autorizados.

72. O sistema deve validar o engenheiro de software que tenta acessar o módulo de autoria do sistema. A validação é realizada pela checagem do nome e da senha do engenheiro de software. Se o engenheiro de software não for cadastrado, o sistema deve emitir mensagem de erro.

73. O acesso ao módulo de navegação é permitido a qualquer engenheiro de software.

\section{C.2. Conflabilmade}

74. O sistema deve ter capacidade para recuperar os dados perdidos da última operação que realizou em caso de falha.

75. O sistema deve fornecer facilidades para a realização de "backups" dos arquivos do sistema.

76. O sistema deve apresentar um "help" como fonte de consulta do engenheiro de software.

\section{C.3. EFICTÊnCIA}

77. O tempo de resposta para as operações de inserção, alteração e exclusão não deve exceder a três segundos. 


\section{C.4. Portabilidade $\cdot$ I}

78. O sistema deve ser implementado para máquina PC/IBM compatível com microprocessador $486 \mathrm{DX}$ ou superior, memória RAM mínima de 8 Mbytes e sistema operacional Windows $95 / 98 / N T$. 
